\title{
políticas sociales
}

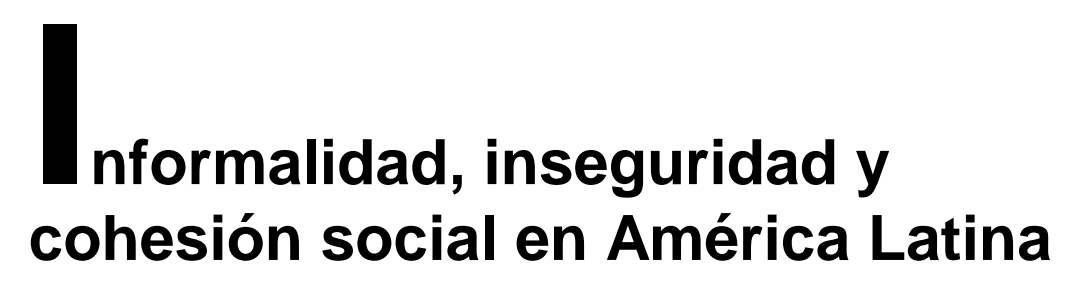

Víctor E. Tókman

División de Desarrollo Social 
Este documento fue preparado por Víctor E. Tókman, Consultor de la Comisión Económica para América Latina y el Caribe (CEPAL). Este trabajo se preparó en el marco del proyecto CEPAL-EUROSOCIAL sobre Cohesión Social en América Latina. Se agradecen los comentarios de Andras Uthoff y la colaboración de Juan Carlos Feres, Ernesto Espíndola y Carlos Daroch en la información sobre sector informal y protección social proveniente de las encuestas de hogares y de Rodrigo Heresi y Olga Ramos en la preparación de los gráficos.

Las opiniones expresadas en este documento, que no ha sido sometido a revisión editorial, son de exclusiva responsabilidad del autor y pueden no coincidir con las de la Organización.

Publicación de las Naciones Unidas

ISSN versión impresa 1564-4162 ISSN versión electrónica 1680-8983

ISBN: 978-92-1-3230405-9

LC/L.2694-P

$\mathrm{N}^{\circ}$ de venta: S.07.II.G.45

Copyright (C) Naciones Unidas, marzo de 2007. Todos los derechos reservados

Impreso en Naciones Unidas, Santiago de Chile

La autorización para reproducir total o parcialmente esta obra debe solicitarse al Secretario de la Junta de Publicaciones, Sede de las Naciones Unidas, Nueva York, N. Y. 10017, Estados Unidos. Los Estados miembros y sus instituciones gubernamentales pueden reproducir esta obra sin autorización previa. Sólo se les solicita que mencionen la fuente e informen a las Naciones Unidas de tal reproducción. 


\section{Índice}

Resumen .5

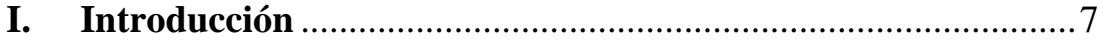

II. Creación de empleo y seguridad en el nuevo entorno económico

1. Crecimiento, empleo y regulaciones.................................... 9

2. Apertura comercial y regulación en el mercado de productos: una relación inversa ............................................ 10

3. Regulaciones en el mercado de productos y en el ámbito laboral: el Consenso de Washington.................................... 11

4. Regulaciones laborales y estabilidad laboral en economías más abiertas

5. Antiguiedad en el trabajo, rotación laboral y productividad .14

6. Regulaciones, inseguridad y cohesión social........................ 18

III. Cohesión social, informalidad y exclusión ...............................21

1. Informalidad, inseguridad y protección ..............................21

2. Informalidad: sector y economía.........................................23

2.1 Sector informal: exclusión con inseguridad a bajos

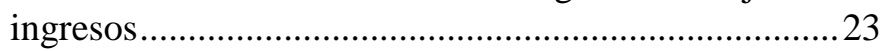

2.2 Informalidad: del sector a la economía ........................24

2.3 Cohesión social: exclusión e incorporación insegura. .25

3. Informalidad productiva-laboral y desprotección ..................26

3.1 Sector informal: informalidad productiva y laboral .....26

3.2 Relación laboral: reconocimiento legal y protección...31

3.3 Informalidad, inserción laboral y cohesión social.........35 
IV. Inserción productiva y laboral: estrategias para la cohesión social................................. 37

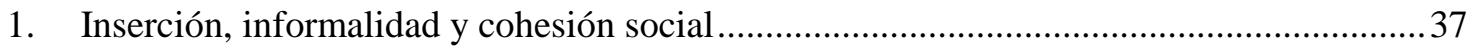

2. Sector informal e inclusión social: una opción estratégica ...............................................38

2.1 Construyendo ciudadanía: de las obligaciones a los derechos de los excluidos .........38

2.2 Desarrollo productivo y regulación de las actividades informales.............................39

2.3 Regulación laboral en empresas informales: derechos laborales en empresas con

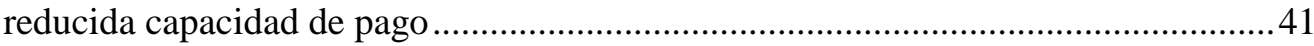

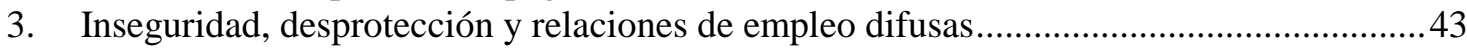

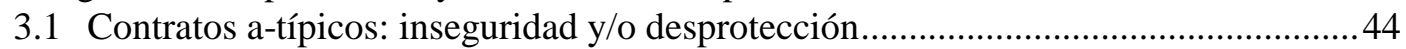

3.2 Relaciones de empleo difusas y regulación para la subcontratación...........................45

3.3 Regulación de la subcontratación: Chile, un avance pionero....................................4

4. Inseguridad laboral en economías más vulnerables: la flexi-seguridad ..............................49

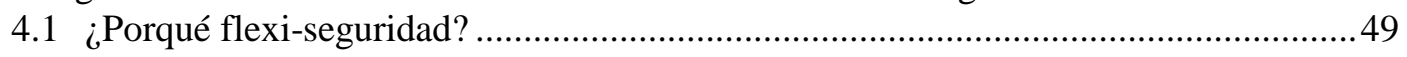

4.2 ¿Es transferible la flexi-seguridad a los países de América Latina? ..........................50

Bibliografía

Anexos

Sugerencias de indicadores de empleo y proteccion para la cohesión social ...........................59

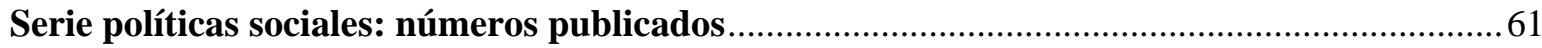

Índice de cuadros

Cuadro 1 Permanencia en el empleo en países de OECD y América Latina ............................15

Cuadro 2 Empleo informal: América Latina, 1990-2005 ......................................................26

Cuadro 3 Diferencias de ingresos según sector y categoría ocupacional en América Latina,

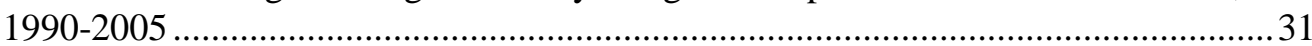

Cuadro 4 Costo laboral en Argentina y Perú según modalidad contractual...............................45

Cuadro 5 Seguridad de empleo y protección laboral en países de la OECD .............................50

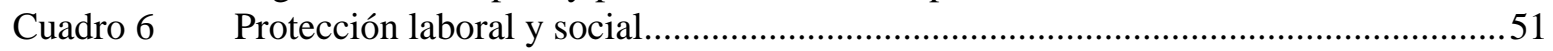

Cuadro 7 Limitantes estructurales a la efectividad de las políticas laborales ..........................53

Cuadro $8 \quad$ Indicadores de empleo y protección para la cohesión social.....................................60

Índice de gráficos

Gráfico 1 Grado de apertura y obstáculos a la iniciativa empresarial ...................................... 11

Gráfico 2 Permanencia en el empleo y edad promedio en países de OCDE y América Latina.... 15

Gráfico 3 Permanencia en el empleo según rigurosidad de la legislación laboral ......................16

Gráfico 4 Permanencia en el empleo y cobertura de negociación colectiva .............................17

Gráfico 5 Permanencia en el empleo y productividad ........................................................ 18

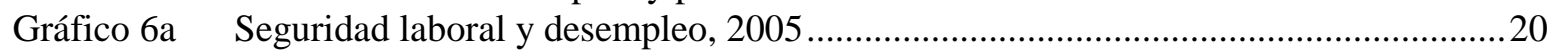

Gráfico 6b Inseguridad y legislación laboral, 2005 .............................................................20

Gráfico 7 Sector informal en América Latina, 1990 y 2005 .................................................27

Gráfico 8a Informalidad y producto per cápita …...................................................................28

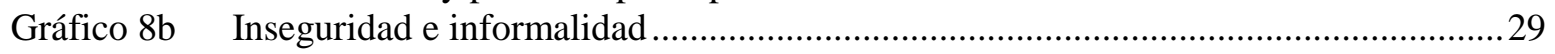

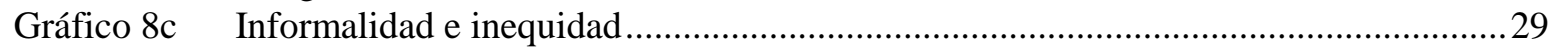

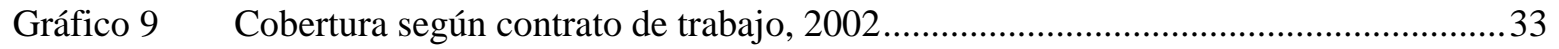

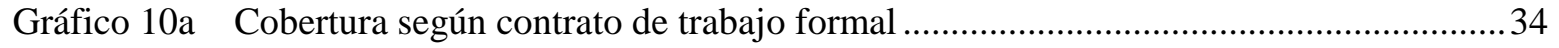

Gráfico 10b Cobertura según contrato de trabajo informal ......................................................... 34 
Este trabajo analiza los efectos de la informalidad y la inseguridad sobre la cohesión social, entendida en un sentido amplio adoptado por la CEPAL (2007). Dicha definición destaca la interacción entre mecanismos de inclusión/exclusión sociales y las respuestas y percepciones de la ciudadanía frente al modo en que operan. La cohesión social vincula los mecanismos de integración y bienestar con la plena pertenencia de los individuos, incluyendo el análisis de las distancias que separan a los miembros de la sociedad.

Se concentra en el estudio de la inserción laboral y la seguridad que dispone la ciudadanía y sus percepciones acerca de la eficacia de los instrumentos disponibles. Dada la existencia de amplias diferencias de productividad que caracteriza a la estructura productiva se profundiza la inserción laboral en la economía informal donde se ubica la mayoría de los ocupados.

Se desarrolla en tres secciones. La primera presenta un marco conceptual que permite analizar la creación de empleo y la seguridad en el nuevo entorno económico y las regulaciones en los mercados de productos y en el ámbito laboral. Se examina la estabilidad laboral y su relación con la inseguridad y la cohesión social. La segunda sección se concentra en la inserción laboral en la economía informal, la que incluye la informalidad productiva y laboral y las relaciones laborales precarias. Ambas son determinantes del grado de cohesión social.

En la última sección el trabajo examina estrategias de inserción laboral e informalidad para avanzar en la cohesión social. Las mismas se fundamentan en la necesidad de construir ciudadanía para asegurar el ejercicio de los derechos a los excluidos y se exploran políticas de 
desarrollo productivo y de regulación de las actividades informales y el acceso a los derechos laborales en empresas con reducida capacidad de pago. Se analizan las relaciones laborales difusas y su efecto sobre el grado de seguridad y protección y los avances que se registran en la regulación de dichas relaciones laborales, en particular en los contratos de trabajo atípicos y las formas de subcontratación.

El trabajo finaliza examinando la relevancia de una estrategia de flexi-seguridad para América Latina. En un marco analítico que incluye la seguridad en el empleo, la protección laboral y social y la percepción de los ciudadanos sobre la eficacia de los instrumentos disponibles, se agrupan los países de la región y se refieren a los "modelos" existentes de flexi-seguridad aplicados por los países desarrollados. El trabajo concluye incorporando las diferencias estructurales entre países latinoamericanos y las distancias existentes con los desarrollados, las que limitan la efectividad de las políticas. 


\section{Introducción}

La cohesión social sintetiza un componente fundamental que caracteriza a los países que progresan en lo económico y que al mismo tiempo, logran distribuir los frutos de ese crecimiento a todos sus ciudadanos. Con ello se asegura un desarrollo más equitativo, pero además, la contribución de todos los ciudadanos a lograr ese crecimiento, aportando en la medida de sus capacidades. El Estado Bienestar construido durante el siglo pasado, particularmente, en los países europeos, sentó las bases de la expansión económica de posguerra en un sistema social que incluyera a los ciudadanos y que dotara de la seguridad necesaria para que se enfrentaran las vulnerabilidades desde una perspectiva sistémica.

La inclusión y la seguridad en dicha concepción se aseguran mediante la inserción laboral plena y protegida y la solidaridad sistémica. La primera, a través del empleo pleno, estable y con protección para cubrir los riesgos en la vida laboral (desempleo, accidentes y enfermedades) y con posterioridad, en la vejez. La segunda, mediante un desarrollo institucional de la protección social basado en dos componentes fundamentales: una legislación laboral que trata de reducir las diferencias en los poderes de negociación protegiendo a los trabajadores y un sistema de protección que compensa las vulnerabilidades que se deriven de una inserción imperfecta.

Este modelo está todavía vigente en los países desarrollados, aunque con adaptaciones para responder al nuevo escenario económico y demográfico en que se desarrolla. También sirvió de orientación en las políticas seguidas en la mayoría de los países de la región, aunque su grado de implementación fue diverso y resultó 
muchas veces incompatible, dadas las diferencias estructurales predominantes. Dos de esas características son: las estructuras de empleo todavía con sectores rurales tradicionales significativos, asalariamiento incompleto e informalidad y la insuficiencia fiscal para financiar las necesidades. El resultado ha sido un sistema incompatible con cobertura reducida y con carencia de instrumentos adecuados para atender a los grupos no asalariados (V. E. Tokman, 2006).

La noción de cohesión social se profundiza en un estudio reciente de la CEPAL (2007) adoptando una definición de la misma que destaca la interacción entre mecanismos de inclusión/exclusión sociales y las respuestas y percepciones de la ciudadanía frente al modo en que dichos mecanismos operan. La cohesión social vincula causalmente, según esta conceptualización, los mecanismos de integración y bienestar con la plena pertenencia de los individuos. Usando la definición de cohesión en la física se tiende a precisar el concepto como un conjunto dado definido por la distancia entre sus elementos (brechas), por la integración entre los elementos y el todo (instituciones) y por la fuerza de atracción entre las partes y el todo (sentido de pertenencia).

Dentro de esta perspectiva de cohesión social el trabajo se concentra en el análisis de la inserción laboral y la seguridad que dispone la ciudadanía y sus percepciones acerca de la eficacia de los instrumentos disponibles. En los países desarrollados la inserción laboral es más homogénea y las diferencias se presentan principalmente como alternativas entre el acceso al empleo o el desempleo abierto, en un contexto que se caracteriza por funcionar en torno al pleno empleo y la existencia de protección a los desempleados. En los países en desarrollo y en América Latina en particular, la inserción laboral presenta una heterogeneidad mayor asociada a las amplias diferencias de productividad que caracterizan a la estructura productiva. Por ello, dicho análisis no puede efectuarse sin profundizar en la inserción laboral en la economía informal donde se ubica la mayoría de los ocupados.

Este trabajo se concentra en el análisis de dos grupos objetivos que constituyen la economía informal. El primero, se refiere a los trabajadores que estando incluidos y ocupados en empresas formales enfrentan una creciente inestabilidad derivada del nuevo escenario económico prevaleciente y la necesidad de mejorar la capacidad de adaptación ante las recurrentes fluctuaciones económicas y la emergencia de nuevos riesgos, que se agregan a los que ya existían, que deben ser cubiertos para mejorar la seguridad de los mismos. El segundo, se refiere a los excluidos y particularmente, a los que laboran en el sector informal en actividades por cuenta propia y en microempresas, incluso familiares, cuya ocupación a baja productividad además de generar ingresos insuficientes queda fuera de los sistemas de protección. Más aún, el resultado económico derivado de los escasos recursos disponibles y la carencia de mejores oportunidades de empleo, convierte esta situación en estructural. Ello requiere de una estrategia de inclusión y no solo de protección, si el objetivo es la ampliación de la ciudadanía económica y social a todos los habitantes de cada país.

El análisis desarrolla un marco conceptual de referencia, cuantifica las dimensiones definidas como elementos de la cohesión social (brechas, instituciones y percepciones) y sugiere un subconjunto de indicadores que podrían incluirse dentro del seguimiento de la cohesión social en los países de la región. 


\section{Creación de empleo y seguridad en el nuevo entorno económico}

\section{Crecimiento, empleo y regulaciones}

En este capítulo se revisan los antecedentes disponibles acerca de las relaciones entre estabilidad laboral y creación de empleo en el contexto económico de la globalización. Previamente resulta necesario destacar algunas evidencias disponibles que pueden contribuir al análisis.

La primera se refiere a la relación existente entre movilidad laboral y aumento de la productividad. Relación esta que constituyó la base del debate del desarrollo décadas atrás. Es todavía claro, como entonces, que los procesos de urbanización e industrialización se correlacionan estrechamente con un crecimiento mayor de la productividad. Cuando se relaciona la movilidad intersectorial con la variación de la productividad entre países se observa que dicha transformación estructural permite ampliar las fronteras dinámicas al trasladarse de sectores declinantes (agricultura) a otros en expansión (industria) (OIT, 2004). Ello no ocurre, sin embargo, con claridad cuando dicho traslado se produce hacia los servicios, como ha sido la experiencia de América Latina durante la posguerra. Prebisch (1970) ya advirtió esta tendencia al formular "la deformación estructural" en la estructura de empleo como consecuencia de la insuficiencia dinámica de las economías latinoamericanas frente a un crecimiento acelerado de la población y particularmente, de la urbana. 
Información más reciente para países miembros de la Organización de Cooperación y Desarrollo Económicos (OCDE) permite también observar una relación inversa entre la percepción de inseguridad laboral y las tasas de transición entre malos y buenos trabajos (OIT, 2004). La movilidad hacia puestos de mayor calidad no solo genera un mayor dinamismo de la productividad, sino que además, son percibidos como más seguros por la población.

Desde la perspectiva de la economía de la regulación, un estudio reciente del Banco Mundial (Loayza, Oviedo y Servén, 2005) analiza las relaciones entre regulaciones y nivel y crecimiento del producto por habitante a partir de una muestra que incluye a 76 países con muy diverso nivel de desarrollo, incluidos 21 de América Latina. Dicha investigación encuentra una correlación negativa entre regulación y nivel y crecimiento, ${ }^{1}$ pero la misma se explica principalmente por la regulación en el mercado de productos siendo no significativa la correlación entre regulaciones laborales y nivel y crecimiento del producto por habitante. Muestra, además, una correlación positiva entre crecimiento y carga tributaria.

El análisis se extiende a la relación entre informalidad y regulación, ${ }^{2}$ encontrando una relación positiva entre ambas. Nuevamente, al igual que en relación al producto, dicha relación se explica principalmente por la regulación del mercado de productos y se compensa, en parte por una relación inversa con la carga tributaria. La correlación entre informalidad y regulación laboral es directa, pero su coeficiente es menos significativo y su magnitud es cercana a un tercio del correspondiente a la regulación del mercado de productos. Ambos análisis destacan la importancia de la regulación de los mercados de producto como determinantes del crecimiento y la informalidad, mientras que no son concluyentes en cuanto a la regulación laboral y sus efectos. La carga tributaria y su relación positiva con el nivel y crecimiento y negativa con la informalidad resulta más difícil de interpretar para los autores, pero confirma la relación conocida de que los países recaudan más impuestos y gastan más en proteger a la población a medida que aumenta su nivel de desarrollo.

La menor importancia de las regulaciones laborales que se encuentra en el estudio mencionado se confirma también en el análisis de los obstáculos para el crecimiento y operación de empresas en países en desarrollo que efectúa también el Banco Mundial en base a encuestas sobre el clima de inversión. Sobre un total de 14 obstáculos identificados, las regulaciones laborales solo son mencionadas como obstáculo severo o mayor por un porcentaje que es superado por once de los obstáculos restantes que incluyen, entre otras, regulaciones en los mercados de bienes y financieros, impuestos y gobernabilidad.

\section{Apertura comercial y regulación en el mercado de productos: una relación inversa}

Las regulaciones en el mercado de productos son determinantes para el crecimiento y ellas son menores en los países más desarrollados que en los en desarrollo y entre los primeros, en aquellos de menor tamaño por su mayor grado de apertura. En el gráfico siguiente se observa esta relación inversa entre un índice del grado de dificultad para iniciar nuevos negocios y el grado de apertura en países de la OCDE. Se observa, asimismo que los países más pequeños y abiertos como Irlanda, Holanda y Noruega son los que presentan las barreras más bajas para iniciar nuevas actividades productivas.

\footnotetext{
El índice de regulación global incluye tres componentes: regulación del mercado de productos, regulación laboral y carga tributaria. Informalidad se define como evasión de la regulación o economía oculta y se cuantifica como una variable latente (como porcentaje del PIB). Los autores reconocen explícitamente en el trabajo que dicha especificación de la informalidad debe ser tomada con cautela, pues dada su definición incluye la acumulación de errores.
} 
Gráfico 1

GRADO DE APERTURA Y OBSTÁCULOS A LA INICIATIVA EMPRESARIAL

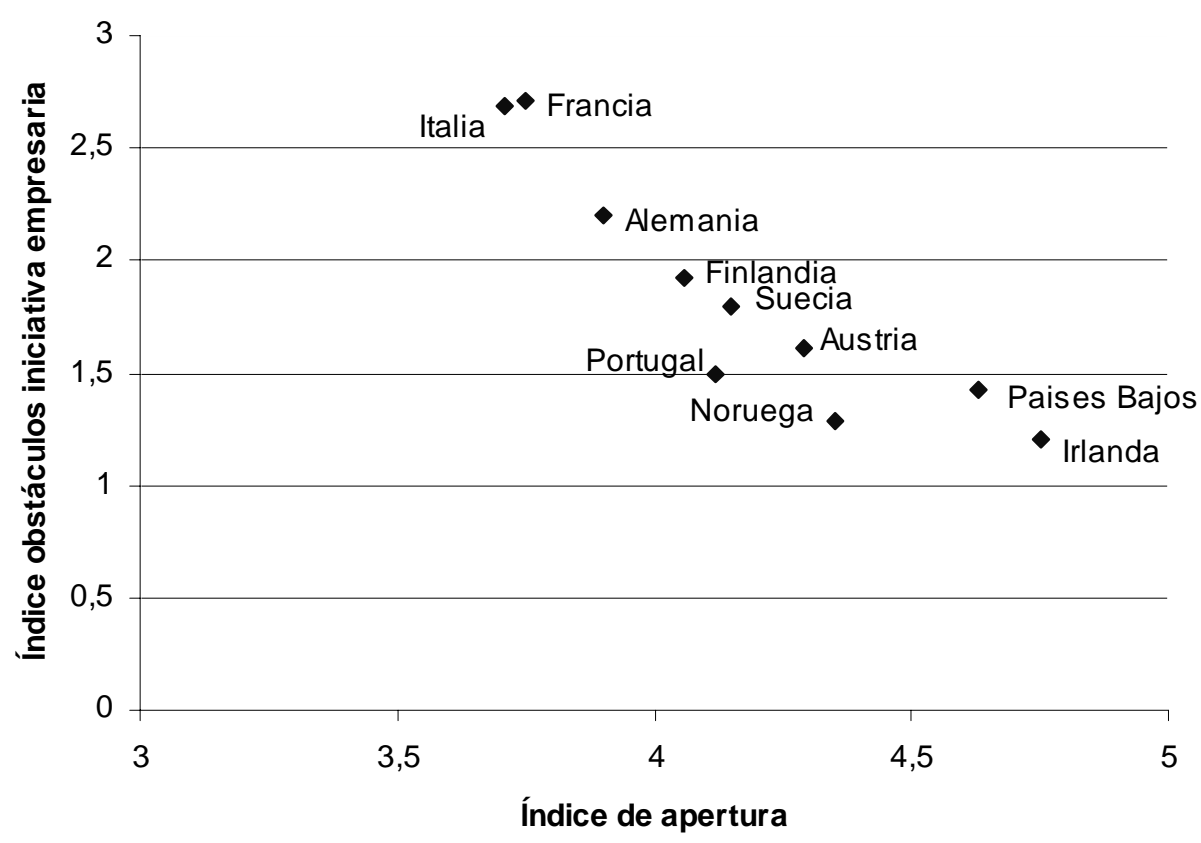

Fuente: OIT (2004).

Notas: Índice apertura: relación logaritmo natural exportaciones más importaciones sobre PIB, 1971-1999. Negocios en 1998, según metodología OCDE. Índice obstáculos: grado de dificultad para iniciar nuevos.

La apertura comercial y financiera en América Latina durante las últimas dos décadas contribuyó a disminuir las regulaciones en el mercado de productos. El estudio del Banco Mundial antes citado, muestra que las regulaciones al comercio se relacionan estrechamente con las barreras de entrada para iniciar nuevos negocios y particularmente, con la regulación en los mercados financieros. Por otro lado, los promedios de los índices de regulación relacionados con el mercado de productos y en particular con el de comercio, muestran que América Latina registra niveles muy superiores a los de los países de OCDE, pero en rangos más cercanos a los países de Asia e inferiores a los de África. En el ámbito comercial, la región registra índices más altos que en los países desarrollados, pero solo Asia del Este y del Pacífico muestran menores regulaciones medias, aunque cercanas a las latinoamericanas y con un grado de dispersión mayor. Lo opuesto ocurre, sin embargo, en las regulaciones laborales donde los índices para América Latina son los más altos del mundo con independencia de la región que se considere. Debe notarse, que a diferencia de lo que ocurre con los otros ámbitos de regulación, los índices correspondientes a los países asiáticos son inferiores a los de los países miembros de OCDE. Ello obedece en parte importante al origen de la legislación laboral vigente en América Latina, cuyas raíces se encuentran en los países latinos de Europa y principalmente en Italia, España y Francia.

\section{Regulaciones en el mercado de productos y en el ámbito laboral: el Consenso de Washington}

El proceso de apertura económica dentro del escenario de globalización al que se han incorporado la mayoría de los países de América Latina, se traduce en una disminución de las regulaciones en el mercado de producto y principalmente, en la facilidad de entrada para desarrollar nuevas 
actividades productivas. Economías más abiertas se exponen a una mayor competencia con el exterior y la estructura productiva debe tener capacidad para responder a los desafíos que la misma presenta. Ello significa un uso más adecuado de los recursos y la necesidad de reestructuraciones productivas.

Existe además, según estudios de la OCDE (Nicoletti at al, 2000), una relación directa entre el grado de exigencia de la regulación de los mercados de productos y de trabajo, esta última medida por un índice que refleja la exigencia de la legislación de protección laboral. En esta relación se fundamenta que la necesidad de aumentar la competitividad mediante la des-regulación de los mercados de productos requiere también la reducción de la exigencia de la protección laboral. Esta relación en el caso de América Latina, constituyó una de las bases del compacto de reformas del Consenso de Washington. En una primera generación se promovieron políticas dirigidas a restablecer los equilibrios macroeconómicos y en cambiar la estrategia de crecimiento desde la sustitución de importaciones a la apertura de los mercados. Se acompañaron además, con dos procesos igualmente importantes: la privatización y la liberalización. Esta trilogía se refuerza mutuamente en el diseño estratégico e instrumental, pues la apertura se acompaña de una menor intervención del Estado y una mayor importancia de los mercados como asignadores de recursos. En lo instrumental ello significó avanzar en la apertura comercial y financiera, disminuir el tamaño del Estado, privatizar empresas públicas y disminuir las regulaciones mediante la mayor competencia en los mercados, particularmente de bienes. Entre los instrumentos se incluyó el de la seguridad jurídica de la propiedad privada, factor indispensable para atraer una mayor inversión privada tanto nacional como extranjera.

El Consenso se fue adoptando progresivamente, aunque con intensidades y a ritmos diferentes en la mayoría de los países de la región. Contribuyeron a su aceptación las urgencias de la crisis de la deuda de comienzos de los años ochenta y los condicionamientos crecientes que se vincularon al reestablecimiento del financiamiento externo oficial y a la reprogramación de la deuda. El ajuste macroeconómico mostró sus éxitos en el corto plazo y la región logró controlar la inflación, reducir el déficit fiscal y comenzar a recuperar los ritmos de crecimiento. Ello se produjo simultáneamente con la transformación estructural que significó pasar a economías abiertas en un período de tiempo sin precedentes en la experiencia mundial. América Latina pasó de constituir uno de los mercados más protegidos del mundo a mediados de los ochenta a constituir una región con aranceles bajos, más uniformes y eliminando barreras no arancelarias hacia comienzo de los años noventa.

Es sólo con posterioridad que surgen nuevas generaciones de reformas que se agregan al compacto de políticas. Entre ellas, las laborales, que constituyeron un componente importante en las reformas de segunda generación. Su inclusión respondió a la necesidad de profundizar la adaptación productiva para competir, trasladando el peso del ajuste al mercado laboral. Dicho traslado, natural por la interrelación de los mercados, recayó de manera sobredimensionada sobre el ámbito laboral dada la ortodoxia que prevaleció en el manejo de las políticas macro-económicas y la incapacidad de anticipar y enfrentar un escenario económico más volátil que se tradujo en mayor vulnerabilidad. Ello contribuyó a aumentar la prioridad por reformas laborales flexibilizadoras y a asignarles resultados potenciales exagerados y sin fundamentos teóricos sólidos.

\section{Regulaciones laborales y estabilidad laboral en economías más abiertas}

El cambio en el régimen macroeconómico con que operan los países determina una relación del empleo más estrecha con la demanda externa, mientras que la posibilidad de expandir la demanda interna o de aumentar los salarios por encima de la productividad encuentran restricciones sea por 
la necesidad de financiarlos o por la imposibilidad de trasladarlos a los precios sin afectar la competitividad. La situación se caracteriza además, por una mayor inestabilidad y una transmisión más acelerada de la misma. De hecho, una economía internacional más integrada junto a la mayor importancia de los aspectos financieros y al cambio acelerado en las tecnologías de información, transforma en instantáneo el proceso de transmisión de beneficios, pero también de los costos involucrados.

Según información analizada por el Banco Mundial (De Ferranti at all, 2000), la inestabilidad de largo plazo, medida por la volatilidad del producto interno bruto, es en América Latina el doble de la de un país industrializado y superior a la de los países del Sudeste Asiático. En el caso del consumo, dicha comparación aumenta a tres veces y sólo es superada por los países de África al sur del Sahara. Según CEPAL (2000), el coeficiente de variación del crecimiento aumentó en $50 \%$ durante la década de los noventa. El diferencial de volatilidad del producto entre América Latina y los países desarrollados alcanza a 1,7 veces en los noventa, siendo mayor que el diferencial existente en los setenta y en el caso del consumo, alcanza a 3,3 veces superando las dos décadas precedentes.

La inestabilidad es alta y no claramente decreciente. Afecta particularmente a los países más abiertos y de menor tamaño aumentando su vulnerabilidad, lo que se une a la carencia de instrumentos adecuados para enfrentarla. Ello genera inseguridad en la medida que se transmite por la vía del mercado de trabajo al empleo, los ingresos y los salarios.

En trabajos anteriores hemos analizado el mecanismo de transmisión y sus efectos sobre el mercado de trabajo (V. E. Tokman, 2003 y 2004). Para los fines del análisis es importante, sin embargo, destacar como la volatilidad se traduce en mayor inseguridad y en muchos casos en desprotección a través del comportamiento del mercado de trabajo en los ciclos. Los ajustes que se producen en dicho mercado resultan no solo de las variaciones recurrentes, sino que además se facilitan por las reformas laborales flexibilizadoras que fueron incorporadas al compacto de políticas.

Aumenta, en primer lugar, la vulnerabilidad al desempleo ante las fluctuaciones en el ritmo de actividad económica y la mayor facilidad de despido. Dicha vulnerabilidad se acompaña además, por una asimetría en el comportamiento de la tasa de desempleo, que aún cuando se relaciona de manera inversa con el ciclo, su reducción en la recuperación no llega a compensar el aumento experimentado en la recesión, particularmente cuando los ciclos adquieren el carácter de recurrentes. Ese es precisamente el escenario de la década de los noventa, con recuperaciones de corta duración que afectan las decisiones de contratación y resultan en tasas de desempleo fluctuantes pero con tendencias crecientes. De un desempleo promedio para América Latina inferior al $7 \%$ a comienzos de los noventa, se pasa a niveles en torno al $11 \%$ en los primeros años de la década siguiente.

En segundo lugar, aumenta la inestabilidad laboral como consecuencia de los procesos de privatización, informalización y precarización que se registran en la estructura de empleo. El paso del empleo público al privado lleva aparejado una mayor exposición al desempleo, pérdidas de protección y estabilidad laboral, aún cuando no necesariamente menores remuneraciones. La informalización y la introducción de contratos de trabajo atípicos, junto al mayor número de trabajadores sin contrato, conllevan a una menor protección y seguridad. La participación del sector público en el empleo no agrícola se contrae del 15,5 al 13,4\% entre 1990 y 2001. Dos de cada tres nuevos empleos generados durante ese período fueron en el sector informal. Aumentaron también los trabajadores sin contrato de trabajo y con contratos diferentes a los por tiempo indefinido. Alrededor del 2002, el $47 \%$ de los asalariados no poseía contrato de trabajo y el $21 \%$ de los que tenía contrato era bajo modalidades diferentes al tiempo indefinido. Ello se traduce en menor protección, ya que sólo el $15 \%$ de los trabajadores sin contrato contribuye a la seguridad social, 
comparado con el $87 \%$ de los con contrato indefinido y del $57 \%$ de los trabajadores con otro tipo de contratos (V. E. Tokman, 2006).

La volatilidad también se observa en las remuneraciones reales. En la década de los ochenta duplica la registrada en los setenta, aún cuando retorna a esos niveles en los noventa (De Ferranti et all, 2000). Ello se explica en gran medida por la reducción significativa y generalizada de las tasas de inflación en la última década. Sin embargo, la menor volatilidad salarial se traduce en una mayor inflexibilidad de los salarios a la baja y traslada el mayor peso del ajuste en los shocks al empleo con el consiguiente aumento del desempleo.

Por último, los efectos en el mercado de trabajo se trasladan a los ingresos de los hogares y determinan las variaciones en la pobreza y en la distribución del ingreso. La pobreza muestra una relación inversa con el crecimiento, aumentando en los ochenta y disminuyendo durante la recuperación de los noventa. La distribución del ingreso también muestra esa asociación con el ciclo, sin embargo, al igual que el desempleo, presenta una asimetría en la recuperación que se traduce en el mantenimiento de los altos niveles de concentración del ingreso que se registran en la región. Aún cuando, se observan avances en disminuir la pobreza, la capacidad de blindaje de los grupos de mayores ingresos ante las crisis, traslada a los grupos medios parte del costo del ajuste. Con ello, la desigualdad no disminuye y la heterogeneidad aumenta. Ello se produce, sin embargo, con alta movilidad, por la mejora de oportunidades educacionales, pero restringida y con descensos producidos por la mayor volatilidad asociada al nuevo escenario económico.

\section{Antigüedad en el trabajo, rotación laboral y productividad}

Los cambios señalados resultan en incertidumbre, la que se asocia a la menor permanencia en el puesto de trabajo y a la mayor rotación laboral. La permanencia en el empleo a fines de los noventa alcanzaba en promedio a 7,6 años en América Latina, mientras que en los países miembros de OCDE era de 10,5 años. La proporción de trabajadores con menos de 2 años de antigüedad era de $38,1 \%$, superando al 24\% registrado en los países desarrollados (De Ferranti y otros, 2000). Información analizada por el BID (2003) confirma que la tasa de rotación para 12 países latinoamericanos varía entre 16 y $35 \%$ y que en México y Brasil la rotación es de un tercio. Ello significa que en un año se crean y destruyen, en promedio, uno de cada tres empleos.

La OIT (2004) encuentra al comparar la antigüedad promedio y los con menos de un año de antigüedad y los de más de 10 anos entre una muestra de países de la OCDE y de América Latina, que los países desarrollados presentan una antigüedad media mayor que los latinoamericanos. Sin embargo, las mismas no se relacionan necesariamente con el nivel de ingreso, sino que están influenciadas por la estructura de edades, el grado de exigencia de la legislación laboral y la extensión de la negociación colectiva.

El cuadro siguiente muestra que la mayor antigüedad promedio se encuentra en Grecia, Japón e Italia (entre 23 y 14 años) y que en los países latinoamericanos varía entre 6,7 en Argentina y 3,9 en Honduras. Sin embargo, debe notarse que en los Estados Unidos la misma alcanza a 6,6, muy similar a la de Argentina a pesar de las diferencias en niveles de desarrollo existentes. Las diferencias se tornan más notorias al compararse el porcentaje de trabajadores con más de 10 años de antigüedad, que van desde un rango entre 52 y $\%$ y los países latinoamericanos que se ubican entre 21 y 10\% (Argentina y Honduras, respectivamente). Los rangos se invierten al compararse el porcentaje de trabajadores con menos de un año de antigüedad. Los países latinoamericanos fluctúan entre 51 y 27\% (Honduras y Argentina respectivamente) y los europeos lo hacen entre15 y menos de 10\% (Unión Europea (UE)-14 países y Grecia y Japón). El gráfico siguiente muestra también la estrecha correlación existente entre la mediana de edad y los años de antigüedad de cada país. Cuanto más joven es la población de un país, menor es la antigüedad laboral promedio porque 
un porcentaje más alto de la población ha estado en la fuerza de trabajo menos tiempo y además, porque los jóvenes cambian de trabajos más frecuentemente que los de edad más avanzadas.

Cuadro 1

PERMANENCIA EN EL EMPLEO EN PAÍSES DE OCDE Y AMÉRICA LATINA

\begin{tabular}{l|c|c|c}
\hline & $\begin{array}{c}\text { Permanencia } \\
\text { media en el } \\
\text { empleo }\end{array}$ & $\begin{array}{c}\text { Porcentaje de } \\
\text { trabajadores con } \\
\text { permanencia < 1 año }\end{array}$ & $\begin{array}{c}\text { Porcentaje de } \\
\text { trabajadores con } \\
\text { permanencia }>\text { 10 años }\end{array}$ \\
\hline Grecia & 13,6 & 9,8 & 52,1 \\
Japón & 12,2 & 8,3 & 43,2 \\
Italia & 12,2 & 10,8 & 49,3 \\
Francia & 11,2 & 15,3 & 44,2 \\
Diez países miembros de la & & & 41,5 \\
UE (14) (salvo Austria) & 10,6 & 14,8 & 41,7 \\
Alemania & 10,6 & 14,3 & 31,5 \\
Dinamarca & 8,3 & 20,9 & 32,1 \\
Reino Unido & 8,2 & 19,1 & 21,2 \\
Argentina & 6,7 & 27,5 & 26,2 \\
Estados Unidos & 6,6 & 24,5 & 20,1 \\
Perú & 6,3 & 29,0 & 18,8 \\
Chile & 5,5 & 34,5 & 16,4 \\
Brasil & 5,3 & 37,2 & 10,1 \\
Honduras & 3,9 & 51,4 & \\
\hline
\end{tabular}

Fuente: OIT 2004.

Nota: La permanencia en el empleo está expresada en años.

Gráfico 2

PERMANENCIA EN EL EMPLEO Y EDAD PROMEDIO EN PAÍSES DE OCDE Y AMÉRICA LATINA

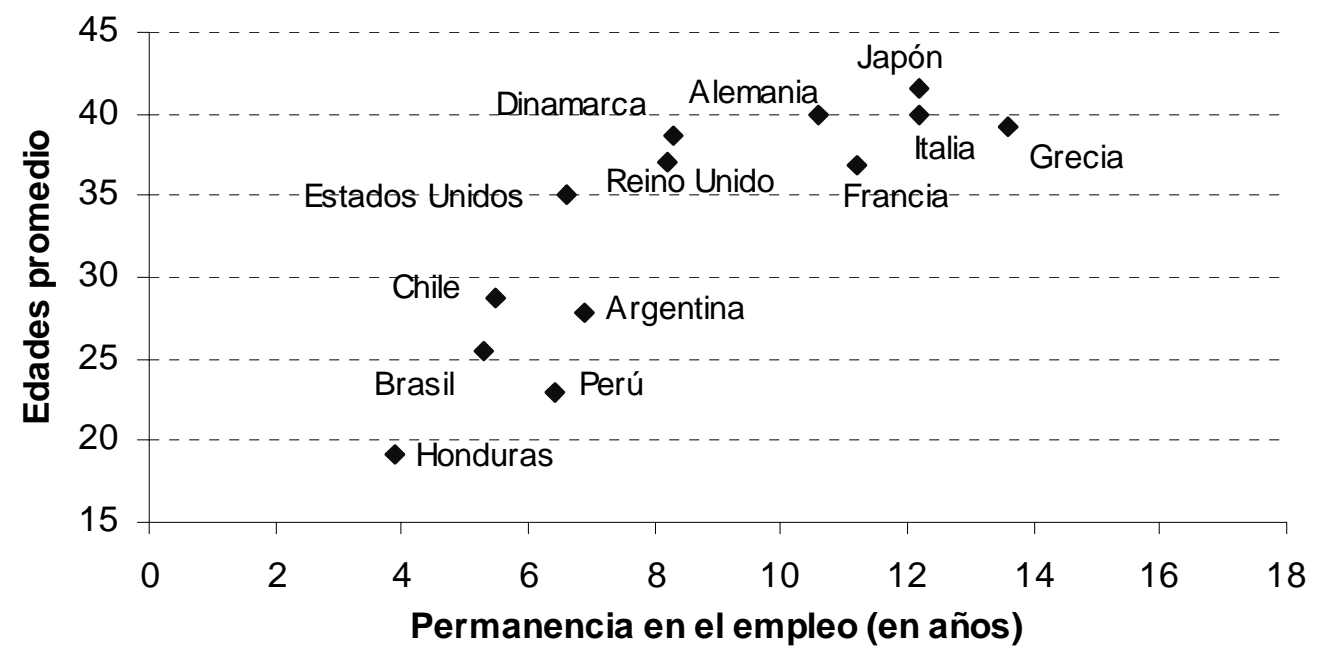

Fuente: OIT 2004.

Por otro lado, los gráficos 3 y 4 muestran la relación entre los factores institucionales y la proporción de trabajadores con más de 10 años de antiguiedad en el trabajo. El grado de exigencia de la legislación laboral y la cobertura de la negociación colectiva se correlacionan con la mayor antigüedad en el trabajo. Ambas instituciones pueden combinarse de manera diferente, aunque predomina en los países europeos la combinación de mayor exigencia de la legislación laboral con 
una cobertura más amplia de la negociación colectiva. Los países de América Latina presentan una legislación laboral más estricta y una menor asociación con la antigüedad en el trabajo, debido tanto al menor cumplimiento de la ley como a una cobertura de negociación colectiva más restringida (con excepción de Argentina). ${ }^{3}$

\section{Gráfico 3 \\ PERMANENCIA EN EL EMPLEO SEGÚN RIGUROSIDAD DE LA LEGISLACIÓN LABORAL}

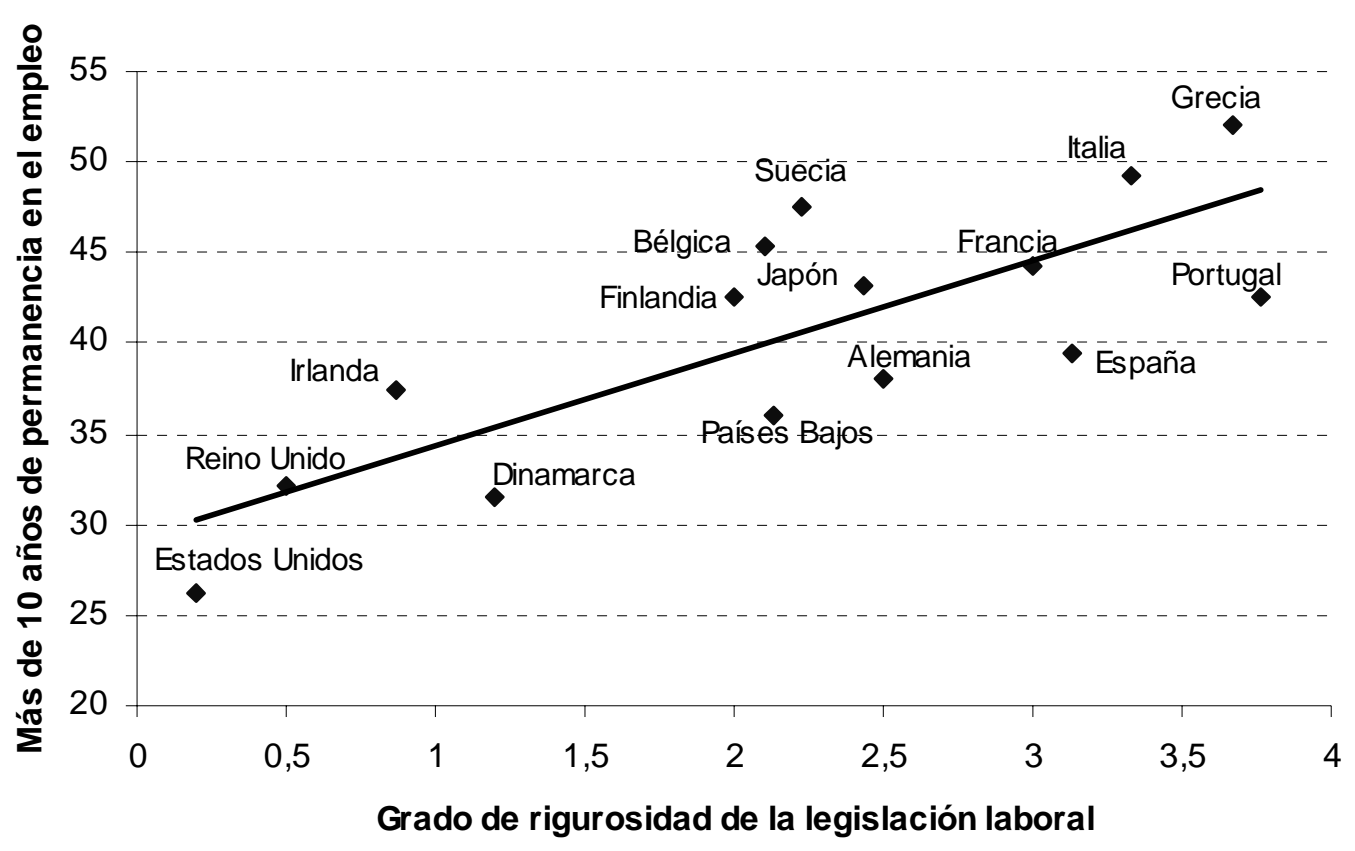

Fuente: OIT, 2004.

Nota: Grado de rigurosidad de la legislación laboral según OCDE (2002) incluye costos directos de despido, notificación y periodo de prueba y existencia de contratos temporarios.

Las reformas laborales flexibilizadoras tienen un efecto negativo sobre la antigüedad. En Perú, por ejemplo, los asalariados previo a las reformas tenían un promedio de 7,5 años y con posterioridad la antigüedad se redujo a 4 años (J. Chacaltana y N. García, 2002). Asimismo, como se verá más adelante, países más abiertos como Dinamarca y Finlandia (al igual que Irlanda y Holanda) presentan legislaciones laborales menos estrictas, pero una amplia difusión de la negociación colectiva, lo que resulta en una permanencia mayor en el empleo. En Estados Unidos y el Reino Unido las legislaciones laborales no son estrictas y el efecto de los sindicatos sobre la antigüedad laboral no es claro. ${ }^{4}$

3 La asociación entre antigüedad en el trabajo y exigencia de la legislación es positive cuando se ajusta por las diferencias en la estructura de edades entre países. Sin embargo, la relación es de menor intensidad que la que se observa en los países de la OCDE en el gráfico 3. El grado de rigurosidad no es estrictamente comparable dado que para América Latina aunque incluye los mismos conceptos que para los países desarrollados la metodología utilizada es diferente a la utilizada por la OCDE. Banco Mundial, (2004).

4 No obstante, en el caso de Estados Unidos la diferencia en antigüedad en el trabajo se observa con claridad en el caso de los trabajadores sindicalizados entre los que el $48 \%$ tiene más de 10 años de antigüedad, comparado con solo $22 \%$ de los no sindicalizados. El promedio de los primeros es similar al registrado en los países europeos. Ello sugiere que la sindicalización y la negociación colectiva son efectivas para estabilizar el empleo de sus afiliados y no del conjunto de los trabajadores. 


\section{PERMANENCIA EN EL EMPLEO Y COBERTURA DE NEGOCIACIÓN COLECTIVA}

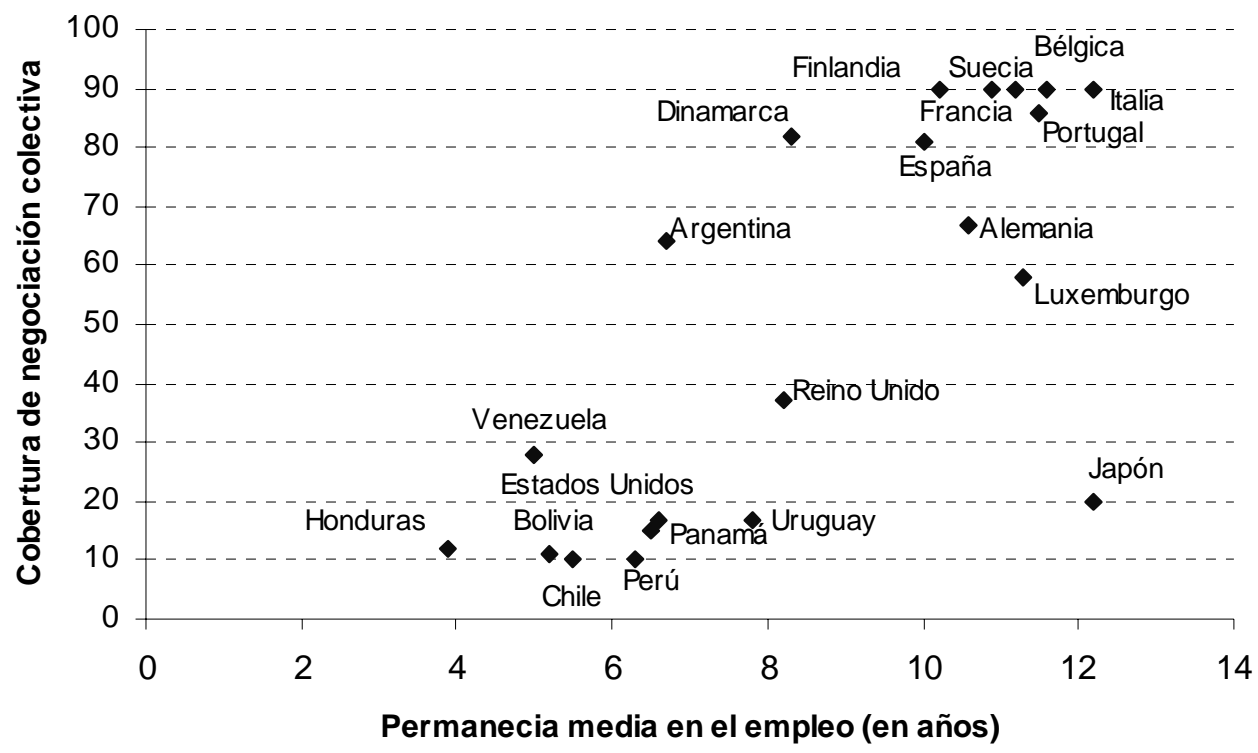

Fuente: OIT 2004

La menor antigüedad en el trabajo tiene efectos sobre la productividad de las empresas. Actúa como desincentivo para los empresarios para invertir en capacitación específica porque no existe la seguridad de que los trabajadores permanecerán hasta que los beneficios de dicha capacitación se materialicen en mayor productividad. Tampoco los trabajadores encuentran incentivos para dedicar tiempo y esfuerzo a la adquisición de una mayor calificación que no sea general y trasladable, pues su horizonte de permanencia resulta insuficiente. Existe una relación inversa entre rotación laboral y capacitación, mientras que la asociación entre capacitación y productividad es positiva. Como lo muestra Batra (2001), estas relaciones se observan en varios países. La probabilidad que una empresa capacite se asocia positivamente con las empresas que innovan y exportan. Las que presentan una mayor rotación, capacitan menos. Las empresas que presentaban mayor nivel de rotación en Perú mostraron una probabilidad inferior en $28 \%$ de invertir en capacitación, que las que registraban mayor estabilidad laboral (J. Chacaltana y N. García, 2002). Existe un trade-off entre flexibilidad y crecimiento de la productividad, debido al debilitamiento de los incentivos para la inversión en capacitación tanto por parte de los empresarios como de los trabajadores (V. E. Tokman, 2004).

Por otro lado, aún cuando la probabilidad de perder el empleo es mayor en América Latina que en los países de la OCDE, la duración del desempleo es significativamente más corta. El 36\% de los desocupados eran de corta duración (hasta un mes) en la década del noventa, mientras que el porcentaje era de $11,4 \%$ en Europa continental y 17,3\% en otros países desarrollados. Por el contrario, la proporción de desocupados de larga duración (un año o más) alcanzó a 11,4 en América Latina comparado con $42 \%$ en Europa. La velocidad de ajuste en América Latina es muy cercana a la prevaleciente en Estados Unidos donde los desocupados de corta duración eran el $39,6 \%$ y los de larga duración alcanzaban al 7,4\%, y en ambos es más rápida que en los otros países desarrollados.

Los estudios disponibles confirman que la rotación laboral afecta inversamente a la productividad. También existe evidencia que la antigüedad en el trabajo afecta los salarios de manera directa. Un año más de antigüedad aumenta el salario en alrededor de 2\% (Farber, 1998). El 
efecto de la antigüedad sobre la productividad es, sin embargo, menos claro. Auer, Berg y Coulibaly (2004) analizan esta relación para trece países europeos entre 1992 y 2002, concluyendo que existe una relación positiva entre ambos. Un $1 \%$ de aumento en la antiguiedad promedio, aumenta la productividad en $0,16 \%$. Sin embargo, el efecto es diferenciado según la antigüedad, al concentrarse los efectos positivos en los niveles intermedios de antigüedad en el trabajo. A medida que la antiguiedad se extiende (a partir de los 10 años y claramente después de los 20 años) los efectos sobre la productividad disminuyen, siendo incluso negativos en el tramo más avanzado. Lo mismo ocurre en los trabajadores con menos de 1 año de antigüedad que muestran un efecto negativo sobre la productividad, tramo en el que se concentran los jóvenes y los contratados bajo modalidades de corta duración.

\section{Gráfico 5}

PERMANENCIA EN EL EMPLEO Y PRODUCTIVIDAD

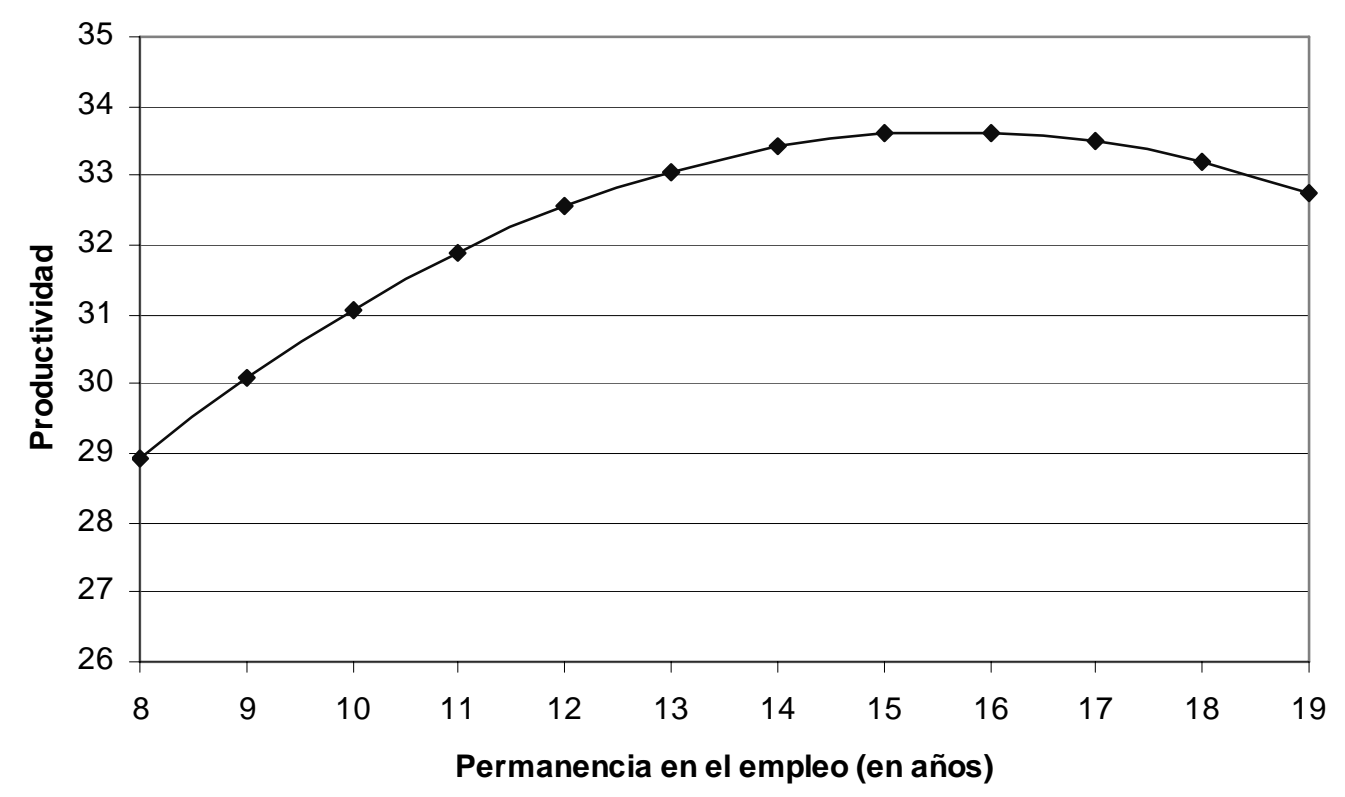

Fuente: Auer, Berg y Coulibaly, 2004.

Esta evolución, como lo advierte un estudio de la OIT (2004), no debe ser interpretada como la evolución de la productividad individual, ni adoptado como criterio para decidir los tiempos óptimos de retención de los trabajadores en la empresa. Sólo señala que tanto la corta duración (menos de 1 año) como la larga (más de 10 años pero especialmente en 15 y 20) pueden tener un efecto negativo sobre la productividad. Como se observa en el gráfico anterior, la productividad crece hasta alcanzar su máximo a los 13,6 años de antigüedad, mientras que en el tramo entre 5 y 10 años se concentra la mayor contribución al aumento de la productividad.

\section{Regulaciones, inseguridad y cohesión social}

La revisión efectuada en este capítulo proporciona fundamentos económicos a las reformas introducidas en América Latina durante las últimas dos décadas. La revisión de las regulaciones en el mercado de productos ha avanzado significativamente mediante la apertura comercial y 
financiera. Los avances en disminuir las barreras para iniciar nuevos negocios han sido menores, pero el tema está instalado y aceptado en las agendas de políticas en la mayoría de los países. Ellos deberían contribuir a acelerar el crecimiento, aunque esto no haya sido el caso generalizado hasta ahora para los países, ni para el promedio de la región.

Las reformas laborales flexibilizadoras han sido también incorporadas, aunque con diferentes intensidades, en las agendas nacionales. Sus efectos esperables sobre el crecimiento son significativamente menores, aunque pueden contribuir positivamente.

Ambas reformas introducen, sin embargo, una mayor inestabilidad que se manifiesta principalmente en el mercado de trabajo por la vía del desempleo, una mayor rotación laboral y menor permanencia en el trabajo y un cambio en las ocupaciones que se acompañan por una menor protección laboral y social. Se introduce además, un conflicto entre inestabilidad laboral, antigüedad en el trabajo y potencial de crecimiento de la productividad. En el caso de esta última, dicho conflicto se concentra en las contrataciones por plazos menores a 1 año y alcanza su máxima contribución alrededor de los 14 años, muy por encima del promedio registrado en los países de la región.

La inestabilidad se asocia a incertidumbre y afecta la cohesión social en países donde la protección laboral y social y los recursos públicos destinados a asegurarlas resultan insuficientes. Ello a pesar de que en varios países las legislaciones laborales incluyen una alta protección, pero cuyos efectos se diluyen por una alta evasión y se concentran en los trabajadores ocupados en las empresas de mayor tamaño. La mayor inestabilidad afecta a toda la población y particularmente, a los hogares de menores ingresos, pero su efecto sobre los trabajadores organizados altera las condiciones prevalecientes y produce una resistencia natural a través de las organizaciones sindicales con mayor capacidad de movilización y de expresión. Las tensiones en la cohesión social no solo se introducen entre excluidos e incorporados, sino también dentro de estos últimos. Es en ese ámbito, donde adquiere mayor visibilidad.

Las percepciones tienden incluso a ampliar la sensación de inestabilidad y se manifiesta en temores por pérdida de empleo superiores a la realidad objetiva prevaleciente. En promedio para América Latina en el 2005, el 75\% está preocupado de quedar sin trabajo en los próximos 12 meses, mientras que el 59\% afirma que en su hogar ha habido un adulto desempleado en los últimos doce meses (Latinobarómetro, 2005). Debe notarse, que la tasa de desocupación promedio para ese año alcanzó al 10\%. La preocupación expresada por este alto porcentaje de los encuestados se contrapone a una baja credibilidad en la protección que proporciona la ley laboral. Solo el $18 \%$ de los consultados se siente protegido por la legislación vigente. Al considerar la información para cada país se observa una alta correlación positiva entre temor a perder el empleo y experiencia de desempleo en el hogar y por otro lado, una relación inversa entre temor a perder el empleo y percepción de protección proporcionada por la legislación laboral. ${ }^{5}$ Venezuela constituye la excepción donde existe un bajo temor a quedar desempleado a pesar del alto porcentaje de hogares que ha
tenido un adulto desempleado en el ultimo año. Ello es consistente, por otro lado, con la percepción que manifiestan los venezolanos de que la legislación laboral es altamente protectora. 
Gráfico 6a

SEGURIDAD LABORAL Y DESEMPLEO, 2005

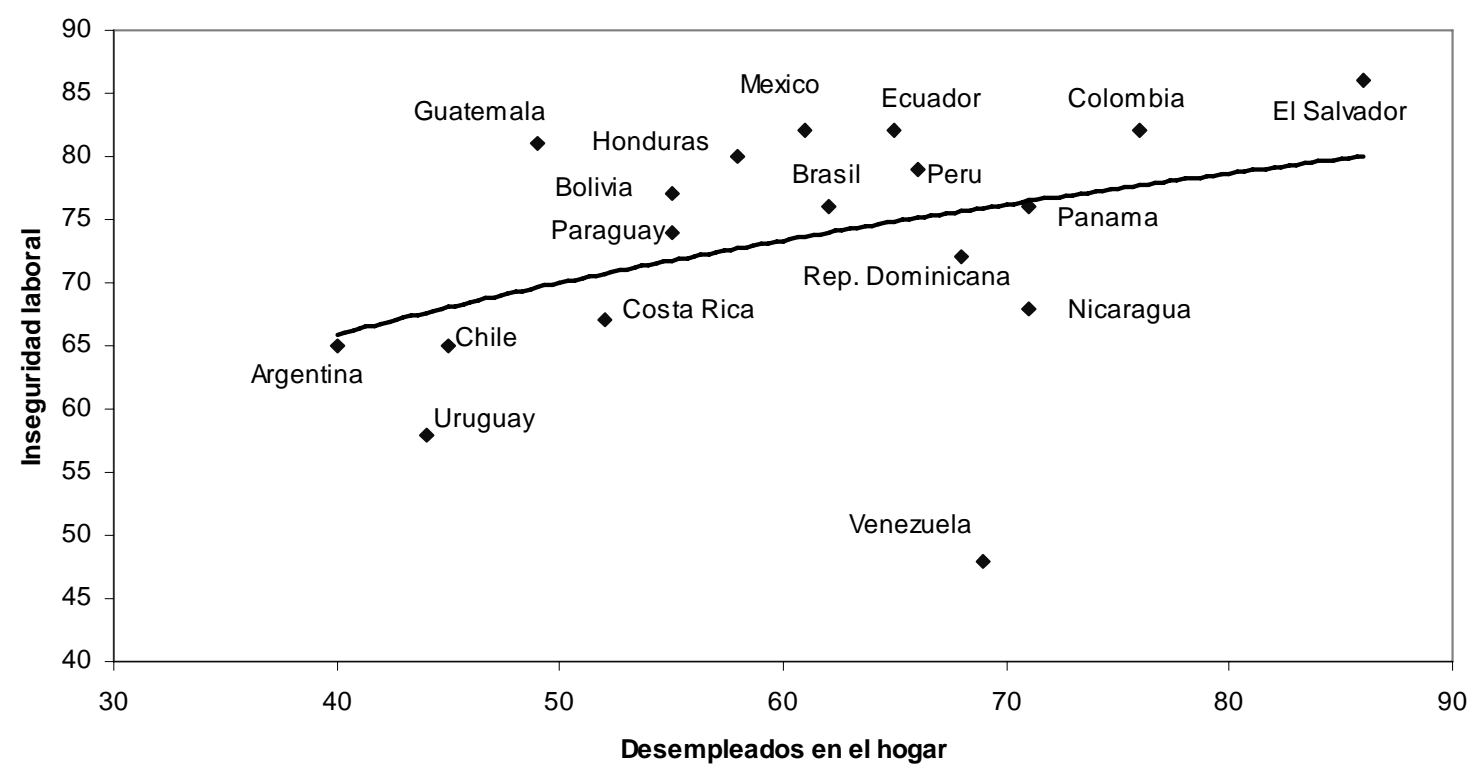

Fuente: Gráficos elaborados en base a encuesta Latinobarómetro 2005.

Nota: Inseguridad incluye la proporción que contesta estar muy preocupado o preocupado de estar desempleado durante los próximos 12 meses. Desempleados en el hogar incluye respuestas afirmativa a si ha habido algún adulto desempleado en los últimos doce meses. Efectividad legislación laboral incluye respuestas se siente muy o bastante protegido por la legislación laboral en el país.

\section{Gráfico 6b}

INSEGURIDAD Y LEGISLACIÓN LABORAL, 2005

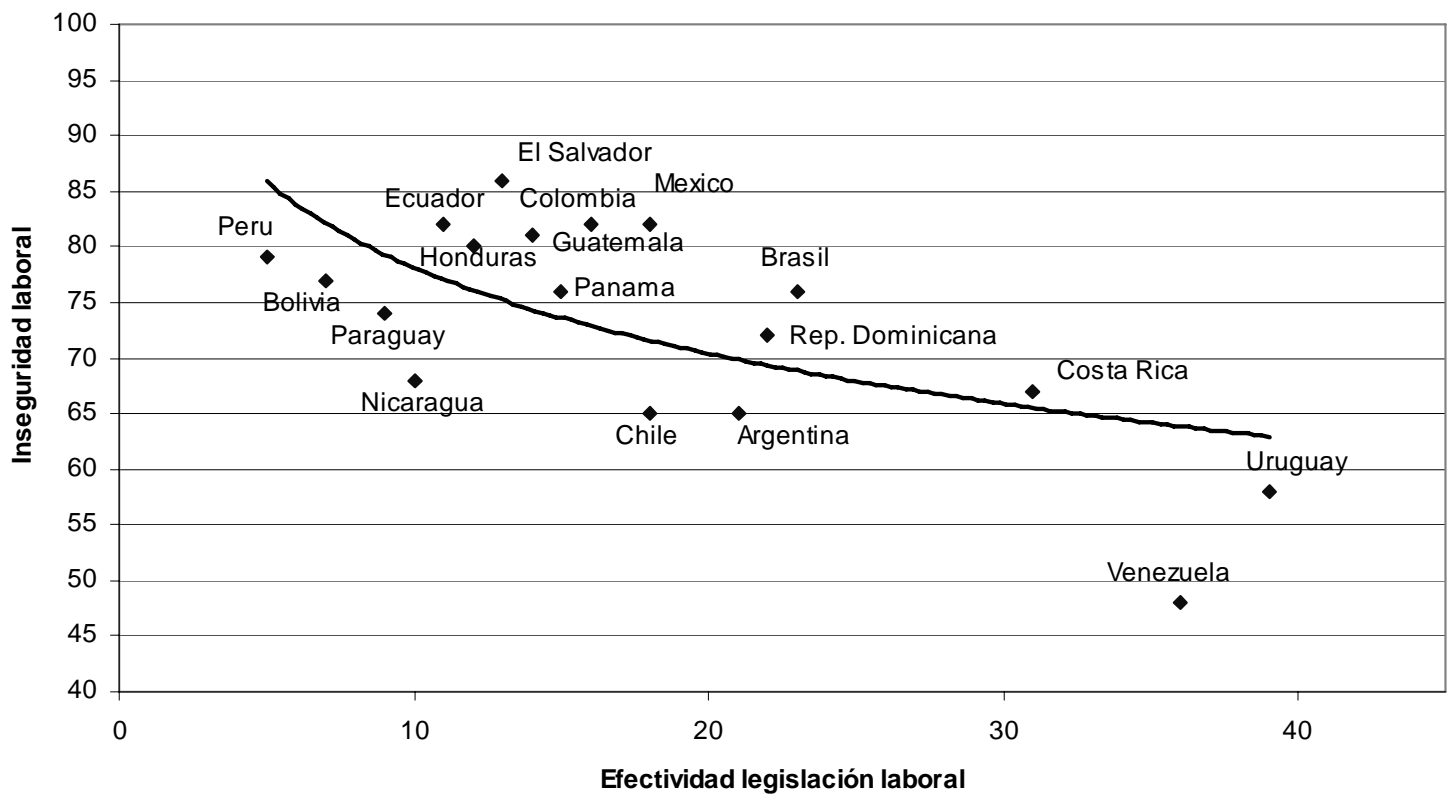

Fuente: Gráficos elaborados en base a encuesta Latinobarómetro 2005.

Nota: Inseguridad incluye la proporción que contesta estar muy preocupado o preocupado de estar desempleado durante los próximos 12 meses. Desempleados en el hogar incluye respuestas afirmativa a si ha habido algún adulto desempleado en los últimos doce meses. Efectividad legislación laboral incluye respuestas se siente muy o bastante protegido por la legislación laboral en el país. 


\section{Cohesión social, informalidad y exclusión}

\section{Informalidad, inseguridad y protección}

La inseguridad asociada al nuevo escenario económico afecta a toda la población independiente de la actividad que desempeñe, particularmente en países donde la protección social no es de cobertura universal y la protección laboral no está diseñada para proteger a los trabajadores frente a los riesgos emergentes. Afecta, sin embargo, en mayor medida a los grupos excluidos que en su mayoría no están protegidos e incluso, quedan al margen de los mecanismos institucionales existentes.

Estos grupos se encuentran ocupados en su mayoría en el sector informal pues carecen de alternativas ante la insuficiencia en la creación de nuevos empleos en los sectores organizados y la inviabilidad de subsistencia en el desempleo al no poseer ingresos propios o protección social. Para ellos la única opción la constituye producir o vender algo con los escasos recursos que poseen que les permita obtener el ingreso necesario para la sobre vivencia personal y de sus familias. Las actividades productivas que desempeñan se desarrollan por lo general, fuera de los marcos legales y de regulación y la población ocupada enfrenta condiciones de alta vulnerabilidad y pobreza. En el se encuentran microempresarios, trabajadores por cuenta propia, asalariados en esas empresas y familiares no remunerados. Por su magnitud y características afecta el grado de cohesión en los países latinoamericanos. Por un lado, de manera 
positiva porque constituye una alternativa de protección tradicional para la familia compartiendo relaciones productivas y de solidaridad entre sus miembros. Por otro, el efecto es negativo pues significa al mismo tiempo la exclusión por su inserción laboral de los sistemas de protección social financiados sobre base contributiva. ${ }^{6}$

La vulnerabilidad no se limita al sector informal, sino que se extiende a todos los que trabajan en unidades productivas reconocidas dentro de los marcos legales y de regulación existentes pero para los que las leyes no se aplican plenamente, sea por insuficiente fiscalización o porque la legislación es inadecuada o impone costos excesivos que conspiran contra su cumplimiento. La magnitud de ocupados que se encuentra en estas condiciones y su grado de inseguridad y desprotección también afecta el grado de cohesión social.

Ambas situaciones serán abordadas en este capítulo. Se analizarán primero los marcos conceptuales disponibles. En segundo lugar, se cuantificará la importancia relativa en la ocupación y las brechas de ingreso y de protección existente y su evolución. El capítulo finaliza con el análisis de estrategias a seguir para promover una mayor cohesión social mediante el avance en una incorporación plena de ambos grupos.

La CEPAL ha planteado desde comienzos de los años noventa la necesidad de introducir un contrato o pacto fiscal y social que centrado en la cohesión social evite los efectos negativos de la necesaria adaptabilidad de los mercados de trabajos para competir en mercados más abiertos. Se propone actuar conjuntamente sobre cuatro pilares: la coherencia de los fundamentos de la política macroeconómica, la generación de empleo, la protección social y la educación y capacitación (CEPAL, 2000 y 2004). Reconociendo que las políticas laborales no bastan para generar empleo, se destaca la necesidad de reactivación de la demanda de empleo y sugiere que si la flexibilidad laboral no está acompañada por un rápido aumento en la demanda se hace necesario una cobertura apropiada de protección laboral, políticas activas en el mercado de trabajo, apoyo al sector informal y el desarrollo del sistema de protección social.

Más recientemente CEPAL (2006), profundiza dicha propuesta y en particular, en relación a la protección social. Recomienda la introducción de un umbral mínimo de protección garantizado para todo miembro de la sociedad, realista en función del nivel de desarrollo y con un margen viable de redistribución entre sectores. Sugiere un esquema progresivo que responda a una doble lógica de equidad. La equidad individual que vincula los aportes con los beneficios y la equidad colectiva que vincula los aportes captados mediante impuestos y los beneficios que no se relacionan con los aportes, sino con las necesidades no cubiertas. Dada la situación existente y los progresos que se pueden esperar mejorando la inserción laboral y por ende, la protección social vinculada al trabajo, CEPAL (2006) destaca la necesidad de avanzar simultáneamente en el desarrollo de sistemas de protección social no vinculados al trabajo sobre base solidaria y con cobertura universal.

Este trabajo se ubica dentro de esa perspectiva sistémica y profundiza su contenido desde los temas laborales y el empleo y en particular, desde la inclusión social. La interacción entre los cuatro pilares mencionados se amplía incorporando los desafíos de políticas públicas que presenta la informalidad en cuanto a su inserción laboral y productiva, el fomento del empleo productivo mediante políticas activas y la formalización y las políticas de inclusión y protección laboral. Todo ello en el marco de la responsabilidad fiscal necesaria para resguardar el crecimiento económico y la estabilidad.

La existencia de sistemas de protección social sobre base no contributiva o mixta reduce o elimina este efecto de la exclusión por inserción laboral. 


\section{Informalidad: sector y economía}

\subsection{Sector informal: exclusión con inseguridad a bajos ingresos}

La definición de sector informal fue introducida por la OIT en su informe sobre Kenya (1972). El mismo destaca que el problema de empleo in países en desarrollo no es de desempleo, sino principalmente uno de trabajar sin percibir ingresos suficientes para sobrevivir. En el se encuentran los "trabajadores pobres". Su interpretación conceptual se efectuó en oposición a la formalidad y sobre la base de la exclusión en relación al acceso a los mercados y los recursos productivos.

Con posterioridad diversas contribuciones enriquecieron el concepto desde muy diversas perspectivas. Se incorporó la lógica de sobre vivencia a partir del análisis del proceso de creación de empleo insuficiente. Este análisis se ubicó en el contexto de la interpretación de Prebisch y la CEPAL sobre el desarrollo en América Latina y concluyó que las actividades en el sector informal eran el resultado de la presión ejercida por el excedente de oferta laboral sobre la insuficiente disponibilidad de nuevos empleos, particularmente de buenos empleos. El resultado es que ante la necesidad de sobrevivir, la gente se ve obligada a buscar soluciones de baja productividad-bajos ingresos sea produciendo o vendiendo algo (Souza y Tokman, 1974 y 1976).

Dichas actividades (soluciones) son de entrada fácil y requieren reducido capital y calificaciones, presentan escasa división de tareas y de jerarquías y la mano de obra está constituida por el patrón que desempeña también funciones de trabajador, los familiares no remunerados y asalariados, generalmente sin contratos de trabajo. El resultado de esta forma de producción es baja productividad e ingresos y desprotección. Debe destacarse, sin embargo, que facilita la distribución del costo de la inestabilidad entre la familia y la unidad de producción. Constituye una alternativa de empleo de alta flexibilidad que permite aprovechar eficientemente los tiempos disponibles de la familia (educación-trabajo de los hijos, cuidado del hogar-empresa de las madres). Permite también utilizar recursos fungibles que desempeñan funciones tanto domésticas como productivas (casa habitación-empresa, transporte familiar-comercial). De hecho, constituyen un mecanismo generado desde la sociedad para enfrentar la carencia de empleo y los riesgos de la desprotección.

A partir de mediados de la década de los ochenta se incorporan nuevas dimensiones. Por un lado, se destaca la importancia de que las actividades del sector se desarrollan fuera de los marcos establecidos por la ley y las regulaciones. Dentro de esta perspectiva se enfatiza la inadecuación de dichos marcos, lo que origina y restringe la expansión productiva de las actividades informales (De Soto, 1986). Por otro lado, se llama la atención sobre las vinculaciones de las actividades informales con las empresas organizadas como consecuencia de la necesidad de descentralización del proceso de producción y de trabajo necesarias para adaptarse a la globalización y a los cambios en la división internacional del trabajo (Portes, Castells y Benton, 1989). En esta perspectiva el sector informal se visualiza como un mecanismo de reducción de costos y de erosión del poder sindical. $^{7}$

Como resultado de tres décadas de contribuciones sobre el tema, el sector informal fue adquiriendo múltiples dimensiones recogiendo más estrechamente la realidad, aunque al costo de nivelar la importancia de los determinantes y por ende, de no jerarquizar las estrategias y políticas que se recomiendan. La OIT, consistente con su visión inicial, concentró su enfoque en las características de las unidades productivas de las actividades (enfoque empresarial), más que en las

7 En rigor, esta vertiente conceptual estuvo presente desde los inicios en el ámbito de la OIT al ser cuestionada por diversos investigadores, la autonomía del sector informal y al poner énfasis en el carácter de asalariados encubiertos que tenían los ocupados en el sector. Para una revisión de este tema véase Lubell, H. (1991). 
características de las personas involucradas (enfoque laboral). ${ }^{8} \mathrm{Su}$ propuesta estratégica asignó prioridad a la creación de empleo productivo en los sectores organizados, pero también en el apoyo para el desarrollo de las actividades informales mediante la promoción del acceso a los recursos productivos y a los mercados más dinámicos. Progresivamente se fue incorporando el ámbito de regulación tanto en los mercados de productos, incluyendo el reconocimiento legal de las actividades, como, más recientemente, el de la regulación laboral (Tokman, 2001).

\subsection{Informalidad: del sector a la economía}

La preocupación por el sector informal como una erosión estructural de la capacidad de protección y por ende de cohesión social, no podía aislarse del creciente proceso de precarización laboral que se observa a partir de mediados de los ochenta y que afecta ya no solo a los que se ocupan en el sector informal, sino principalmente, a los trabajadores en empresas formales. La pérdida de hegemonía del contrato de trabajo por tiempo indefinido y los crecientes vacíos de la legislación laboral para incluir relaciones de empleo emergentes adquirieron un lugar de importancia en la agenda. Las reformas laborales que se incorporaron al compacto de reformas económicas resultaron en una pérdida de protección para los trabajadores con contrato de trabajo y en un aumento de trabajadores sin contrato. La intensificación de la subcontratación entre empresas, puso en evidencia la falta de precisión en la asignación de responsabilidades por la protección laboral y social de los trabajadores involucrados.

Surgen numerosas iniciativas que destacan esta situación. La primera son los estudios efectuados sobre las reformas laborales flexibilizadoras en América Latina que mostraron el avance del proceso de precarización por introducción de contratos atípicos. El Perú, por ejemplo, adopta una reforma laboral a comienzos de los años noventa que introduce nueve modalidades de contratos de duración determinada y nuevas formas para externalizar la relación laboral mediante creación de empresas de servicios temporales, de empresas de servicios complementarios y cooperativas de trabajadores. Como resultado, el porcentaje de asalariados sin contrato o con contrato temporal se expande desde 49\% a más de 70\% entre 1990 y 1996.

La segunda es la adopción por parte de la OIT de un nuevo convenio internacional del trabajo ( $\mathrm{N}^{\circ}$ 177) sobre protección del trabajo a domicilio en 1996. Dicho Convenio, se aplica al trabajo a domicilio cuando el producto o servicio es especificado por el empleador y se considera que existe una relación laboral descentralizada, debiendo ser tratada como la de asalariado, teniendo en cuenta las características especiales del trabajo a domicilio. El Convenio asigna a los trabajadores a domicilio el derecho a incorporarse a las organizaciones que prefieran y a protección laboral. La responsabilidad por el cumplimiento de esta obligación es compartida entre empleadores e intermediarios.

La tercera iniciativa se refiere a la protección de los derechos de los trabajadores estableciendo efectivamente cuando existe una relación de empleo con el objetivo de "combatir relaciones de empleo disfrazadas", "asegurar normas aplicables a todas las formas contractuales que involucren multi-partes" y "establecer quién es responsable por la protección debida". Dicha discusión, iniciada en 1998, culminó con la adopción de una Recomendación en la Conferencia Internacional del Trabajo de junio del 2006. La misma fue adoptada sin el apoyo de los empleadores miembros de Organización, dejando en evidencia que las opiniones divergentes sobre la materia continúan pendientes.

La precariedad, el trabajo no declarado y la informalidad en el mercado de trabajo crecen y se utilizan como sinónimos. Trabajo desprotegido y precario se concentra en el sector informal,

8 La Conferencia Internacional de Estadísticas Laborales acordó en 1991 definir el sector de acuerdo al primer enfoque. 
pero también en empresas formales o en cadenas de producción para reducir costos y aumentar la flexibilidad. Ello llevó a la OIT a ampliar el concepto de sector informal que introdujo a comienzos de los setenta, incorporando a nuevo concepto: la economía informal. Esta última incluye el sector informal, pero agrega a todos los trabajadores ocupados, directa o indirectamente, por las empresas formales.

El nuevo concepto de economía informal, aprobado por la Conferencia Internacional del Trabajo del 2002, considerando que la definición de sector no captura adecuadamente todas las dimensiones de empleo informal, recomienda que los trabajadores deben ser clasificados como formales o informales de acuerdo a su status laboral. No propone eliminar el concepto de sector informal sino ampliarlo al de economía informal. La unidad de análisis en la nueva definición son los puestos de trabajo, los que se agregan a la unidad de producción considerada informal. La innovación principal es la inclusión como informales a todos los trabajadores independientemente de donde trabajen, cuya relación de empleo no está sujeta a los estándares establecidos por la legislación laboral, impuestos, protección social y otros beneficios laborales (vacaciones, enfermedades del trabajo, indemnizaciones por despido, etc.). Esto significa en definitiva agregar al sector informal a todos los trabajadores no plenamente protegidos ocupados en empresas mayores de 5 trabajadores.

\subsection{Cohesión social: exclusión e incorporación insegura}

Los avances efectuados para clarificar la relación de empleo con el objetivo de asegurar la protección laboral y social de los trabajadores deben ser apreciados. Sin embargo, su contribución a enfrentar los problemas del sector informal es menos clara. La combinación de unidades de análisis al considerar tanto la unidad productiva como el puesto de trabajo contribuye a captar la situación de los que se ocupan en el sector informal. En el coexisten baja productividad, inseguridad y desprotección. Por el contrario, aún cuando la relación laboral permite identificar a los trabajadores sin protección plena con independencia de en que tipo de unidad productiva se desempeñen, los mismos no constituyen sectores excluidos asimilables a los anteriores.

En particular, al trasladar el énfasis de los análisis desde la forma de producción a la relación de empleo, se deja de lado la capacidad de las empresas de contribuir a la protección de sus trabajadores o incluso, la de los empresarios y sus familias. En las unidades productivas del sector informal, esa capacidad es la que no alcanza para cubrir con las obligaciones que se asocian a la formalidad. Las que incluyen no solo las responsabilidades laborales con los trabajadores sino también las asociadas con el funcionamiento de las empresas (regulaciones, pagos de impuestos y otras). La existencia de relaciones laborales encubiertas no declaradas o no contempladas en la legislación laboral así como el incumplimiento de la legislación existente obedece a otras causas y amerita diferentes soluciones.

Es cierto que ni los ocupados en el sector informal pueden calificarse como totalmente desprotegidos, ni que los ocupados en empresas formales están plenamente protegidos en comparación con los que poseen contratos de trabajo permanentes. También es cierto que existen dentro del sector informal actividades como el trabajo a domicilio que constituye una relación de empleo encubierta cuando produce para empresas formales o intermediarios. Ello debería ser incorporado explícitamente en la legislación laboral identificando los niveles de responsabilidad por el cumplimiento de las obligaciones. Sin embargo, estas situaciones están más difundidas dentro de las actividades formales que crecientemente recurren a la descentralización productiva y del proceso de trabajo como mecanismo para disminuir los costos de producción, particularmente los laborales. Por ello es importante identificar las magnitudes y características de las diferentes situaciones, así como los ámbitos de políticas públicas más adecuados para avanzar en la creación de empleos más seguros y más protegidos. 


\section{Informalidad productiva-laboral y desprotección}

En esta sección se examinará la informalidad tanto desde la perspectiva productiva como laboral y se analizarán los principales indicadores disponibles. El sector informal, donde coinciden unidades productivas de reducido tamaño y trabajadores con relaciones laborales generalmente no reconocidas legalmente y sin protección plena se analizará en la primera parte. En la segunda, el análisis incorporará desde una perspectiva laboral más general a todos los trabajadores, con independencia de donde laboren cuyas relación laboral no es reconocida legalmente o si lo es, sus obligaciones no se cumplen plenamente.

\subsection{Sector informal: informalidad productiva y laboral}

El 50,3\% de la ocupación no agrícola en América Latina se encontraba en el sector informal en el 2005. ${ }^{9}$ El $55 \%$ desempeña trabajos por cuenta propia, 33\% se encuentra en microempresas de menos de 5 trabajadores y el resto, $12 \%$, se ocupa en el servicio doméstico. El sector informal crece sostenidamente desde 1990 pasando del 47,5\% al 50,3\% en la actualidad. Sólo durante los tres años más recientes se observa una estabilización en el tamaño del sector asociado a la recuperación económica y del empleo con posterioridad a las crisis ocurridas a fines de los noventa y comienzos de la presente década. Los ocupados por cuenta propia y las microempresas aumentan su participación, mientras que el servicio doméstico se mantiene estable. De los 2,8 puntos porcentuales de aumento de la informalidad durante los 15 años, 1,5 proviene de las microempresas y 1,2 del crecimiento de los trabajadores independientes.

Cuadro 2

EMPLEO INFORMAL: AMÉRICA LATINA, 1990-2005

(Porcentajes de la ocupación no agrícola)

\begin{tabular}{c|c|c|c|c|c|c}
\hline Años & $\begin{array}{c}\text { Sector } \\
\text { informal }\end{array}$ & $\begin{array}{c}\text { Micro- } \\
\text { empresas }\end{array}$ & Empleadores & Trabajadores & $\begin{array}{c}\text { Servicio } \\
\text { doméstico }\end{array}$ & $\begin{array}{c}\text { Trabajadores } \\
\text { por cuenta } \\
\text { propia }\end{array}$ \\
\hline 1990 & 47,5 & 15,2 & 3,2 & 12,0 & 5,7 & 26,6 \\
2000 & 49,7 & 15,7 & 3,4 & 12,3 & 5,6 & 27,9 \\
2002 & 50,2 & 16,3 & 3,7 & 12,6 & 5,6 & 28,3 \\
2005 & 50,3 & 16,7 & 3,6 & 13,1 & 5,8 & 27,8 \\
\hline
\end{tabular}

Fuente: CEPAL sobre la base de encuestas de Hogares de cada país.

Nota: Incluye información para 15 países. Cuenta Propia no calificados.

Los promedios para América Latina no reflejan la diversidad de situaciones que se observan por países, tanto en la dimensión como en la evolución del sector informal. El gráfico siguiente presenta una tipología de situaciones al considerar el tamaño del sector en 1990 y en 2005 . Incluye además los promedios regionales en ambos años (líneas horizontales) lo que permite observar la posición relativa de los países en relación al promedio y agrega una diagonal que permite diferenciar los países donde disminuye el sector informal (bajo la diagonal), de los que registran una expansión (sobre la diagonal). En el cuadrante superior se ubican los países que registran un tamaño del sector informal por encima del promedio regional en ambos años y en el inferior ocurre lo contrario.

9 Se refiere al promedio simple de 15 países latinoamericanos. Al utilizar la mediana como indicador del conjunto de países el sector informal alcanza a cerca de $55 \%$ en el mismo año. 
Se encuentran en el primero los países andinos y la mayoría de los centroamericanos, fluctuando el sector informal entre un máximo de $71 \%$ en Bolivia a un mínimo de $55 \%$ en El Salvador, con un promedio de $61 \%$. En el cuadrante inferior, donde el sector informal registra niveles inferiores al promedio regional, se encuentra Chile con un tamaño de 32\%, que es el mínimo para la región, hasta un rango de 43-44\% donde se ubican Brasil, México, Panamá y Uruguay. En Costa Rica el sector informal alcanza a $40 \%$, mientras que el promedio para el grupo en su conjunto alcanza a $41 \%$. Las diferencias entre los extremos llegan a casi 40 puntos porcentuales y aún entre los promedios se observan diferencias de 20 puntos porcentuales. Ello indica la heterogeneidad de situaciones nacionales que componen América Latina en su conjunto. La evolución durante los últimos 15 años es, sin embargo, más homogénea. Solo cuatro países registran una disminución de la informalidad (Chile, Argentina, Brasil y El Salvador), mientras que en el resto aumenta.

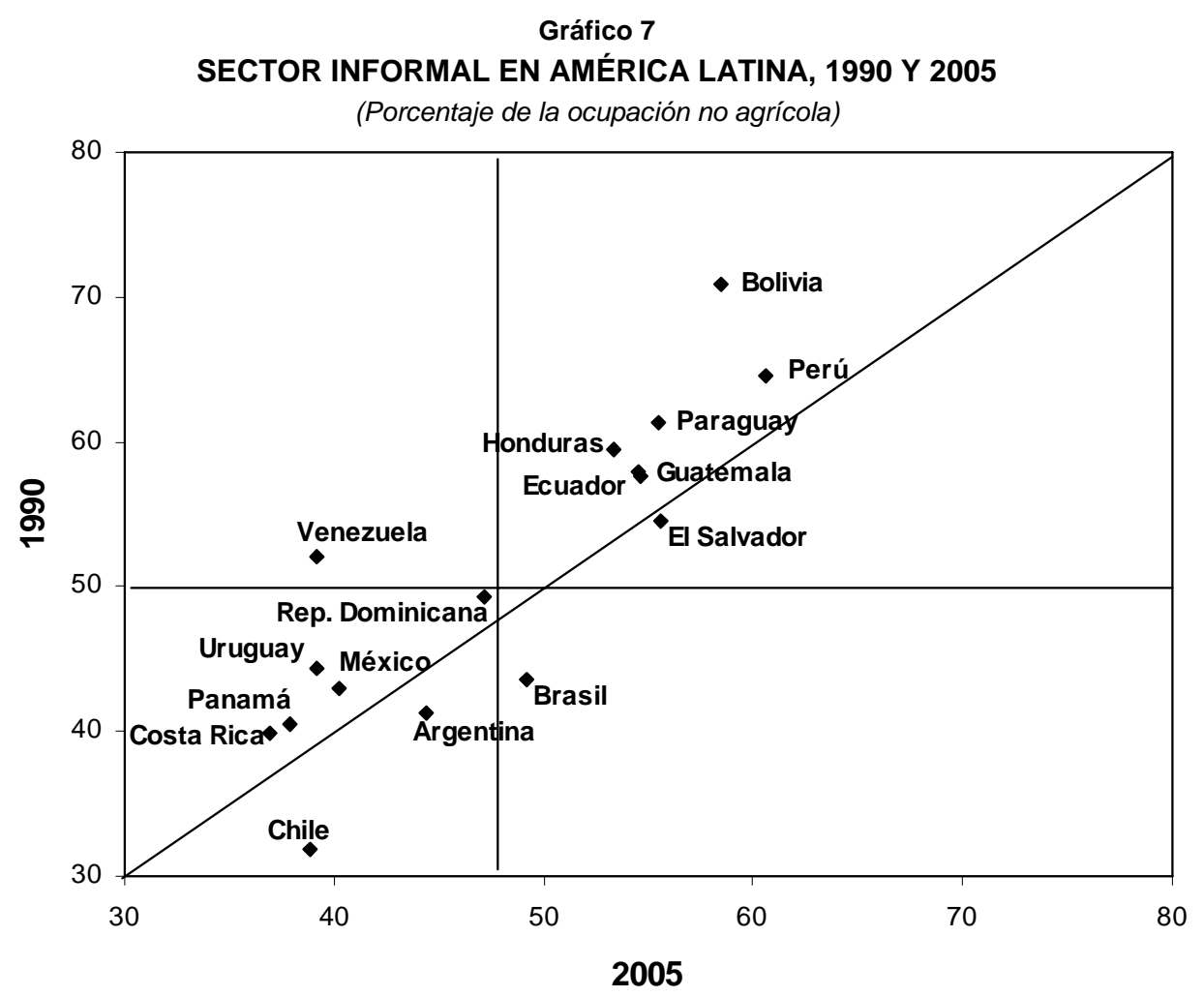

Fuente: CEPAL en base a encuestas de hogares de cada país.

Tres relaciones importantes para analizar la relación entre informalidad y cohesión social son las que existen entre informalidad y el nivel del ingreso por habitante, la percepción de inseguridad y el grado de equidad. Como lo muestra el panel de gráficos siguiente, la primera revela una significativa relación negativa mientras que en las dos siguientes dicha relación es positiva, aunque de menor significación. A mayor nivel de ingreso por habitante, menor es el tamaño del sector informal. Esta relación observada entre los países latinoamericanos se manifiesta con mayor claridad si se incluyen países desarrollados (Banco Mundial, 2004). El mayor grado de desarrollo significa una mayor homogeneidad productiva y una inserción laboral más uniforme. Puede también interpretarse como la existencia de un menor grado de regulación, particularmente en los mercados de bienes ya que, como señalamos más arriba, la asociación con la regulación en el mercado de trabajo es menos importante. 
La segunda relación muestra que la mayor informalidad está acompañada por una mayor percepción de inseguridad. ${ }^{10}$ Ello se deriva de que el sector informal es percibido negativamente debido a que los ocupados en el mismo obtienen ingresos bajos, las actividades que desempeñan son de baja productividad y los puestos son inestables y con escasa protección. Por el contrario, cuanto menor es la proporción de la fuerza de trabajo ocupada en el sector informal, mayor es la valoración de que el mismo puede constituir una alternativa más segura al menos durante los períodos de contracción de la demanda de empleo en los sectores más organizados. Ello es importante en países, como los latinoamericanos, donde los seguros de desempleo son inexistentes o compensan a los cesantes solo muy parcialmente. Esta evidencia no parece apoyar la interpretación de que la existencia del sector informal es el resultado de decisiones voluntarias de los individuos debido a la posibilidad de obtener mayores ingresos.

La tercera relación sugiere que la mayor informalidad se encuentra en los países con más inequidad. Ello ocurre claramente en países como Bolivia, Honduras y Guatemala que presentan la más alta informalidad junto a la mayor concentración de ingresos. En menor medida también se observa en Brasil y Perú. Por el contrario, los países con menor inequidad en la región, Uruguay y Costa Rica, también son los que presentan la menor informalidad. Chile constituye un caso intermedio ya que registra la menor informalidad de la región pero su distribución en comparación con los países latinoamericanos se encuentra en un nivel de concentración intermedio. La desigualdad de ingresos se asocia a una mayor concentración de activos y alta heterogeneidad productiva y se manifiesta en altas brechas de ingresos. Los grupos medios son menos significativos al reducirse las posibilidades de inserción en estratos intermedios. Por el contrario, no es sorprendente encontrar que en los países que se han caracterizado por una mayor igualdad e integración social son los registran los menores niveles de informalidad.

\section{Gráfico 8a \\ INFORMALIDAD Y PRODUCTO PER CAPITA}

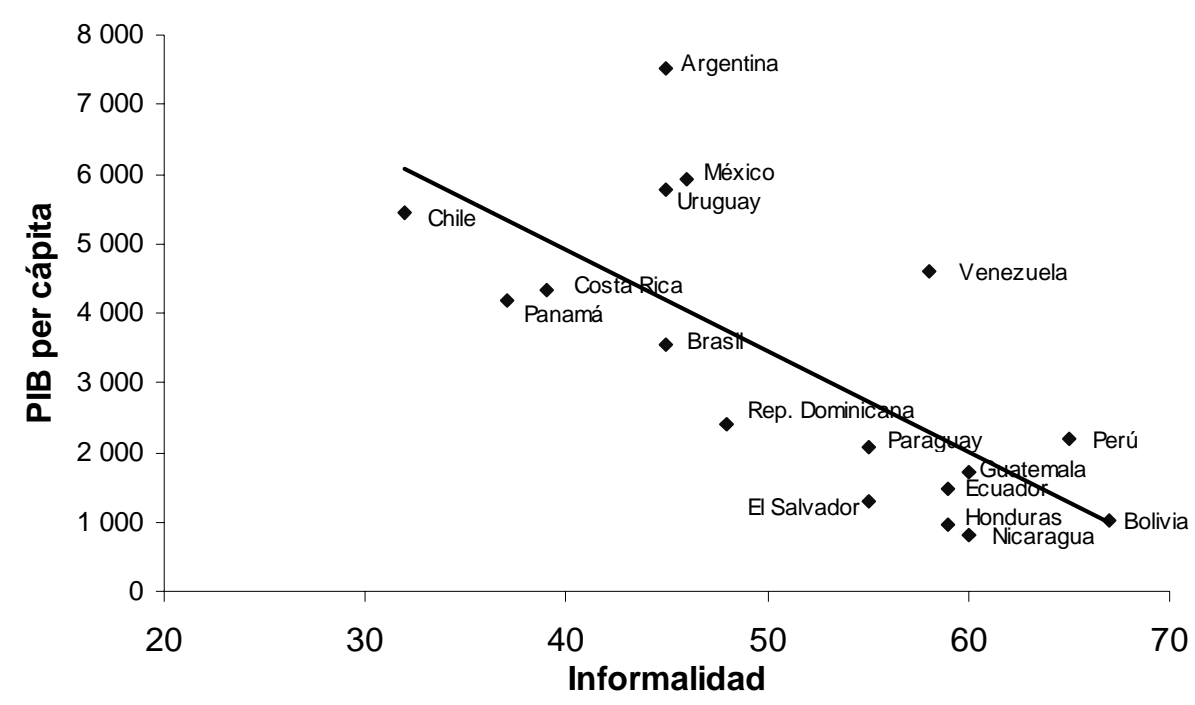

Fuente: Elaborado con información para el año 2005 de Informalidad e inequidad, CEPAL, 2005. Producto por persona PPT. Banco Mundial. Inseguridad Latinobarómetro 2005.

10 Venezuela constituye la excepción con una percepción baja de inseguridad y un alto empleo informal. Si se excluye del gráfico 8b, la pendiente de la línea de tendencia se torna más pronunciada. 


\section{Gráfico 8b \\ INSEGURIDAD E INFORMALIDAD}

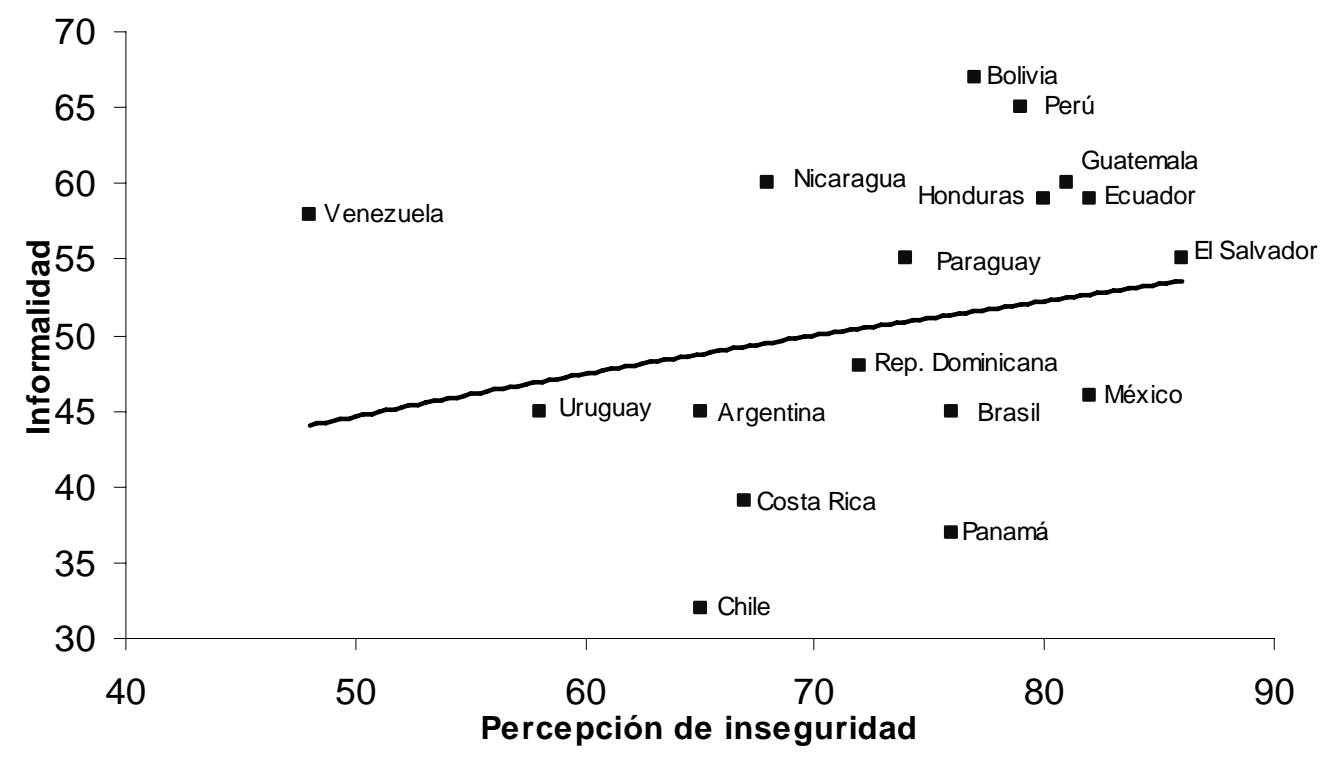

Fuente: Elaborado con información para el año 2005 de Informalidad e inequidad, CEPAL, 2005. Producto por persona PPT. Banco Mundial. Inseguridad Latinobarómetro 2005.

\section{Gráfico 8c \\ INFORMALIDAD E INEQUIDAD}

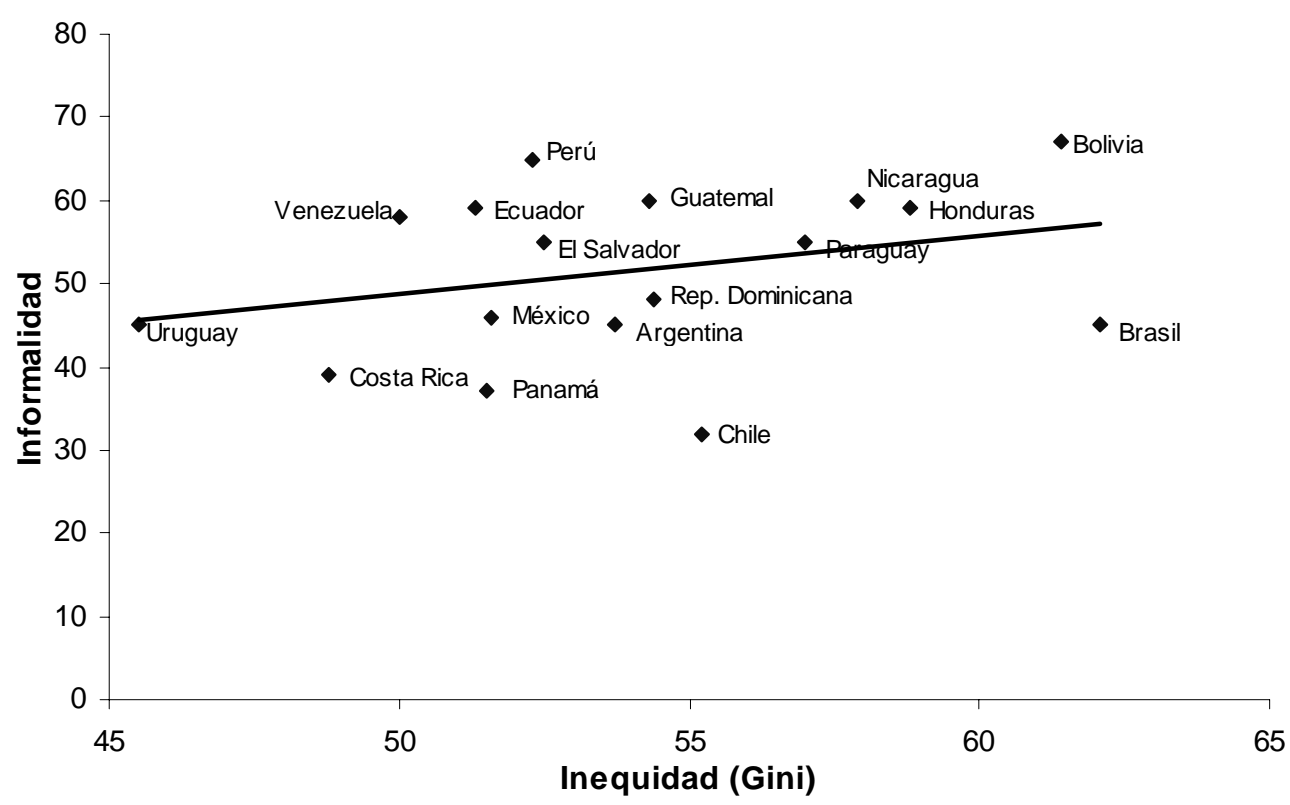

Fuente: Elaborado con información para el año 2005 de Informalidad e inequidad, CEPAL, 2005. Producto por persona PPT. Banco Mundial. Inseguridad Latinobarómetro 2005. 
El sector informal constituye la fuente de ingresos más importante de los pobres en América Latina. El 65\% de los que se ubican en los dos quintiles inferiores de la distribución está ocupado en el sector informal. El porcentaje alcanza al $74 \%$ entre los más pobres que se encuentran en el primer decil. Por el contrario, la mayoría de los informales no es pobre sino que incluye también ingresos medios que se ubican en los deciles quinto, sexto y séptimo de la distribución. El trabajo es la fuente casi exclusiva de ingresos autónomos. ${ }^{11} \mathrm{El}$ análisis del sector informal adquiere, por ende, importancia tanto en relación a la pobreza como a la distribución de ingresos y a la cohesión social. Por ello, conviene también observar los cambios en la estructura de empleo dentro del sector y en especial, las brechas de ingreso dentro del sector y en relación con el sector formal.

El cuadro 3 presenta la magnitud y evolución de las brechas de ingresos entre 1990 y el 2005. Las diferenciales son amplias y crecientes. En promedio para los 15 países con información disponible la brecha entre el sector formal y el informal creció del 59 al $81 \%$ en el período analizado. Las brechas entre asalariados según el sector de ocupación, que eran menores que para el los ocupados en su conjunto durante los años noventa, alcanzan niveles similares hacia el 2005. Dicha expansión más reciente en la brecha de ingresos entre trabajadores se relaciona por un lado, con las diferencias de productividad entre empresas según tamaño. Las empresas de mayor tamaño aumentaron su brecha de productividad con posterioridad al ajuste reciente y traspasaron en parte dichos aumentos a los salarios. Por otro lado, la mayor organización e importancia de la negociación colectiva en dichas empresas contribuye también a mejorar la participación de los trabajadores en los ingresos generados. Por el contrario, en las empresas informales con menos de 5 trabajadores, e incluso en las pequeñas empresas (6 a 50 trabajadores), la globalización y los ajustes han significado un deterioro ante la competencia de productos importados de menor precio, el acceso restringido al crédito y la competencia desigual que se genera en mercados más concentrados. Ello afecta los ingresos de las micro y pequeñas empresas y en consecuencia, a los salarios de los trabajadores.

El trabajo independiente en el sector informal constituía una alternativa neutra frente al trabajo asalariado en el sector privado y ventajosa en relación al asalariado en empresas informales de menos de 5 trabajadores. Sin embargo, la situación cambia durante el período. En el 2005, los ingresos de los trabajadores independientes son $20 \%$ inferiores a los de los trabajadores del sector privado y aunque continúan siendo superiores a los de los asalariados en micro empresas, la diferencia se reduce de 51 a $26 \%$. En el primer caso debe considerarse que los independientes están sujetos a una alta inestabilidad de ingresos y carecen de protección laboral y social. Aunque la independencia que permite este tipo de ocupación contribuye a tornarla atractiva, se requiere además que los ingresos percibidos sean convenientes. Ante esta situación, más que una decisión voluntaria, el recurrir a estos trabajos parece constituir una opción al desempleo y adquiere un carácter forzado.

Los diferenciales de ingresos entre empleadores y trabajadores en empresas formales e informales permiten corroborar que si bien las brechas en las empresas de mayor tamaño superan a las registradas en las microempresas, ambas diferencias disminuyen durante el período aunque en las empresas grandes se estabilizan en el 2005 al nivel del 2000. Ello no ocurre en el caso de las microempresas que muestran una caída sostenida en la diferencial, lo que es consistente con el deterioro en la situación de las empresas de menor tamaño ya señalada y con la recuperación de los salarios mínimos. Ante esta situación cabe interrogarse sobre porqué los empleadores de microempresas no se trasladan al sector informal. La comparación de brechas sugiere sin embargo, que aún desde la perspectiva de los ingresos potenciales dicha opción no parece viable. Resultaría

11 Alrededor del 90\% del ingreso autónomo proviene del trabajo, porcentaje que disminuye particularmente entre los pobres si se incluyen los ingresos por subsidios públicos. 
conveniente si un microempresario puede acceder a los ingresos promedios registrados por los empresarios en empresas de más de cinco trabajadores pues les permitiría multiplicar por 2,2 veces sus ingresos, pero no resultaría atractivo convertirse en asalariado en el sector formal porque su ingreso se reduciría a menos de la mitad de lo que percibe en la actualidad. La reconversión para los microempresarios encuentra además barreras tanto de acceso, particularmente al crédito y al hecho que las microempresas constituyen en su mayoría soluciones empresariales quasi-familiares cuya adaptabilidad permite utilizar flexiblemente mano de obra familiar y compatibilizar los tiempos de trabajo con las responsabilidades fuera del mismo (madre, trabajo-cuidado e hijos, trabajo-educación).

Cuadro 3

DIFERENCIAS DE INGRESOS SEGÚN SECTOR Y CATEGORÍA OCUPACIONAL EN AMÉRICA LATINA, 1990-2005

\begin{tabular}{l|r|r|r}
\hline & $\mathbf{1 9 9 0}^{\mathbf{a}}$ & $\mathbf{2 0 0 0}^{\mathbf{a}}$ & $\mathbf{2 0 0 5}^{\mathbf{a}}$ \\
\hline Ocupados sector formal / Ocupados sector informal & 1,59 & 1,72 & $\mathbf{1 , 8 1}$ \\
Asalariados empresas > 5 / Asalariados empresas <= 5 & 1,46 & 1,54 & $\mathbf{1 , 8 1}$ \\
Trabajador independiente / Asalariados privados & 1,04 & 0,79 & $\mathbf{0 , 7 9}$ \\
Trabajador independiente / Asalariados empresas <= 5 & 1,51 & 1,25 & $\mathbf{1 , 2 4}$ \\
Empleadores empresas > 5 / Asalariados empresas > 5 & 6,31 & 5,19 & $\mathbf{4 , 6 6}$ \\
Empleadores empresas <= 5 / Asalariados empresas <= 5 & 4,52 & 4,11 & $\mathbf{3 , 8 2}$ \\
\hline
\end{tabular}

Fuente: CEPAL, en base a encuestas de hogares de cada país. Incluye 15 países.

${ }^{\text {a }}$ : Alrededor de.

\subsection{Relación laboral: reconocimiento legal y protección}

El acceso a la protección laboral y social constituye un factor determinante del grado de cohesión social. A su vez, la inserción laboral y el reconocimiento legal de la relación laboral prevaleciente constituyen requisitos imprescindibles para acceder a dicha protección. Los desocupados en países sin seguros de desempleo enfrentan una doble exclusión: por carencia de empleo y por desprotección. La forma de incorporación también influye. Las relaciones laborales se refieren a formas de trabajo subordinadas que prevalecen entre empleadores y trabajadores en el ámbito de las empresas y en el sector público, donde el gobierno se desempeña como empleador.

Trabajos recientes muestran las diferencias de protección que resultan en América Latina de diversas formas de inserción y relación laboral (CEPAL, 2006 y V. E Tokman, 2006). ${ }^{12}$ Solo el $18 \%$ de los ocupados en el sector informal contribuye a la seguridad social, mientras que el $68 \%$ de los que laboran en el sector formal tiene cobertura. La inserción mediante el empleo en la informalidad genera desprotección, aunque el grado de la misma es variable entre países. Países con menor informalidad y mayor cobertura de protección, presentan menores diferencias entre coberturas según el tipo de inserción laboral. En Costa Rica, Chile y Uruguay, entre el 35 y el 40\% de los ocupados en el sector informal posee cobertura, mientras que en Guatemala, Nicaragua, Perú y Paraguay la cobertura registrada fluctúa entre 2 y $3,5 \%$.

Es importante también la modalidad de inserción laboral aún dentro del sector informal. Solo $13 \%$ de los ocupados como trabajadores independientes y micro empresarios posee cobertura de protección, mientras que el $22 \%$ de los asalariados en microempresas de hasta 5 trabajadores

12 Dada la escasa información disponible, en ambos trabajos se adopta la cotización a la seguridad social en pensiones como indicador de protección. Dicho indicador es más exigente que los de protección laboral, pero se considera que constituye un componente necesario de la protección al trabajador. 
registra algún grado de cobertura. Por otro lado, entre los asalariados, la naturaleza del empleador y el tamaño de la empresa son importantes para determinar la cobertura de protección. El 83\% de los empleados públicos posee protección, mientras que solo la mitad de los asalariados en el sector privado acceden a la misma. El $22 \%$ de asalariados en microempresas que tiene protección, se compara con el $67 \%$ de los asalariados en empresas el resto de las empresas y el sector público.

A pesar de las diferencias señaladas entre los asalariados, la existencia de una relación laboral explícita y reconocida o no, con independencia de en que tipo de unidad productiva se desarrolla, permite efectuar un análisis en mayor profundidad. Este análisis se desarrollará desde una doble perspectiva. Primero, en relación con el reconocimiento legal de la relación laboral y segundo, del acceso a la protección social que se asocia a dicho reconocimiento o a su carencia. Ello requiere examinar la importancia de los contratos de trabajo escritos o su inexistencia y el tipo de contratos, así como la cobertura de protección que se relaciona con las diferentes situaciones ocupacionales. $^{13}$

Los asalariados en promedio para América Latina constituyen alrededor del 63.5\% de la ocupación urbana. Dos tercios entre ellos están ocupados en empresas privadas formales y en el sector público, mientras que el tercio restante lo hace en microempresas informales y en el servicio doméstico. ${ }^{14}$ El $62 \%$ posee un contrato de trabajo, mientras que el $38 \%$ trabaja sin reconocimiento legal de su situación laboral. ${ }^{15}$ El $74 \%$ de los que poseen contrato, dicho contrato es por tiempo indefinido y el resto lo hace con otros tipos de contratos. Si a los que poseen un contrato diferente al por tiempo indefinido se agregan los que no poseen contrato escrito, más de la mitad de los asalariados en América Latina se encontraría en situación de "informalidad" ${ }^{16}$ Dicha proporción varía entre países desde un mínimo de $21 \%$ en Argentina hasta un máximo de $74 \%$ en Bolivia.

Es necesario, sin embargo, analizar que significa en términos de protección el poseer contrato y la diferencia que existe entre distintas modalidades contractuales. El contrato de trabajo constituye un reconocimiento legal de la relación laboral y se refleja en una mayor cobertura que en promedio para los que lo poseen es de $80 \%$. La inexistencia de contrato escrito no significa la carencia total de protección, pero sí una pérdida significativa de la misma. El 19\% en promedio de los que se encuentran sin contrato tienen protección. El tipo de contrato también influye. El 86\% de los que poseen contratos por tiempo indefinido tienen protección, mientras que para los que están sujetos a otro tipo de contratos la cobertura de protección disminuye al $61 \%$. Cobertura esta que es inferior a la del contrato por tiempo indefinido, pero más que triplica la registrada para los trabajadores sin contrato.

La cobertura de protección para los que poseen contrato de trabajo varía entre países desde 96\% en Chile, 92\% en México y 90\% en Panamá a 66\% en Bolivia y Argentina. Este último país, como se señaló muestra la proporción más alta en la región de asalariados con contrato, pero su grado de cobertura se ubica entre los más bajos. Las diferencias señaladas sugieren una gama de situaciones de "informalidad", pues existe diversidad en cuanto al acceso a la protección para una relación laboral similar dependiendo de su reconocimiento y de su situación contractual específica.

13 Debe señalarse que el índice de cobertura de protección se refiere exclusivamente a aportes para pensiones vinculados a la relación laboral. No incluye los derechos que pueden cubrirse mediante sistemas de protección social no contributivos, universales y solidarios. Para los fines del análisis este indicador, además de ser el único disponible para un número significativo de países, constituye una proxy relevante en cuanto al cumplimiento de las obligaciones laborales que emanan del contrato de trabajo.

14 Promedio aritmético de 16 países en 2002.

15 Promedio aritmético referido a siete países con información completa disponible para 2002 (Argentina, Bolivia, Chile, Ecuador, Guatemala, México y Panamá). El promedio para 10 países (incluyendo lo anteriores y Brasil, El Salvador y R. Dominicana) que presenta información de asalariados con contratos el porcentaje de los con contrato disminuye ligeramente a 59\% y el de los sin contrato aumenta a $38 \%$.

16 Informalidad definida en términos de la OCDE como trabajo no regular, estable y protegido. Incluye trabajadores por cuenta propia, a tiempo parcial y temporales. 
Más aún, como lo ilustra el caso de Argentina, el reconocimiento legal no significa necesariamente acceso a la protección social.

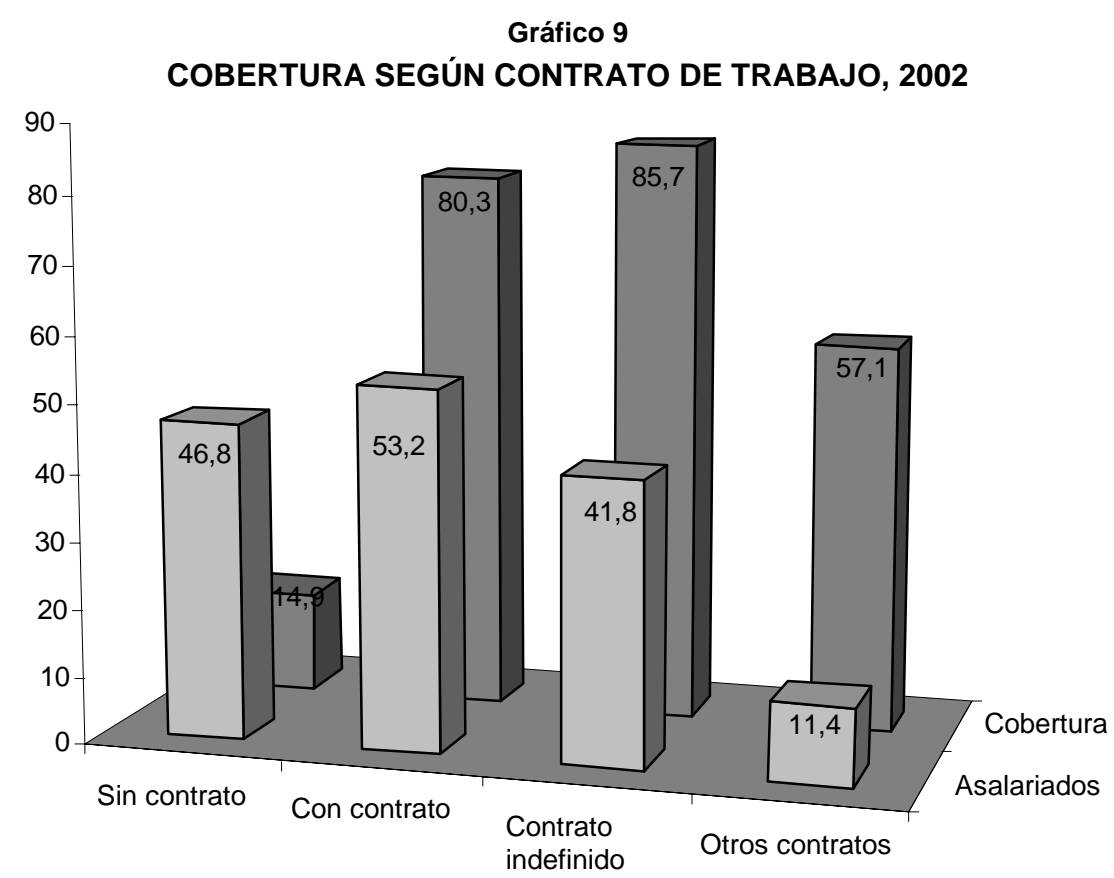

Fuente: Elaborado en base a encuestas de hogares de siete países.

Nota: Asalariados: en \% del total; cobertura: en \% del total de cada categoría.

La heterogeneidad existente entre los asalariados en su conjunto de acuerdo a su situación contractual aumenta en complejidad cuando se diferencia la situación de los que trabajan en empresas formales y el sector público, de la de los que laboran en el sector informal. El $74 \%$ de los asalariados en el sector formal posee contrato de trabajo, mientras que el $26 \%$ labora sin reconocimiento legal de su relación laboral. Estas proporciones se invierten cuando se refieren al sector informal. La mayoría de los asalariados en microempresas y servicio doméstico, 68\%, trabaja sin contrato y solo el $32 \%$ posee contrato de trabajo escrito. A su vez, los asalariados en el sector formal se dividen en partes casi iguales por tipo de contrato. El 55\% posee contratos por tiempo indefinido, pero el $45 \%$ trabaja bajo contratos de modalidades diversas. La situación es sustancialmente diferente en el sector informal, donde la mayoría de los asalariados que poseen contrato de trabajo, dicho contrato es de duración indeterminada. La utilización de contratos atípicos se concentra en empresas de mayor tamaño, incluyendo crecientemente el sector público. Ello no significa necesariamente que los asalariados en el sector informal gocen de protección y estabilidad, sino que son menos los que cuentan con contrato de trabajo y además, como veremos a continuación, el cumplimiento de las obligaciones contractuales es también menor.

La cobertura de protección de los asalariados con contrato en el sector formal alcanza a un $85 \%$ e incluso, al $29 \%$ de los que no poseen relación laboral reconocida. Los porcentajes de cobertura para los asalariados en el sector informal disminuyen significativamente a $50 \%$ de los que poseen contrato y a $10 \%$ de los sin contrato. Asimismo, poseer contratos por tiempo indefinido se traducen en grados de protección diferentes según donde se trabaje. Para los asalariados en el sector formal la cobertura alcanza al $89 \%$, mientras que contratos similares en el sector informal solo cubren con protección al $63 \%$ de los que lo poseen. Más aún, los asalariados con contratos atípicos en el sector formal acceden a la protección en una proporción mayor que los que lo logran 
con contratos por tiempo indefinido en el sector informal. Un trabajador permanente, al menos contractualmente, en el sector informal, mejoraría su salario obteniendo un puesto asalariado en el sector formal y tendría además, mayor acceso a protección aunque su contrato no fuera por tiempo indefinido.

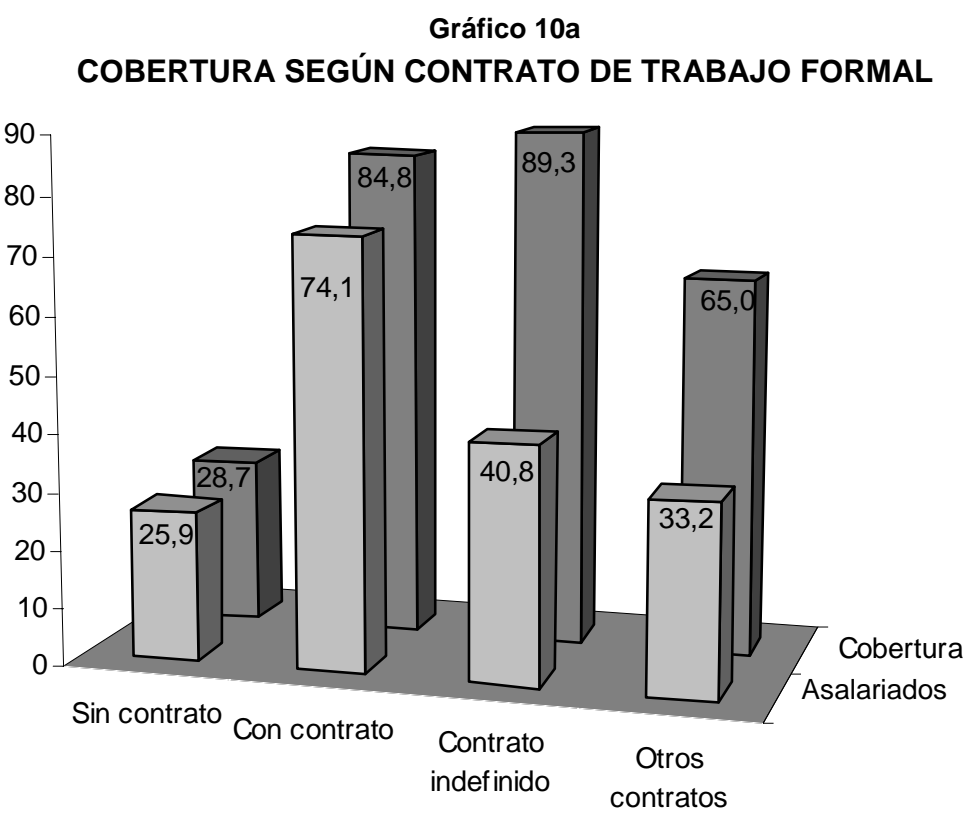

Fuente: Elaborado en base a encuestas de hogares de siete países.

Nota: Asalariados: en \% del total; cobertura: en \% del total de cada categoría específica.
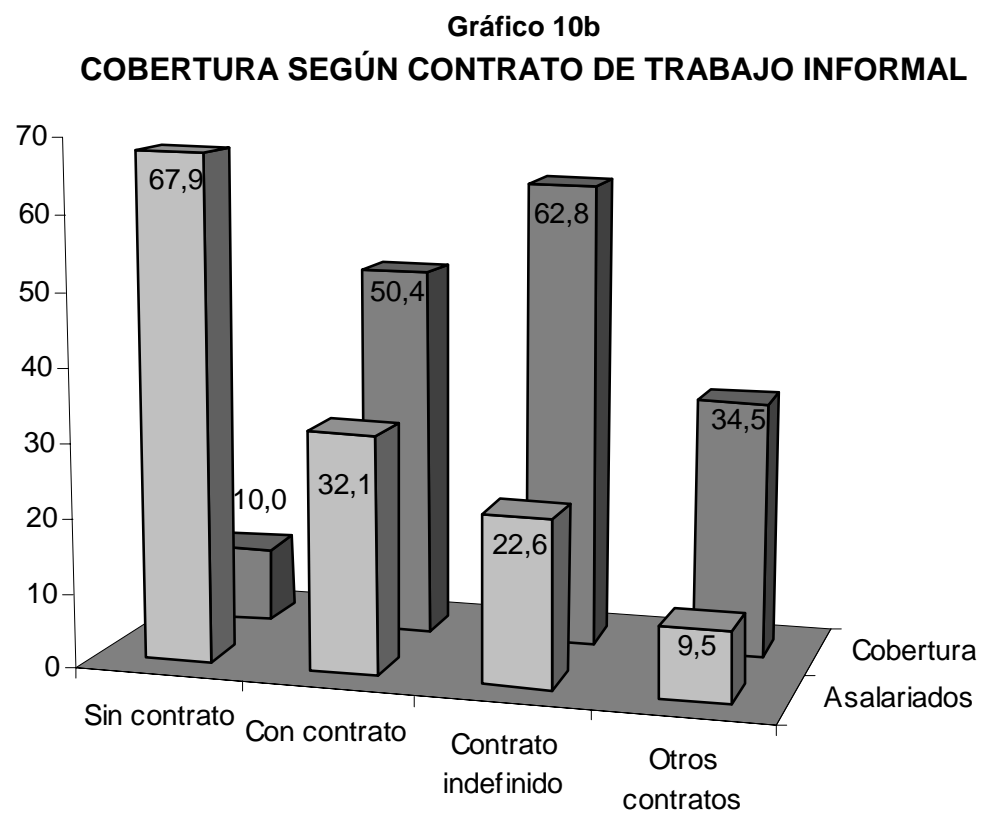

Fuente: Elaborado en base a encuestas de hogares de siete países.

Nota: Asalariados: en \% del total; cobertura: en \% del total de cada categoría específica.

La situación contractual de los asalariados en el sector formal muestra una relación inversa con el tamaño del sector informal, pero también se vincula con la orientación de las reformas 
laborales que se introdujeron en cada país. En Argentina, Chile, México y Panamá, los asalariados con contrato en las empresas de mayor tamaño y en el sector público superan al $80 \%$, alcanzando al 94\% en Panamá. Al otro extremo en Bolivia y Guatemala el porcentaje es de alrededor de 55\%. Además en el primer grupo una alta proporción de los trabajadores con contrato los posee por tiempo indefinido. El 93\% en Argentina y alrededor de 80\% en Chile y Panamá.

Sin embargo, las coberturas no muestran el mismo ordenamiento, ni tampoco lo hacen las diferencias de cobertura de acuerdo a la situación contractual. Chile y Panamá alcanzan una cobertura de protección casi universal para los trabajadores con contrato por tiempo indeterminado, 97 y $96 \%$ respectivamente y la cobertura en otros contratos también alcanza altos porcentajes, 92 y $82 \%$ respectivamente. En estos dos países, incluso alrededor del $40 \%$ de los que no tienen contrato de trabajo están cubiertos. Por el contrario, A pesar del alto porcentaje de reconocimiento legal de la relación laboral registrado en Argentina, sólo el $82 \%$ de los que poseen contrato por tiempo indefinido tienen cobertura de protección. Las diferencias con las coberturas en otros contratos, entre los cuales se encuentran diversas modalidades introducidas por las reformas laborales de los noventa, son también significativas. En promedio los asalariados argentinos con contratos a-típicos solo están cubiertos el 18\%, es decir, un quinto de la proporción cubierta en los contratos por tiempo indefinido. Además, no poseer contrato de trabajo en Argentina equivale a desprotección plena, ya que solo el $8 \%$ de los asalariados que se encuentran en tal situación tienen cobertura.

La heterogeneidad de situaciones se observa también en las coberturas de los trabajadores del sector informal. En Chile el 93\% de los trabajadores en el sector informal con contrato, el 94\% de los con contrato por tiempo indefinido y el $85 \%$ de los con otro tipo de contrato de trabajo están cubiertos. Situación similar, aunque con menores niveles de cobertura y mayor diferenciación por tipo de contrato se observa en México y Panamá. Por otro lado, en Argentina solo el $28 \%$ de los asalariados con contrato, el 30\% de los con contrato indefinido y el $4 \%$ de los con otro tipo de contratos tiene cobertura de protección. En Bolivia, Guatemala y Ecuador el porcentaje de asalariados que trabajan en microempresas o en el servicio doméstico sin contrato supera al $90 \%$ en los dos primeros países y alcanza al $80 \%$ en el último. La cobertura de protección para ellos solo alcanza a alrededor del $5 \%$ en promedio para los tres países. En ellos, trabajar en el sector informal como asalariado significa hacerlo sin reconocimiento de su relación laboral y sin protección alguna.

\subsection{Informalidad, inserción laboral y cohesión social}

El análisis anterior permite rescatar algunas conclusiones sobre la informalidad y el tipo de inserción laboral que afectan el grado de cohesión social. La forma y la intensidad en que estas relaciones se manifiestan varían, como se señaló anteriormente, según las realidades nacionales. Nos limitaremos a mencionar las más relevantes referidas a los promedios.

En primer lugar, en el sector informal se produce una estrecha coincidencia ente unidad productiva y relación laboral. Más aún, el predominio de formas de inserción laboral independientes en proporción significativa no permite definir la existencia de una relación laboral. Coexisten asimismo, con relaciones laborales que se manifiestan de manera difusa lo que dificulta su reconocimiento y la asignación responsabilidades por el cumplimiento de las obligaciones. Existen, además responsabilidades que van más allá de la unidad productiva informal e involucran a terceras empresas, como es el caso de la subcontratación y la intermediación. Cuanto más significativo es el tamaño del sector y su permanencia en el tiempo, mayores serán los obstáculos para avanzar en la cohesión social tanto por la percepción de los involucrados como por la falta de reconocimiento legal de su existencia productiva y laboral.

En segundo lugar, el sector informal es el empleador principal de los pobres, no solo de asalariados sino también de trabajadores por cuenta propia. Pero a ello se agrega su importancia como fuente de ocupación para estratos medios bajos, donde coexisten empresarios, asalariados e 
independientes ocupados en unidades productivas, tanto informales como formales e incluso en el sector público. En consecuencia, las políticas dirigidas a este sector son importantes tanto para disminuir la pobreza como para mejorar la equidad.

En tercer lugar, el análisis de las diferencias de ingresos por sector de ocupación y por modalidad de inserción laboral contribuye a entender la evolución del grado de cohesión social. Brechas crecientes entre ocupados formales e informales, e incluso entre asalariados según que laboren en micro empresas o en empresas de mayor tamaños no conducen a la homogeneidad sino al contrario, a aumentar la diferenciación existente. Se observan brechas de ingresos crecientes entre los ocupados en el sector informal y los que lo hacen en el formal. Lo mismo ocurre entre los trabajadores. Asimismo, el trabajo independiente que continúa siendo una opción válida e incluso favorable al trabajo asalariado en micro empresas, ha dejado de serlo con respecto a los asalariados en empresas de mayor tamaño. Las diferenciales de ingresos entre empleadores y trabajadores, son mayores en empresas de mayor tamaño que en las pequeñas y han tendido disminuir en ambas aunque lo hacen más rápido en las pequeñas. Ello sugiere que los micro emprendimientos han debido enfrentar una competencia creciente en un entorno económico poco favorable, lo que se traslada a los asalariados tornándose menos atractivas para empleadores y trabajadores y se justifican principalmente por la carencia de mejores oportunidades de empleo fuera del sector informal.

En cuarto lugar, las diferencias de acceso a la protección laboral y social que se derivan de las modalidades de inserción entre sectores y dentro de ellos y de su regulación introducen un factor adicional de heterogeneidad que afecta la cohesión social. Las diferencias de cobertura de protección entre ocupados en el sector informal y el formal, así como dentro del informal según se trabaje de manera independiente o como asalariado son significativas.

En quinto lugar, los asalariados deberían constituir el grupo o clase social más homogénea según los modelos interpretativos usuales al compartir una relación laboral similar y al depender de su trabajo para la obtención de los ingresos. Sin embargo, observamos que las diferencias entre asalariados en el sector informal y en el formal son significativas tanto en cuanto a remuneraciones como a protección. Las mismas involucran también diferencias en cuanto al reconocimiento legal de su relación laboral y a la modalidad contractual a que están sujetos. Dos tercios de los asalariados está ocupado en el sector formal y el tercio restante lo hace en el informal. Tres cuartos entre los primeros tiene contrato de trabajo pero aún en las empresas formales existen un cuarto de los asalariados sin contrato de trabajo. En el informal la situación es peor. La carencia de contrato afecta a más de dos tercios de los asalariados en el sector, pero el tercio restante que lo posee accede en su mayoría a contratos por tiempo indefinido. En el sector formal se observa que los contratos por tiempo indefinido llegan al $55 \%$ de los que tienen contrato de trabajo, pero que el $45 \%$ trabaja con otro tipo de contratos.

Ello afecta el acceso a la protección social y laboral porque el reconocimiento legal de la relación laboral abre la puerta a la protección y los contratos de mayor duración son los que se asocian con una alta protección que da seguridad de empleo y de ingresos durante la vida activa del trabajador y con posterioridad mediante una pensión. Pero contrariamente a lo usualmente supuesto, ni los contratos a-típicos significan desprotección, aunque si inseguridad en cuanto a permanencia eventual en el puesto de trabajo, ni la falta de contrato de trabajo es equivalente a la desprotección total. Todo ello genera situaciones diferentes entre ciudadanos supuestamente homogéneos en las visiones simplificadas de la realidad. Las percepciones en definitiva se fundan en esas realidades y en consecuencia, el avance hacia una mayor cohesión social debe abordar como tarea importante la disminución de las diferencias existentes tanto en la esfera productiva como en las relaciones laborales y en la protección. A este tema se refiere el próximo capítulo. 


\section{Inserción productiva y laboral: estrategias para la cohesión social}

\section{Inserción, informalidad y cohesión social}

El análisis efectuado hasta ahora permite identificar tres formas de inserción productiva y laboral que tensionan la cohesión social. La primera, es la existencia de un sector informal significativo y no decreciente. Es allí donde se concentra el empleo y obtienen sus ingresos la mayoría de los pobres y las capas medias inferiores. Son empresarios y trabajadores y muchos entre ellos, desempeñan ambas funciones simultáneamente. Constituyen los excluidos al combinar bajos ingresos, desprotección e inestabilidad.

La segunda forma de inserción afecta a los trabajadores ocupados en empresas formales o en cadenas productivas bajo distintas modalidades de subcontratación, incluyendo al trabajo a domicilio, que no gozan de seguridad laboral ni protección plena. Ella se asocia a la falta de cumplimiento de la legislación laboral o a los vacíos existentes que no permiten transparentar las relaciones de empleo ocultas y las obligaciones y responsabilidades que significan. Están incluidos por su inserción laboral, pero al estar afectados por desprotección e inseguridad laboral, dicha inserción es precaria.

La tercera forma de inserción afecta de manera más general a los trabajadores que enfrentan nuevos riesgos vinculados al cambio en el funcionamiento económico. Dichos riesgos se asocian a la mayor 
vulnerabilidad que se produce por una inserción más amplia a los mercados internacionales y a la necesidad de ajustar la estructura productiva y las relaciones laborales para aumentar la competitividad. Ello genera una demanda por flexibilidad en un marco regulatorio que no incorpora adecuadamente la protección de los afectados. Constituyen los trabajadores organizados y con relaciones laborales formales. El problema en este caso es de inseguridad, pérdida de protección y carencia de ingresos compensatorios durante la transición.

La cohesión social se afecta a través del mercado de trabajo al aumentar la inseguridad y la desprotección y particularmente, al registrarse un amplio sector de excluidos. Países con ciudadanos excluidos, inseguros y desprotegidos difícilmente alcanzan niveles aceptables de cohesión social. Como avanzar en esta dirección es el objetivo de esta sección. Para ello desarrollaremos tres opciones estratégicas no excluyentes diseñadas para responder a las necesidades específicas que surgen en los tres grupos identificados anteriormente. Sobre la base de una opción estratégica ya presentada de incorporación del sector informal a la modernización (Tokman, 2004), se profundizarán los aspectos laborales. Posteriormente se examinarán las opciones para mejorar el cumplimiento de la regulación laboral y su efectividad. Por último, se profundizará la propuesta estratégica ya presentada con anterioridad por CEPAL (2004a y 2006), de avanzar hacia la flexi-seguridad. De manera similar al sector informal, la profundización se centrará en los aspectos relacionados con la regulación laboral y las políticas para el mercado de trabajo. En conjunto, estas tres vías de propuestas configuran una estrategia sistémica, aunque en este trabajo el énfasis se coloca en el empleo.

\section{Sector informal e inclusión social: una opción estratégica}

\subsection{Construyendo ciudadanía: de las obligaciones a los derechos de los excluidos}

El sentido de pertenencia constituye un eje central de la cohesión social y ella se logra mediante la adquisición de titularidad de los derechos sociales, lo que significa incluir a todos los ciudadanos en la dinámica del desarrollo y en el bienestar que dicho desarrollo promueve. Los países de América Latina han registrado importantes progresos en materia de derechos civiles y políticos con el predominio de la Democracia de los Estados de Derecho, después de un largo período de gobiernos autoritarios y restricción de libertades. La agenda en la actualidad se ha desplazado hacia la ciudadanía social pues la misma constituye una condición para enfrentar las desigualdades existentes. Tales desigualdades obstaculizan a muchos de pertenecer y ser reconocidos como miembros de la sociedad (CEPAL, 2007).

Un desarrollo basado en la ciudadanía social implica aceptar la decisión de una sociedad de vivir entre iguales, aunque ello no significa homogeneidad de formas de vivir. La pobreza, la informalidad y la exclusión, además de identificar carencias de acceso a recursos, bajos ingresos y vulnerabilidades, constituyen la carencia de ciudadanía en la medida que se les niega la titularidad de los derechos sociales y el derecho a estar socialmente protegido. En definitiva, tal situación afecta el sentido de pertenencia que se adquiere con la inclusión y la participación (CEPAL, 2006 y 2007). Es dentro de esta perspectiva adoptada por CEPAL en sus trabajos más recientes, que puede inscribirse una reorientación estratégica de incorporación del sector informal a la modernidad. ${ }^{17}$

Dicha reorientación se basa en tres principios básicos. Primero, invertir el orden prevaleciente de buscar la inclusión comenzando por el cumplimiento de las obligaciones; cuando

17 Una presentación más detallada de dicha propuesta puede encontrarse en Tokman (2001,2004 y 2006). 
para los afectados su razón de exclusión es la falta de habilitación de sus derechos económicos y sociales. Solo comenzando por estos, estarán en condiciones de cumplir con sus obligaciones. Segundo, la extensión de la formalización se justifica, no ya desde la perspectiva de los sectores incluidos, sino principalmente, por los beneficios que el acceso a dicha formalidad puede significar para el desarrollo de las actividades y de las personas ocupadas en el sector informal. Por último, una reorientación como la que se sugiere tiene que estar acompañada de una transformación cultural de los que laboran en el sector informal. Los efectos esperados no se producen automáticamente, sino que requieren nuevos comportamientos y actitudes de los involucrados para generar un ambiente más propicio para el desarrollo de sus actividades. La formalización abre la puerta a la ciudadanía económica y social y ellas constituyen, a su vez, un requisito para la pertenencia y la plena incorporación a una sociedad más incluyente.

\subsection{Desarrollo productivo y regulación de las actividades informales}

Se propone adaptar los requisitos de formalización a las posibilidades de cumplimiento de los informales, lo que sin constituir sistemas duales, signifique la adecuación del sistema de regulación existente para facilitar su cumplimiento pleno. Las regulaciones han sido diseñadas para empresas de mayor tamaño y sectores más organizados, sin contemplar las posibilidades de los que no están en condiciones de cumplir con los requisitos exigidos. En algunos casos se requerirá reducirlos o cambiarlos; en otros, lo que se requiere es alterar la estrategia para alcanzarlos. A partir de un cambio de orientación que privilegia el reconocimiento de la formalidad, antes que comenzar por exigir el cumplimiento de las obligaciones que ella impone, se proponen mecanismos que incluyen desde el reconocimiento de títulos de propiedad, la separación patrimonial entre empresa y empresario informal, la habilitación en el ámbito tributario, el reconocimiento de la relación laboral existente y el desarrollo del comercio ambulante en condiciones de mayor estabilidad y seguridad.

La adecuación señalada generará mejores condiciones para el desarrollo de las actividades informales. La ampliación del acceso al crédito requiere el reconocimiento legal del capital; la posibilidad de asumir riesgos de negocios sin afectar el patrimonio familiar se deriva de la introducción de formas jurídicas más adecuadas para construir y desarrollar empresas; la introducción de técnicas contables que permitan mejorar la gestión; y el reconocimiento de existencia de relaciones laborales constituyen requisitos previos para mejorar la productividad, invertir en capacitación y avanzar en el cumplimiento de las obligaciones de protección laboral y social.

En el sector informal se encuentra tanto empresas como familias que desarrollan actividades productivas. Dentro de estas se incluyen tanto empresarios como trabajadores. En este contexto la separación de funciones y responsabilidades se dificulta, más aún cuando el empresario también es trabajador y la familia combina actividades laborales con otras fuera del mercado de trabajo, como las tareas del hogar en las mujeres y la educación en el caso de los hijos. En este contexto, la factibilidad de avanzar en el proceso de formalización depende principalmente de la capacidad de crecimiento de la unidad productiva. De igual manera la posibilidad de reconocer y regular las relaciones laborales, en general ocultas, que se encuentran en el sector, depende de la capacidad de cumplimiento de las obligaciones por las empresas lo que en última instancia, está asociado al éxito de la empresa informal en su incorporación a la modernización. Es por ello que el desarrollo productivo de las actividades informales debe abordarse de manera simultánea con el avance en el ámbito laboral.

Existe una basta experiencia en apoyo productivo de las actividades informales facilitando el acceso a los recursos productivos (capital-crédito, calificaciones-formación y tecnologías) y a los mercados (organización, localización). Nos concentraremos, sin embargo, en los temas regulatorios 
por su efecto sistémico potencial. En este nivel se encuentran el reconocimiento legal del capital y la facilidad para establecer negocios. Ambos presentan perspectivas interesantes para apoyar las unidades productivas. Como pioneramente sostuvo De Soto (1986 y 2001), el reconocimiento legal del capital de los informales mediante métodos simplificados puede facilitar el acceso al crédito al constituir una garantía real requerida usualmente por los bancos y prestamistas. Por otro lado, las dificultades de procesamiento burocrático de las autorizaciones para iniciación de actividades derivadas tanto de la multiplicación de disposiciones legales y reglamentarias, como de la ineficiencia en la burocracia gubernamental para procesarlas. El avance en estas direcciones puede contribuir a facilitar la expansión productiva de las actividades informales.

En una perspectiva más integrada como la analizada en el capítulo I de este trabajo, el Banco Mundial muestra la importancia de las regulaciones en el mercado de bienes como determinante principal del crecimiento del producto por habitante. Ellas se refieren a la facilidad de entrada, apertura comercial, eficiencia de los mercados financieros, credibilidad de los contratos, y procesamiento de quiebras. Por otro lado, como lo señala un estudio reciente de la OIT (2006), aunque estas regulaciones afectan a las empresas en general, son las de menor tamaño las que se ven afectadas desproporcionadamente al no contar con los recursos necesarios para enfrentar los obstáculos que se encuentran en el ambiente para hacer negocios.

El estudio del Banco Mundial permite, asimismo, observar la importancia de cada componente de regulación en el mercado de bienes para 21 países de América Latina comparado con las otras regiones del mundo. Estas regulaciones en conjunto en América Latina superan en 2,6 veces el nivel observado en los países de OCDE y son mayores que las registradas en los países del Asia, siendo solo inferiores a las prevalecientes en África y Medio Oriente. La situación por componentes es más diversificada. Todos los indicadores comparan desfavorablemente con los de la OCDE encontrándose las mayores distancias en relación al comercio y a los contratos. Sin embargo, los indicadores muestran que América Latina presenta los niveles más bajos de barreras en los mercados financieros y en el comercio internacional en relación a todas las regiones en desarrollo, lo opuesto ocurre en relación a la facilidad de entrada y a la credibilidad de los contratos en los cuales se registran niveles cercanos a los existentes en los países del África al sur del Sahara.

La regulación de los mercados de bienes persigue corregir las fallas que se producen en mercados no regulados. Se selecciona los nuevos entrantes para asegurar que la calidad de los productos y reducir externalidades como la contaminación. El registro se asocia entonces con un control de calidad social que protege los intereses del público en general y las relaciones entre empresas. Sin embargo, según un estudio del Banco Mundial (2004), el cumplimiento de normas de calidad disminuye cuando el número de procedimientos de entrada aumenta y los niveles de contaminación no disminuyen cuando se introducen más requisitos ambientales. El efecto real es un no deseado crecimiento del sector informal. Procedimientos de entrada complejos y costosos incentivan a los empresarios a operar en la informalidad

El análisis anterior sugiere, en primer lugar, que existe espacio para avanzar en todos los ámbitos de regulación señalados en relación a los países desarrollados. En segundo lugar, que la situación de apertura comercial y modernización financiera ha registrado avances notorios y por último, que los rezagos más importantes se concentran en las regulaciones de entrada para hacer negocios y en la credibilidad de los contratos. Estos ámbitos afectan particularmente el desarrollo de las actividades informales, las que en definitiva, deben operar fuera de los marcos regulatorios existentes. Sin embargo, existen ámbitos de regulación que protegen las condiciones sanitarias y ambientales que, aunque puedan requerir más tiempo y signifiquen más recursos para procesarlos, están dirigidos a cautelar la salud y la calidad de vida de la sociedad en su conjunto. El empleo no debería expandirse al costo del deterioro de las condiciones sanitarias y ambientales. 


\subsection{Regulación laboral en empresas informales: derechos laborales en empresas con reducida capacidad de pago}

En el sector informal se encuentra una doble situación. Por un lado, una alta concentración de trabajadores ocupados sin que la legislación laboral se aplique plenamente y por otro, una escasa capacidad de las unidades productivas informales para enfrentar las obligaciones que se asocian a la existencia de una relación laboral.

El porcentaje de trabajadores sin contrato o con contratos a-típicos supera el $90 \%$ en países como Bolivia y Guatemala o alcanzan a alrededor del $85 \%$ en México y Ecuador. A su vez, la cobertura de pensiones para los ocupados en el sector informal alcanza en América Latina al 18\% en comparación con el 68\% que registran los ocupados en el sector formal. En parte, esta diferencia de cobertura se explica por la importancia de los trabajadores por cuenta propia en el sector informal, que cotizan de manera voluntaria y lo hacen solo el 6\% entre ellos. Las distancias de cobertura entre asalariados son menores dado que la cobertura de los trabajadores en empresas de menos de 5 trabajadores es del 24\%, mientras la de los asalariados en empresas de mayor tamaño alcanza al $66 \%$. Para la mayoría, la protección laboral y social no constituye un derecho al carecer de una relación laboral reconocida jurídicamente.

Por otro lado, las microempresas de menos de 5 trabajadores muestran una incapacidad de absorción de los costos involucrados en la formalización de sus trabajadores. En Colombia de 277 microempresas encuestadas sólo el 15\% pagaba alguna prestación (Gómez, 1998). El 65\% no podía pagar seguridad social, el $67 \%$ no podía contribuir con prestaciones laborales y seguridad social y el $76 \%$ no podía pagar los costos laborales en su totalidad. Un alto porcentaje de las microempresas colombianas no podían cumplir con las obligaciones dados sus márgenes de utilidades, ventas y precios vigentes al momento de efectuar la encuesta. Para poder absorberlos, se estima que las ventas tendrían que duplicarse.

En Perú, al igual que en Colombia, sólo el 15\% de las microempresas entre 2 y 5 trabajadores estaría en condiciones de absorber la totalidad de costos laborales. Si lo hicieran, el 28,6\% tendría que reducir sus utilidades al menos a la mitad; en el 39,3\% disminuirían más de la mitad pero menos del $75 \%$ y el $32 \%$ restante reduciría sus utilidades entre 76 y $100 \%$. Por otro lado, más de la mitad de esas microempresas no pagaba ningún costo laboral y el 49,5\% cumplía parcialmente con algunas obligaciones. Ninguna de las empresas encuestadas cancelaba todos los costos laborales (Yáñez, 1998).

El reconocimiento de la relación laboral, incluyendo pruebas de existencia de contratos no escritos sino verbales como el cumplimiento de horarios y el pago de remuneraciones periódicas registradas en la contabilidad o avalada por presencia de testigos, permitiría dar un primer paso hacia las relaciones laborales reguladas y protegidas. Ello, a su vez, contribuye a constituir ciudadanos que poseen credenciales para incorporarse a la protección laboral y social en el caso de los trabajadores y a la lógica de los negocios en el caso del micro-empresario que debe adecuarse a una relación de trabajo formal. El reconocimiento de la existencia de esta relación genera una presión por gestionar la unidad productiva con criterios empresariales $y$ no como un emprendimiento familiar.

No obstante, este primer paso se enfrenta a posibilidades restringidas de cumplimiento tanto por la incapacidad de absorción de los costos ya mencionada, como porque el diseño de la protección responde a las características de las empresas de mayor tamaño. Puede ser necesario un ajuste de la legislación vigente para tornarla más pertinente. Pero la adecuación no debe confundirse con la desregulación, porque responder mejor a las necesidades de las microempresas no puede convertirse en una justificación para el deterioro de las condiciones laborales existentes. Ello no excluye introducir perfeccionamientos que respondan a demandas justificadas para 
aumentar la eficiencia en el funcionamiento del mercado de trabajo organizado. ${ }^{18}$ Esta vía presenta como ventaja enfrentar la reducción de los costos de la regulación sin afectar la unicidad del sistema al reducirse para todos y no solo para los informales. Son particularmente recomendables en relación a la regulación en el mercado de bienes, las que se refieren a disminución de barreras de acceso, regímenes simplificados de registro, y reducción y unificación de trámites y procedimientos, entre otros.

Una alternativa que surge es si la regulación del sector informal debe constituir un sistema especial, diferenciado del vigente para el resto de las actividades y personas ocupadas en el sector formal. Esto implica introducir sistemas duales o preferenciales, práctica seguida por varios países como Argentina, Brasil y Perú. La diferenciación resulta inconveniente tanto por razones de eficacia de regulación, como de principios. La diferenciación introduce una apertura a la elusión fiscal y laboral y genera barreras al crecimiento de las microempresas cuando establece montos máximos de capital. En el ámbito laboral, la diferenciación afecta principios porque acepta un trato diferente de los trabajadores ante la ley, dependiendo del tamaño de la empresa en que estén ocupados. Por ello, para los aspectos laborales la preferencia es por un sistema único de regulación (OIT, 1991).

No se excluyen, por cierto, diferenciaciones de tratamiento como la introducción de sistemas simplificados de impuestos o programas de créditos con tasas preferenciales. Aún en los temas laborales existe una tendencia a aceptar formas que se adapten mejor a las características de las pequeñas unidades productivas en lo referente a la negociación colectiva.

Otra alternativa de políticas diferenciadas para la incorporación de los informales a un régimen único es reconocer la existencia de una situación dual de hecho, pero sin convertirla en de derecho. Esto significa no introducir sanciones. Se reconoce la existencia de incumplimiento, pero se tolera. Sin embargo, esta opción no puede aceptarse sobre la base de los principios involucrados ni porque significa renunciar a intervenir para mejorar la situación prevaleciente. Debe reconocerse la realidad y las causas existentes, pero ello no debe conducir a la abstención de intervención.

Esta intervención puede incluir la introducción de un piso mínimo laboral obligatorio para todas las micro-empresas. Un primer componente de este piso estaría constituido por los principios y derechos fundamentales en el trabajo establecidos en la Declaración de la OIT de 1998. ${ }^{19}$ Ellos se refieren a la libertad de asociación y de negociación colectiva, al no uso de trabajo esclavo ni de trabajo infantil y a la no discriminación. Constituyen, de hecho, derechos humanos trasladados al ámbito del trabajo. Podría también incorporarse al menos tres aspectos adicionales relacionados con las condiciones de trabajo: salario mínimo, horas de trabajo y accidentes y enfermedades del trabajo. ${ }^{20 \text { y } 21}$

La obligatoriedad de respeto del piso mínimo no es contradictoria con acompañar el proceso de adopción con una lógica de tolerancia que tenga en cuenta las limitaciones que se enfrentan en las unidades informales. Dicha tolerancia no debe extenderse a los derechos fundamentales, aunque

18 De acuerdo a Vega (2005) casi la mitad de los países latinoamericanos han reformado sus legislaciones y regulaciones laborales justificadas en la promoción de las micro y pequeñas empresas. En general los esfuerzos han sido disperses y tímidos, pero en países como Perú y Paraguay, regimenes especiales fueron introducidos.

19 Declaración de Principios y Derechos Fundamentales en el Trabajo, adoptada por la Conferencia Internacional del Trabajo de la OIT en junio de 1998.

20 Este piso mínimo ampliado se ha incorporado en los Acuerdos de Libre Comercio entre Estados Unidos y varios países, los que se incluyen a México, Chile, los países de Centroamérica y República Dominicana (CAFTA), Panamá, Colombia, Perú y Ecuador (estos tres últimos sin sanción definitiva en la actualidad).

21 Dos obligaciones adicionales asociadas al contrato de trabajo que podrían incluirse en el piso mínimo son los derechos de maternidad y pensiones, los que según la evidencia disponible, son los que menor cumplimiento registran en empresas de reducido tamaño. Estas prestaciones deberían ser cubiertas sobre base no contributiva, particularmente en empresas con reducida capacidad de pago, aunque con contribuciones progresivas a medida que aumenta dicha capacidad o por un período determinado. 
es aceptable en relación a las condiciones de trabajo. La exigibilidad inmediata de los primeros puede significar la destrucción de empleo, pero este es un trade-off que no debería aceptarse cuando se trata de valores irrenunciables. Se propone además, que la implementación de las mismas sea materia de seguimiento, promoción y fiscalización con procedimientos que consideren la especificidad del sujeto de regulación.

Una modalidad en esta dirección se refiere a establecer compromisos de avance en el cumplimiento con metas explícitas a alcanzar, al estilo de lo que se efectúa en el seguimiento de algunas normas internacionales del trabajo en la OIT. Otro componente es reconocer que parte del incumplimiento responde a ignorancia de la obligación legal. Esta situación es entendible tanto por las características de los empleadores informales como por las restricciones de recursos para contratar profesionales que puedan prestar asesoría. La inspección debería incluir un componente pedagógico o incluso, como lo ha hecho Chile a partir del 2001, la sustitución de la multa por capacitación del empresario informal bajo la supervisión de las autoridades del trabajo. ${ }^{22}$

Una estrategia innovativa de vigilancia del cumplimiento de la legislación laboral en micro y pequeñas empresas fue propuesta por la OIT recientemente (2006). La propuesta supone que la regulación será más efectiva cuantas más opciones existan para reforzar el cumplimiento. Dichas opciones permitirían fiscalizar y corregir situaciones de manera gradual. En la base de la pirámide de acciones propuestas se incluye la capacitación sobre derechos y normas del trabajo con incentivos para las Micro y Pequeñas empresas para formalizarse y reconocer las obligaciones laborales que ello implica. Un segundo nivel incluye el seguimiento del cumplimiento de las obligaciones laborales. Este seguimiento puede incorporar cooperación de la administración del trabajo con organizaciones que representen a los actores sociales. Un tercer nivel incluye advertencias por incumplimiento y finalmente, sanciones punitivas de acuerdo a lo previsto en la legislación ante dicho incumplimiento.

La propuesta de introducción de un piso mínimo no significa aceptar que los que laboran en el sector informal tendrán solo acceso a derechos laborales restringidos, al excluirse varios incorporados en la mayoría de las legislaciones laborales existentes y particularmente, los de protección social. Con ello, constituirían ciudadanos sociales de segunda clase. Por el contrario, lo que se propone es reconocer la necesidad de avanzar en el ámbito laboral mejorando la capacidad de cumplimiento de las empresas informales y comprometiéndolas en esa dirección. Al mismo tiempo, se reconoce que el tránsito puede tomar tiempo y por ello, debe complementarse en la esfera del bienestar para garantizar el acceso a la salud y a las pensiones con carácter universal, particularmente para aquellos que durante su vida laboral no logran cubrir estas necesidades. Ello incluye la protección a la maternidad que en muchos países ya constituye una responsabilidad pública y no de las empresas. El derecho de protección debe garantizarse de manera universal y la modalidad corporativa promoverse hasta donde sea posible, pero reconociendo que la misma será incapaz de asegurar protección social para todos.

\section{Inseguridad, desprotección y relaciones de empleo difusas}

La inseguridad y la desprotección se asocian con la inexistencia de relaciones de trabajo reconocidas legal y explícitamente, pero también con situaciones reguladas por contratos diferentes al contrato de trabajo por tiempo indefinido. Este constituía el contrato casi hegemónico, pero su

22 Esta iniciativa permite a los empleadores de micro empresas hasta 9 trabajadores que sean sancionados, sustituir la multa por la asistencia a un curso (no superior a dos semanas) sobre legislación laboral dictado por la Dirección del Trabajo. Este beneficio se puede usar solamente una vez en el año y supone que el empleado ha corregido la situación que dio origen a la sanción (Vergara, 2005). 
utilización ha debido competir crecientemente con nuevas formas contractuales introducidas por reformas laborales que buscan dotar de una mayor flexibilidad al mercado de trabajo para facilitar y reducir los costos de los ajustes que recurrentemente deben enfrentar las empresas en el marco de economías más abiertas.

En esta sección abordaremos desde la perspectiva de las políticas dos situaciones. La primera referida a los trabajadores bajo formas contractuales atípicas y la segunda, a aquellos trabajadores bajo relaciones laborales difusas o no suficientemente reconocidas como tales en la legislación laboral. Dentro de esta situación se encuentran las relaciones laborales desarrolladas producto tanto de la descentralización del proceso de producción y de trabajo a nivel nacional como derivados de la globalización. Se encuentra además la descentralización del trabajo más antigua vinculada a los comienzos de la industrialización (particularmente en confecciones) que se desarrolla como trabajo a domicilio. Para finalizar se incluirá una respuesta reciente en términos legislativos para regular las relaciones laborales en la subcontratación en el caso de Chile.

\subsection{Contratos a-típicos: inseguridad y/o desprotección}

De acuerdo al análisis efectuado en el capítulo II, las relaciones de empleo sujetas a contratos diferentes al por tiempo indefinido son consideradas como parte de la economía informal con independencia de la unidad productiva en que desarrollen su actividad. Se destacó asimismo, que las relaciones de empleo sin contrato o bajo este tipo de contrato constituyen la mayoría del empleo en las micro-empresas las que a su vez, se caracterizan por una capacidad de absorción de los costos limitada; mientras que los contratos atípicos utilizados en las empresas formales e incluso, en el sector público aumentan su participación. Constituyen respuestas de política laboral para dotar de mayor flexibilidad y reducir los costos, particularmente de despido.No afectan en general la protección de los trabajadores mientras estén empleados, ni son ilegales porque las reformas introdujeron e incentivaron el uso de estas nuevas formas contractuales.

Esto puede observarse, por ejemplo, en países como Argentina y Perú, que introdujeron reformas laborales más comprensivas que alteraron la estructura contractual prevaleciente. El cuadro siguiente de muestra la evolución de los costos salariales en el sector manufacturero en ambos países durante la década de los noventa. Como puede observarse, los costos laborales según los trabajadores sean contratados como permanentes o temporales no difieren significativamente. En Perú son idénticos y en Argentina, difieren en 5\%. Ello refleja el cumplimiento de obligaciones laborales y por ende, de protección similar. La diferencia que se encuentra proviene de dos fuentes diferentes. La primera, es en relación a los trabajadores sin contrato y no registrados donde las diferencias de costos laborales son entre 42 y $55 \%$. La segunda, se produce cuando los contratos son promovidos como se observa en Argentina en 1996 producto de las reformas laborales de comienzos de los noventa y en Perú, durante todo el período con los contratos de formación para jóvenes. La reducción del costo laboral en ambos países durante el período analizado se deriva de la combinación de trabajadores bajo diferentes formas contractuales en las empresas lo que permitió en Argentina reducir el costo laboral del 49 al 40\% y del 55 a 22\% en Perú.

Si bien puede generarse una pérdida de protección al recurrirse a nuevas modalidades contractuales, el efecto prevaleciente es de una mayor inseguridad derivada de la incertidumbre acerca de la continuidad después de la fecha de vencimiento del contrato vigente. La inseguridad afecta tanto la situación familiar del trabajador como la productividad al disminuir los incentivos para el aprendizaje y la innovación. Por ello, se sugiere introducir límites a la utilización de estos contratos, concentrándose las posibilidades de flexibilización en el contrato de largo plazo. 


\section{COSTO LABORAL EN ARGENTINA Y PERÚ SEGÚN MODALIDAD CONTRACTUAL}

Cuadro 4

(Circa 1990-2002)

\begin{tabular}{l|c|c|c|c}
\hline & $\mathbf{1 9 9 1}$ & $\mathbf{1 9 9 6}$ & $\mathbf{2 0 0 0}$ & $\mathbf{2 0 0 3}$ \\
\hline Argentina & $\mathbf{1 , 5 3}$ & $\mathbf{1 , 3 8}$ & $\mathbf{1 , 3 6}$ & $\mathbf{1 , 4 0}$ \\
Permanentes & 1,66 & 1,48 & 1,43 & 1,49 \\
Por Agencia & 1,61 & 1,45 & 1,41 & 1,46 \\
Temporales no promovidos & 1,59 & 1,41 & 1,37 & 1,42 \\
Temporales promovidos & & 1,33 & & \\
Período de prueba & & 1,26 & & \\
No registrados & 1,07 & 1,07 & 1,07 & 1,07 \\
\hline & $\mathbf{1 9 8 9}$ & $\mathbf{1 9 9 7}$ & $\mathbf{2 0 0 1}$ & \\
\hline Perú & 1,34 & 1,25 & 1,22 & \\
Permanentes & 1,59 & 1,55 & 1,55 & \\
Temporales & 1,59 & 1,55 & 1,55 & \\
En formación & 1,02 & 1,01 & 1,01 & \\
Destacados & 1,57 & 1,54 & 1,54 & \\
Sin contrato & 1,00 & 1,00 & 1,00 & \\
\hline
\end{tabular}

Fuente: Chacaltana (2005)

Nota: Se refiere al costo salarial y no salarial expresado en relación al salario en la industria manufacturera.

Esta ha sido la experiencia de España, país pionero en la flexibilización laboral en el margen mediante contratos atípicos introducidos por la reforma laboral de 1981. El resultado fue un aumento de la participación de contratos temporales del 10 al 31\% entre 1980 y 1992. Con posterioridad, se adopta una contrarreforma en 1997 que reduce los costos de despido para los contratos permanentes que se adopten a partir de esa fecha y se apliquen a menores de $30 \mathrm{y}$ mayores de 45 años, trabajadores discapacitados y desempleados de largo plazo. Más recientemente en 2006, se acuerda de manera tripartita llevar el uso de contratos a tiempo fijo a los niveles de los países de la UE. Ello mediante la conversión a permanentes de contratos a tiempo fijo por más de 24 meses en la misma empresa y en el mismo puesto; bonos a las empresas por cuatro años cuando ofrezcan contratos sin término a grupos vulnerables (mujeres, jóvenes, desempleados de largo plazo, etc.).

Argentina siguió una orientación similar de flexibilización como la de España en las reformas laborales de 1991 y 1995. También lo hizo en las contrarreformas de 1998 y 2000 limitando el uso de contratos atípicos y reduciendo las obligaciones en los contratos indefinidos. En Brasil la reforma de 1998 introduce contratos atípicos pero condicionados a la creación efectiva de nuevos puestos de trabajo para disminuir el potencial de sustitución de contratos y traslada a la negociación colectiva la determinación de los límites máximos para su introducción.

\subsection{Relaciones de empleo difusas y regulación para la subcontratación}

Un segundo ámbito de importancia se refiere relaciones de empleo que son difíciles de establecer y en las cuales las obligaciones y los derechos de las partes no son claros; o en intentos de ocultar la existencia de dicha relación, o donde existen vacíos en el marco legal o en la interpretación o en la aplicación. Ello puede traducirse en pérdida de protección de los trabajadores. Son crecientemente importantes en el contexto de globalización y descentralización de la producción, siendo necesario establecer los derechos de los trabajadores y quién es el empleador responsable.

Consecuente con este objetivo la OIT inició un proceso de análisis conducente a la adopción de normativa internacional a partir de 1998 y en junio de 2006 genera una recomendación en relación a la relación de empleo. Se recomienda a los países "clarificar y adaptar la cobertura de leyes y regulaciones relevantes para garantizar la protección efectiva de los trabajadores que 
desarrollan su trabajo en el contexto de una relación de empleo". La protección debe definirse "por la ley y práctica nacional" y debe incluir "la amplitud, cobertura y responsabilidad por su implementación".

Se recomienda también establecer si efectivamente existe una relación de empleo y distinguir entre trabajadores subordinados y cuenta propias. Para ello se destaca la importancia de identificar la realidad del desarrollo del trabajo y la remuneración periódica del trabajador, sin importar como se caracteriza en cualquier acuerdo o contrato acordado entre las partes. En relación al desarrollo del trabajo se determinan como indicadores importantes si las instrucciones y el control no pertenecen al trabajador; si involucra la integración del trabajador en la empresa, si se efectúa solo para el beneficio de otra persona, si debe llevarlo a cabo personalmente, dentro de horas específicas de trabajo, si requiere de habilidades personales y si involucra la provisión de herramientas materiales y maquinarias.

Sugiere perseguir las relaciones de empleo disfrazadas $\mathrm{u}$ ocultas mediante arreglos contractuales que esconden el verdadero status legal. Se recomienda asegurar normas aplicables a todas las formas contractuales incluyendo aquellas que involucren multi-partes y el establecimiento del responsable o responsables por la protección.

La recomendación y el análisis desarrollado durante casi una década presenta todavía numerosos vacíos, pero avanza en establecer un marco que permite especificar relaciones laborales ocultas e identificar, aunque de manera general las responsabilidades tanto directas como las que se generan en relaciones de subcontratación. Sirve también para que los países desarrollen su propia legislación teniendo en cuenta los marcos generales establecidos.

Es también necesario abordar la situación de los trabajadores a domicilio, abordada por la OIT en 1996 adoptando un convenio internacional y una recomendación que aporta una mayor precisión para la formulación del marco legal y las políticas dirigidas a los mismos. El trabajo a domicilio constituye una forma de producción de larga data que en apariencia puede considerarse como una actividad desarrollada por cuenta propia o en asociación familiar. Sin embargo, en numerosas ocasiones el mismo constituye trabajo asalariado dependiente desarrollado fuera de las empresas pero a beneficio de una empresa sub-contratante o a intermediarios. Son actividades predominantemente desarrolladas por mujeres, con ayuda familiar, incluso niños, y que no están contempladas en la legislación laboral lo que determina la inexistencia de una relación de empleo reconocida y la consiguiente desprotección y ausencia de capacidad de negociación.

Junto con el avance normativo en la OIT, se fueron desplegando esfuerzos en diversos niveles, de análisis, acción y organización dirigidos a generar conciencia de la situación y a presionar por la adopción de políticas de apoyo productivo, protección y organización. ${ }^{23}$

El convenio de la OIT define el trabajo a domicilio como el trabajo realizado por una persona en su casa o en otro lugar que no sea el lugar de trabajo del empleador, que resulta en un producto o servicio según especificaciones dadas por el empleador con independencia de quien provee las maquinarias o los materiales e insumos. Por su trabajo percibe una remuneración. Son considerados trabajadores independientes cuando posee un grado de autonomía o independencia económica aceptable según la legislación y regulación nacional o decisiones judiciales. Por empleador se entiende toda persona que directamente o a través de intermediarios, ofrece trabajo a domicilio en beneficio de su negocio o actividad.

23 Dos de los ejemplos más destacables se encuentra en la India con la experiencia de Self Employment Women Association (SEWA) y a nivel internacional, con Women in Informal Employment Globalizang and Organizing (WIEGO) red mundial que incluye a organizaciones nacionales e internacionales, académicos y miembros vinculados al desarrollo. 
Establece como objetivo de las políticas nacionales la igualdad de trato entre trabajadores a domicilio y otro tipo de trabajadores teniendo en cuenta sus características especiales. La igualdad de trato incluye el derecho a crear o asociarse a organizaciones de su preferencia y de participar en las actividades de esas organizaciones (libertad de asociación), protección contra la discriminación, edad mínima de trabajo, remuneración y protección en seguridad y salud en el trabajo, seguridad social y maternidad.

Como se observa el piso de derechos establecido coincide con el sugerido más arriba para las micro-empresas con el agregado de la seguridad social y maternidad. La recomendación que acompaña al convenio especifica que en relación a la protección social y de maternidad se puede extender la seguridad social existente para incluirlos, adaptar los sistemas disponibles para cubrirlos o bien desarrollar nuevos sistemas o fondos para los trabajadores a domicilio. ${ }^{24}$

\subsection{Regulación de la subcontratación: Chile, un avance pionero}

Dentro del marco analítico y del conjunto de recomendaciones efectuadas a nivel internacional es interesante destacar la aprobación reciente en Chile de una Ley de Subcontratación que entrará en vigencia en enero del 2007. Según la última encuesta laboral disponible de la Dirección del Trabajo de Chile del 2004, un 50\% de las empresas chilenas externaliza parte de su producción y un 20,7\% subcontrata la realización de su actividad económica principal. ${ }^{25}$ El Ministerio del Trabajo estima que el $35 \%$ de la fuerza laboral no son contratados directamente por las empresas principales, sino que prestan servicios a través de la subcontratación y el suministro de personal.

La ley ${ }^{26}$ distingue entre el trabajo en régimen de subcontratación y el suministro de personal. El primero se refiere a una empresa que contrata a otra para realizar un servicio o ejecutar una obra utilizando la empresa subcontratada sus propios trabajadores y puede además, suministrar los materiales. La empresa contratista en este caso es el empleador de los trabajadores subcontratados. El suministro de personal se refiere a una empresa que encarga a una empresa de servicios transitorios que le suministre personal por un período determinado. La empresa principal es quién debe dirigir a la persona suministrada y se constituye en su empleador.

El criterio seguido en la ley es restringir el suministro solo para trabajos de corta duración y para tareas excepcionales (reemplazos, actividades ocasionales o urgentes, etc.) y regularlas para asegurar el cumplimiento de las obligaciones laborales (inscripción, entrega de una garantía por 250 Unidades de Fomento $^{27}$ para cubrir sueldos y previsión de trabajadores en caso de incumplimiento de obligaciones por quiebra y ser independientes de la empresa a las que proporciona trabajadores). A diferencia de la práctica actual, se introduce un plazo máximo de 180 días, sin posibilidad de renovación para el trabajo suministrado para evitar que se transformen de hecho en permanentes pero sin el contrato correspondiente.

Como se señaló, en el caso de subcontratación la empresa contratista es el empleador de los trabajadores subcontratados por lo que mientras trabajen en la empresa principal debe organizarlos y fiscalizarlos. La ley solo admite un control y otorga la responsabilidad a la empresa principal en

24 El convenio C177 y la recomendación R184 aunque tienen un grado de obligatoriedad diferente, en la práctica como el primero requiere ser ratificado por parte de los países que aceptan esa obligación y solo tres países lo han hecho hasta ahora, ambos tienen un carácter similar de recomendación para la mayoría de los países.

25 Las actividades más importantes que se externalizan son servicios legales, comercialización, informática, seguridad, aseo y alimentación. Es frecuente también en cajeros de supermercados y bancos, ejecutivos de venta, operadores de centros de llamadas, secretarias, entre otros.

26 Ley 20123 aprobada el 16/10/2006 que Regula trabajo en régimen de subcontratación, el funcionamiento de empresas de servicios transitorios y el contrato de servicios transitorios.

27 Instrumento reajustable equivalente en la actualidad a US\$ 34,70 por 1 UF. 
materias de seguridad, prevención de accidentes de trabajo y enfermedades profesiones y condiciones de higiene de los trabajadores subcontratados.

Aunque los trabajadores subcontratados son personal que no pertenece a la empresa principal, la ley establece responsabilidades laborales y de seguridad social respecto a los mismos. Previo a la nueva ley dicha responsabilidad era subsidiaria, es decir, solo debía responder ante incumplimiento de las obligaciones por parte de la empresa contratista. La ley transforma dicha responsabilidad en solidaria, lo que significa que debe responder conjuntamente con el contratista por el cumplimiento de las obligaciones.

Sin embargo, la propia ley establece modalidades que permiten restringir la responsabilidad de la empresa principal en el ejercicio del derecho de información y el derecho de retención. El primero implica que la empresa deberá fiscalizar el cumplimiento de las obligaciones del contratista con sus trabajadores y ello se hará mediante la exigencia de entrega por parte de esta de certificados de cumplimiento de obligaciones laborales entregados por la Dirección del Trabajo. Ejerciendo dicho derecho, su responsabilidad se transforma en subsidiaria. Al detectar la empresa principal incumplimientos laborales por parte del contratista puede adicionalmente ejercer su derecho a retener de los pagos a efectuar según contrato y destinarlos directamente a los trabajadores. Los incumplimientos se refieren a todo tipo de cotizaciones, salud, pensiones seguro de cesantía y de accidentes de trabajo e indemnizaciones.

En síntesis, la ley establece con claridad las normas para operar en un marco de subcontratación sea a través de suministro de personal o mediante empresa subcontratista. A la primera modalidad se la regula y se la restringe para asegurar tanto el cumplimiento de las obligaciones laborales como evitar la competencia espuria con trabajadores con contratos directos con la empresa principal. Se regula la operación del suministrador y se obliga a establecer una garantía monetaria para ser utilizada en caso de incumplimiento. Para la subcontratación entre empresas se establece el requisito de independencia para evitar la creación de contratistas como mecanismo de elusión de las obligaciones y se transforma la responsabilidad en solidaria entre la empresa y el contratista. Sin embargo, para que ella no desincentive el uso de esta práctica que tiene ventajas como mecanismo de flexibilización del proceso de producción y de trabajo se recurre a la certificación de cumplimiento por parte de la autoridad laboral, junto al derecho de exigirla por parte de la empresa y de retener los montos necesarios para enfrentar los costos que se deriven del incumplimiento. La empresa principal se convierte entonces en un agente indirecto de fiscalización y el contratista recibe una presión adicional para cumplir las obligaciones con sus trabajadores.

Es interesante destacar el anuncio de Telefónica Chile que anticipándose a la vigencia efectiva de la ley analizada ha anunciado que contratará 900 de los 1.700 trabajadores que prestan servicios a través de empresas contratistas en los próximos tres meses. ${ }^{28}$ Ellos pasarán a ser contratados directos de la empresa, quedando el resto bajo régimen de subcontratación siendo trabajadores que se desempeñan dentro de la empresa sino en dependencias distintas. Este es un efecto también positivo de la ley, ya que no solo busca regularizar a los que queden laborando bajo régimen de subcontratación, sino también generar incentivos para darle mayor permanencia a los contratos. El caso de Telefónica, empresa de capitales españoles, que se adjudicó los teléfonos en la privatización ocurrida en varios países de la región, es paradigmático. Dicha adjudicación fue acompañada de una profunda reestructuración de las relaciones laborales, externalizando, en el caso de Chile, un tercio de su personal. Situación similar ocurrió en los otros países la que estuvo también acompañada por fuertes cuestionamientos sindicales.

28 Diario La Tercera, 25/11/2006. 


\section{Inseguridad laboral en economías más vulnerables: la flexi- seguridad}

\section{1 ¿Porqué flexi-seguridad?}

Economías más abiertas e integradas a los mercados internacionales requieren flexibilidad para adaptarse a la mayor volatilidad y acortar los tiempos y costos asociados al ajuste. La flexibilidad, particularmente la laboral, tiene como contrapartida una mayor inseguridad y afecta la posibilidad de alcanzar un crecimiento sostenible. Por ello, el desafío es como conciliar la necesidad de flexibilidad con la también necesaria seguridad laboral.

La seguridad laboral no solo constituye un objetivo demandado por los trabajadores sino que además, genera externalidades positivas en diferentes ámbitos (OIT, 2004 y 2004b y Boyer, 2006, entre otros). La seguridad de ingresos contribuye a sostener la demanda y favorece a las expectativas. La de empleo, constituye un incentivo para invertir en calificaciones específicas requeridas por las empresas. La de representación, contribuye a generar un mayor compromiso y aceptación del cambio tecnológico. La de salud, incluyendo accidentes laborales, favorece a la productividad y al bienestar. La de capacidades, por último, contribuye a aumentar la productividad y la adaptabilidad de los trabajadores ante los cambios. Ello proporciona fundamento económico, más allá del social, a la necesidad de resguardar la seguridad laboral.

En América Latina esta demanda por restablecer ciertos equilibrios se produce en un contexto donde las reformas económicas generaron una mayor volatilidad y donde las reformas laborales orientadas principalmente a la flexibilización, la trasladaron hacia los trabajadores y sus familias. El resultado ha sido una mayor inseguridad y desprotección, lo que en definitiva genera un malestar con respecto a las propias reformas y tensiona la cohesión social. Surge entonces la interrogante si es esta la única forma de enfrentar el desafío de la flexibilidad. La experiencia de los países desarrollados parece sugerir lo contrario.

Al compararse las regulaciones e instrumentos de seguridad de empleo y de protección laboral se observan distintas combinaciones según las realidades nacionales prevalecientes (OIT, 2004, Boyer, 2006). No hay un modelo único, sino que predominan diferentes combinaciones de seguridad de empleo y seguridad laboral y social con resultados diversos. Dichos resultados se manifiestan tanto en la capacidad de crecimiento como en la percepción de seguridad que manifiestan los ciudadanos.

Los resultados extremos se encuentran por un lado, en Japón y los países del Mediterráneo (cuadrante superior-derecho) que poseen una legislación laboral estricta que resulta en una antigüedad en el empleo alta, pero un gasto en políticas del mercado de trabajo que es relativamente bajo. La percepción de inseguridad es la más alta. Por otro lado, en los países del Norte de Europa (cuadrante inferior izquierdo) que son los más abiertos y de tamaño medio, la percepción de seguridad es la más alta. Ella es el resultado de una baja seguridad en el empleo regulada por la legislación, pero en cambio la seguridad se protege mediante un mayor gasto en políticas de mercado de trabajo. La seguridad está determinada en este grupo no tanto por la ley, sino por la política de protección. En el primer grupo, por el contrario, una legislación laboral estricta no acompañada por una política de protección laboral no evita una alta sensación de inseguridad. 
Cuadro 5

SEGURIDAD DE EMPLEO Y PROTECCIÓN LABORAL EN PAÍSES DE LA OCDE

\begin{tabular}{|c|c|c|c|}
\hline & \multicolumn{2}{|c|}{ Protección Laboral } \\
\hline & & Alta & Baja \\
\hline \multirow{4}{*}{ 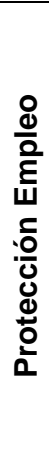 } & \multirow[t]{2}{*}{ Alta } & $\begin{array}{l}\text { Antigüedad: } 2^{\circ} \text { más larga } \\
\text { PMT gasto: } 2^{\circ} \text { más alto } \\
\text { Seguridad Ley laboral: } 2^{\circ} \text { más estricta } \\
\text { Percepción seguridad empleo: } 2^{\circ} \text { más } \\
\text { alta }\end{array}$ & $\begin{array}{l}\text { Antigüedad: la más larga } \\
\text { PMT gasto: } 2^{\circ} \text { más bajo } \\
\text { Seguridad Ley laboral: la más estricta } \\
\text { Percepción seguridad empleo: la más } \\
\text { baja }\end{array}$ \\
\hline & & Francia, Alemania, Suecia & Japón, Portugal, Grecia, Italia, España \\
\hline & \multirow[t]{2}{*}{ Baja } & $\begin{array}{l}\text { Antigüedad: } 2^{\circ} \text { más corta } \\
\text { PMT gasto: el más alto } \\
\text { Seguridad Ley laboral: } 2^{\circ} \text { menos estricta } \\
\text { Percepción seguridad empleo: la más alta }\end{array}$ & $\begin{array}{l}\text { Antigüedad: la más corta } \\
\text { PMT gasto: el más bajo } \\
\text { Seguridad Ley laboral: la menos estricta } \\
\text { Percepción seguridad empleo: } 2^{\circ} \text { más } \\
\text { baja }\end{array}$ \\
\hline & & $\begin{array}{l}\text { Dinamarca, Bélgica, Holanda, Finlandia, } \\
\text { Irlanda }\end{array}$ & Estados Unidos, Reino Unido \\
\hline
\end{tabular}

Fuente: OIT (2004).

Situaciones intermedias se ubican, por un lado, en Francia, Alemania y Suecia (cuadrante superior-izquierdo) que combinan una antigüedad en el empleo alta, con seguridad en el empleo por ley y alta protección laboral en caso de despido tanto activa como pasiva. La percepción de los ciudadanos en esos países es de seguridad, pero no la más alta. Lo mismo ocurre en Estados Unidos y Reino Unido (cuadrante inferior-derecho), donde existe una baja percepción de seguridad en el empleo, aunque no la más baja entre los países considerados, producto de una legislación poco exigente y un bajo gasto en políticas del mercado de trabajo. Ello resulta en alta rotación laboral y la más corta antigüedad en el trabajo.

Las percepciones de seguridad en el empleo dependen también del efecto que tenga la combinación de instrumentos sobre el crecimiento y el desempleo. La información disponible para el período 2000-2004 muestra que los dos grupos con mayor flexibilidad laboral son los que crecieron más rápido y sus tasas de desempleo son las menores. Sin embargo, los países anglosajones mostraron un crecimiento mayor entre los dos grupos, pero los del Norte de Europa fueron los que más exitosos en reducir el desempleo.

Lo anterior sugiere que las prescripciones no son únicas y que el diseño puede ser variable. La inseguridad resulta de la flexibilidad, pero parece ser tolerable en condiciones de alto dinamismo como el que muestran Estados Unidos y el Reino Unido. La flexibilidad normativa acompañada por alta protección también es consistente con un alto dinamismo pero además, con una percepción de alta seguridad. Ello parece ocurrir en Irlanda, Dinamarca, Holanda, Finlandia y Bélgica. También resulta en percepción de seguridad la combinación de legislación estricta y protección alta como en los países de mayor tamaño en Europa y Suecia. Son los que más mantienen los lineamientos del Estado Bienestar, pero su dinamismo económico ha sido más lento.

\section{2 ¿Es transferible la flexi-seguridad a los países de América Latina?}

Existen al menos dos factores que justifican transferir esta política a América Latina. Los países de la región son en su mayoría medianos y pequeños y su grado de apertura es alto. Por ende son más vulnerables y dado su tamaño, tienen escasas posibilidades de suavizar la intensidad de los ciclos antes de que se difundan al interior de sus economías. Por otro lado, la estrategia seguida basada en la apertura requiere de flexibilidad para estar en condiciones de competir en los mercados internacionales y al mismo tiempo, se necesita seguridad para compensar a los afectados y para generar incentivos para aumentar la productividad. 
Sin embargo, existen diferencias que anticipan que dicha opción puede contribuir a abordar el problema de inseguridad laboral, pero que será insuficiente. En particular, la existencia de un amplio sector informal que se traduce en exclusión social y económica determina que los efectos de la flexi-seguridad solo podrán beneficiarlos indirectamente y tomarán tiempos largos. Existen además, restricciones fiscales que conspiran contra la viabilidad de financiar un sistema de protección laboral y social suficientemente amplio y generoso como para dotar de seguridad a toda la población.

Lo anterior no significa descartar la flexi-seguridad como opción estratégica. Por el contrario, como se ha sostenido por CEPAL, (2004a y 2006) y por Tokman, (2004), es necesario completar la estrategia de flexi-seguridad para adaptarla a las condiciones existentes en la región. La combinación de seguridad en el empleo y protección es necesaria, pero será insuficiente sino se acompaña de una estrategia de inclusión económica y social. Desde luego la viabilidad de una estrategia de estas características depende de las condiciones de cada país, por lo que puede resultar útil completar el análisis efectuado más arriba para los países de OCDE examinando las condiciones prevalecientes en los países de la región.

\begin{tabular}{|c|c|c|c|}
\hline & \multicolumn{2}{|c|}{$\begin{array}{c}\text { Cuadro } 6 \\
\text { PROTECCIÓN LABORAL Y SOCIAL }\end{array}$} \\
\hline & & \multicolumn{2}{|c|}{ Protección Laboral } \\
\hline & & Alta & Baja \\
\hline \multirow{4}{*}{ 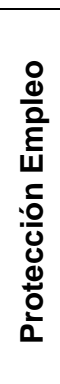 } & \multirow[t]{2}{*}{ Alta } & $\begin{array}{l}\text { Legislación laboral estricta: } 2^{\circ} \text { más alta } \\
\text { Gasto en protección social: } 2^{\circ} \text { más alta } \\
\text { Percepción de inseguridad: } 2^{\circ} \text { más baja }\end{array}$ & $\begin{array}{l}\text { Legislación laboral estricta: la más alta } \\
\text { Gasto en protección social: } 2^{\circ} \text { más bajo } \\
\text { Percepción de inseguridad: la más alta }\end{array}$ \\
\hline & & Brasil y Venezuela & $\begin{array}{l}\text { México, Panamá, Paraguay, Colombia, } \\
\text { Ecuador y Perú }\end{array}$ \\
\hline & \multirow[t]{2}{*}{ Baja } & $\begin{array}{l}\text { Legislación laboral estricta: la más baja } \\
\text { Gasto en protección social: el más alto } \\
\text { Percepción de inseguridad: la más baja }\end{array}$ & $\begin{array}{l}\text { Legislación laboral estricta: } 2^{\circ} \text { más baja } \\
\text { Gasto en protección social: } 2^{\circ} \text { más bajo } \\
\text { Percepción de inseguridad: } 2^{\circ} \text { más alto }\end{array}$ \\
\hline & & Uruguay, Chile, Argentina y Costa Rica & $\begin{array}{l}\text { Nicaragua, El Salvador, Honduras, } \\
\text { Bolivia, Guatemala y R. Dominicana }\end{array}$ \\
\hline
\end{tabular}

Fuente: Legislación laboral, según índice de grado de exigencia de despidos, incluye flexibilidad de contratación y despidos, Banco Mundial, Doing Business, 2004.

Nota: Gasto protección social en porcentaje del PIB, incluye pensiones, CEPAL, Panorama Social, 2005. Percepción de inseguridad: Latinobarómetro, 2005.

Se pueden distinguir en América Latina, al igual que en los países miembros de la OCDE, cuatro grupos de países según la combinación de instrumentos que utilicen para buscar la seguridad laboral, así como los resultados que se obtienen según la percepción que expresan los ciudadanos en cada país. Dichos instrumentos son el grado de exigencia de la legislación laboral en cuanto a despidos y la importancia de los recursos públicos que se destinan a la protección laboral y social. En el cuadrante superior izquierdo, se incluyen los países que poseen legislaciones laborales altamente protectoras y que destinan una proporción también significativa para financiar el gasto en protección. Esta combinación se observa en Brasil y Venezuela ${ }^{29}$ con buenos resultados a juzgar por la percepción baja de inseguridad que expresan sus ciudadanos. La situación, particularmente en Brasil, es similar aunque en magnitudes diferentes, al diseño observado en los países de mayor tamaño en Europa. Al otro extremo, en el cuadrante inferior derecho se ubican los países de menor tamaño, más abiertos y con ingresos más bajos. ${ }^{30}$ Ellos presentan mayores similitudes con el

29 Debe señalarse que en Venezuela el gasto en protección es muy inferior al de Brasil, pero el grado de exigencia de la legislación
laboral se ve reforzado por una muy alta credibilidad de la población consultada en relación a la efectividad de la misma.
La excepción en cuanto al grado de apertura la constituye Bolivia. 
modelo anglo-sajón al combinar una legislación laboral menos exigente y un reducido gasto en protección. Sus ciudadanos tienen una percepción de inseguridad alta, aunque no la mayor del conjunto de países de la región. Se incluyen en este grupo los países de Centro América, República Dominicana y Bolivia.

Los cuadrantes restantes presentan también situaciones asimilables a la de los países desarrollados en cuanto a la mezcla de instrumentos e incluso en sus efectos sobre la seguridad, a pesar de las diferencias estructurales que existen y a las que nos referiremos más abajo. La opción seguida por México, Panamá y los países Andinos es asegurar la permanencia en el empleo mediante legislaciones laborales que encarecen significativamente el despido, pero destinan escasos recursos a la protección. La percepción de inseguridad es, sin embargo, la más alta de los cuatro grupos. En el cuadrante inferior izquierdo, se encuentran países que poseen menor grado de exigencia en su legislación y destinan una proporción significativa de recursos públicos a la protección. Aunque las distancias en comparación con la intensidad de uso de ambos instrumentos no permiten, sin embargo, efectuar analogías. En los países desarrollados las legislaciones laborales son más flexibles y el gasto público en protección es mayor. ${ }^{31}$ No obstante, sus ciudadanos expresan el mayor nivel de seguridad comparados con el resto de países latinoamericanos. Se incluyen en este grupo Uruguay, Chile, Argentina y Costa Rica.

Es obvio que los efectos de las diversas modalidades de flexi-seguridad son de menor alcance en la región que en los países de la OCDE, pero son relevantes en cuanto permiten confirmar que existen opciones que pueden aplicarse en los países latinoamericanos. La efectividad de estas políticas es función del grado de urbanización y formalización del mercado laboral, tanto en lo referente a la importancia y naturaleza de las relaciones laborales como al tamaño de las unidades productivas. El cuadro 7 incorpora la dimensión de estas variables a los cuatro grupos definidos en el cuadro 6, lo que permite observar que los países ubicados en el cuadrante inferiorizquierdo son los más urbanizados y los que registran un mayor grado de asalariamiento y una informalidad más reducida.

En promedio, el $82 \%$ de la ocupación es no agrícola, el $73 \%$ de los ocupados urbanos son asalariados y el $60 \%$ de la ocupación no agrícola esta en el sector formal. Es en ellos donde las políticas de protección del empleo y protección laboral y social alcanzan mayor efecto y se traducen en una percepción de seguridad alta en relación a los demás países de la región. Al otro extremo en el cuadrante inferior derecho donde se ubican los países más abiertos y de menor tamaño que poseen legislaciones laborales no muy exigentes y protección baja. Se observa también el efecto potencial más reducido de las políticas laborales. En ellos se registran los menores niveles de urbanización, de asalariamiento y de formalización. Sólo el 56\% de la ocupación está en actividades no agrícolas, el $45 \%$ entre ellos es asalariado y el 58\% está ocupado en el sector informal. Se observa también una alta percepción de inseguridad (aunque no la más alta) y una efectividad reducida de las políticas laborales. Los dos grupos restantes se encuentran en situaciones estructurales intermedias, superando el grupo ubicado en el cuadrante superiorizquierdo al del cuadrante superior-derecho tanto en urbanización como en formalidad, invirtiéndose la relación en la proporción de asalariados entre ambos grupos. ${ }^{32}$

31 Esta observación se aplica no solo a los países de este grupo, sino con mayor justificación al resto de los países incluidos en el análisis.

32 Los grupos definidos a partir de las variables de los cuadros 5 y 6 , se presentan más difusas en cuanto a las dimensiones relacionadas a las estructuras y grado de modernidad del mercado laboral, particularmente en relación a los dos grupos intermedios. 


\section{LIMITANTES ESTRUCTURALES A LA EFECTIVIDAD DE LAS POLÍTICAS LABORALES}

\begin{tabular}{|c|c|c|c|}
\hline & \multicolumn{2}{|c|}{ Protección Laboral } \\
\hline & & Alta & Baja \\
\hline \multirow{6}{*}{ 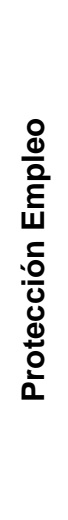 } & \multirow[t]{3}{*}{ Alta } & $\begin{array}{l}\text { Urbanización: la más alta } \\
\text { Asalariamiento: } 2^{\circ} \text { más alta } \\
\text { Formalización: } 2 \text { más alta }\end{array}$ & $\begin{array}{l}\text { Urbanización: } 2^{0} \text { más bajo } \\
\text { Asalariamiento: } 2^{\circ} \text { más bajo } \\
\text { Formalización: } 2^{\circ} \text { más bajo }\end{array}$ \\
\hline & & $\begin{array}{l}\text { Efectividad política laboral: 20 más alta } \\
\text { Percepción de seguridad: } 2^{\circ} \text { más alta }\end{array}$ & $\begin{array}{l}\text { Efectividad política laboral: 2o más baja } \\
\text { Percepción de seguridad: la más baja }\end{array}$ \\
\hline & & Brazil y Venezuela & $\begin{array}{l}\text { México, Panamá, Paraguay, Colombia, } \\
\text { Ecuador y Perú }\end{array}$ \\
\hline & \multirow[t]{3}{*}{ Baja } & $\begin{array}{l}\text { Urbanización: } 2^{\circ} \text { más alta } \\
\text { Asalariamiento: el más alto } \\
\text { Formalización: la más alta }\end{array}$ & $\begin{array}{l}\text { Urbanización: el más bajo } \\
\text { Asalariamiento: el más bajo } \\
\text { Formalización: el más bajo }\end{array}$ \\
\hline & & $\begin{array}{l}\text { Efectividad política laboral: la más alta } \\
\text { Percepción de seguridad: la más alta }\end{array}$ & $\begin{array}{l}\text { Efectividad política laboral: la más baja } \\
\text { Percepción de seguridad: } 2^{\circ} \text { más baja }\end{array}$ \\
\hline & & Uruguay, Chile, Argentina y Costa Rica & $\begin{array}{l}\text { Nicaragua, El Salvador, Honduras, } \\
\text { Bolivia, Guatemala y R. Dominicana }\end{array}$ \\
\hline
\end{tabular}

Fuente: V. E. Tokman, 2006.

Nota: Urbanización: porcentaje de ocupación no agrícola sobre total. Asalariamiento: porcentaje de asalariados en la ocupación no agrícola. Formalización: Ocupación en el sector formal sobre total no agrícola.

Debe reiterarse al concluir que los ordenamientos efectuados permiten distinguir entre países pero referidos a sus vecinos geográficos e ilustran con mayor amplitud la combinación de políticas de empleo y de protección laboral. Las distancias existentes aún entre grupos con mayores similitudes aparentes son significativas. ${ }^{33}$ Al compararse, por ejemplo, los recursos destinados por los grupos de países que en ambas regiones registran una mayor seguridad, se observa que mientras en la OCDE esos países destinan entre el 3,5 y el 5\% del PIB a políticas de empleo activas y seguros de desempleo, los países en esa situación en América Latina se ubican en torno a 1,5\% del PIB. Por otro lado, una situación similar se presenta en relación a las limitantes estructurales que afectan la incidencia de las políticas. Al comparar ambos grupos de países se observa que en los miembros de OCDE. La urbanización supera al 96\% y el asalariamiento es mayor que 92\%, mientras que los cuatro países latinoamericanos ubicados en el mismo grupo que presentan la mayor potencialidad en cuanto al alcance de las políticas laborales registran en promedio coeficientes de 82 y $73 \%$ respectivamente.

33 Se comparan, para ejemplificar, los promedios de Uruguay, Chile, Argentina y Costa Rica con los de Dinamarca, Bélgica, Holanda, Finlandia e Irlanda, ubicados en el cuadrante inferior-izquierdo en los cuadros 5 y 6. 



\section{Bibliografía}

Auer, P., Berg, J. y Coulibaly, I., 2004, Is a more stable workforce good for the economy? Insights into the tenure- productivity-employment relationship, Ginebra, OIT, Employment Strategy Working Paper 15.

Banco Mundial, 2004, Doing Business in 2004. Understanding Regulation, World Bank, IFC and Oxford University Press, Washington D.C..

BID, 2003, Se buscan buenos empleos. Los mercados laborales en América Latina. Informe de Progreso Económico y Social en América Latina 2004, Washington D.C..

Boyer, R., 2006, Employment and decent work in the era of flexicurity, ParisJourdan Sciences Economiques, Paris.

CEPAL, 2007, Cohesión Social. Inclusión y sentido de pertenencia en América Latina y el Caribe, CEPAL, Naciones Unidas, Santiago. 2006, La protección social de cara al futuro. Acceso, financiamiento y solidaridad, CEPAL, Naciones Unidas, Santiago 2004a, Desarrollo Productivo en Economías Abiertas, CEPAL, Naciones Unidas, Santiago.

2004, Panorama Social 2004, Santiago.

2000, Equidad, Desarrollo y Ciudadanía, volumen I, CEPAL, Alfaomega, Colombia.

1990, Transformación productiva con equidad: La tarea prioritaria del desarrollo de América Latina y el Caribe en los noventa, CEPAL, Naciones Unidas, Santiago.

Chacaltana, J., 2005, Dimensiones de la productividad del trabajo en las empresas de América Latina. Un estudio comparativo de Argentina, Panamá y Perú, OIT, Oficina Regional para América Latina y el Caribe, Lima.

Chacaltana, J. y N. García, 2002, Estabilidad laboral, capacitación y productividad, Red de políticas de empleo- CIIES, Lima.

De Ferranti, D., G. Perry y otros, 2000, Asegurando el futuro en una economía globalizada, Washington D.C, Banco Mundial. 
De Soto, H, 1986, El otro Sendero. La revolución informal, Instituto Libertad y Democracia, Lima. 2001, El misterio del capital, Editorial El Comercio, Lima.

Farber, H, 1998, Mobility and stability: the dynamics of change in labor markets, Princeton University, Industrial Relations Section, Working Paper 400, Princeton.

Gómez, L. R., 1998, Marco legal, caracterización y políticas de apoyo a la microempresa en Colombia, parte A en Desafíos de la modernización y el sector informal urbano. El caso de Colombia, Gómez, L. R, Huertas, G. y Olea, D, Documento de Trabajo, N 87, OIT, Lima.

Latino barómetro, 2005, Informe Latino barómetro 2005: 1995-2005, Diez años de opinión pública, Santiago.

Loayza, N., Oviedo, A. M., Servén, L., 2005, The impact of regulation on growth and the informal sector: cross country evidence, no publicado, Banco Mundial, Washington, D.C..

Lubell, H. 1991, The informal sector in the 1980s and 1990s, OCDE, Development Center Studies, Paris.

Nicoletti, G., Scarpetta, S., Boyland, O., 2000, Summary indicators of product market regulation with an extension to employment production legislation, Paris, OCDE Economics Department, Working Paper 226, Paris.

OCDE, 2002, Employment Outlook 2002, OCDE, Paris.

OIT, 2006, Business environment, labor law and micro- and small enterprises, Committee on Employment and Social Policy, Governing Body $297^{\text {th }}$ session, Ginebra. 2004, World Employment Report 2004-2005, Ginebra. 2004b, Economic Security for a Better World, OIT, Ginebra. 1991, Dilemma of the informal sector, Report of the Director-General presented at the $78^{\circ}$ International Labour Conference, Ginebra.

1972, Employment, income and equality. A strategy for increasing productive employment in Kenya, Ginebra.

Portes, A., Castells, M., y Benton, L., 1989, The informal economy. Studies in advanced and less Developer countries, Baltimore and London, The John Hopkins University Press.

Prebisch, R., 1970, Transformación y Desarrollo, Banco Interamericano de Desarrollo, Washington, D.C..

Souza, P. R. y Tokman, V. E., 1976, El sector informal urbano en América Latina, Revista Internacional del Trabajo, volumen 94, 3, OIT, Ginebra.

Tokman, V. E., 2006, Inserción Laboral, mercados de trabajo y protección social, CEPAL, Serie Financiamiento del Desarrollo 179, Santiago.

2004, Las dimensiones laborales de la transformación productiva con equidad, CEPAL, Serie Financiamiento del Desarrollo 150, Santiago.

2003, Hacia una visión integrada para enfrentar la inestabilidad y el riesgo, en Revista de la CEPAL 81 , Santiago.

2001, De la informalidad a la modernidad, OIT, Santiago.

Vega-Ruiz, M. L., 2005, La reforma laboral: un análisis comparado, OIT, Lima.

Yánez, A. M., 1998. La legislación laboral y su impacto en la microempresa: costos y desafíos, Capítulo I en Chávez, E., Yánez, A. M. Luna, C. De la Flor, R. Fuentes, S. y Robles, M. Perú: El sector informal frente al reto de la modernización, OIT, Lima. 


\section{Anexo}





\section{Sugerencias de indicadores de empleo y protección para la cohesión social}

El análisis efectuado en este trabajo permite identificar un conjunto mínimo de indicadores que serian útiles de revisar de manera sistemática en forma periódica. Los mismos se dirigen al seguimiento de dos dimensiones de la cohesión social, la distancia entre los distintos integrantes de la sociedad y el sentido de pertenencia que los mismos experimenten y manifiesten. Ambas dimensiones se abordan desde la perspectiva del empleo y la protección laboral y social. La lista de indicadores coincide en parte con la propuesta presentada por J. C. Feres (CEPAL) y en parte, con los indicadores de Laaken de la UE. Incluye también un conjunto de indicadores adicionales.

La primera dimensión busca identificar brechas en la inserción laboral y en el acceso a la protección social. Los indicadores referidos al empleo pretenden identificar las personas afectadas por el desempleo, su hogar de pertenencia, sus características personales, la duración del desempleo y la dispersión en la situación entre regiones o ciudades de un mismo país. Ellos contribuirían a considerar el desempleo no solo en cuanto a su magnitud, sino además a quienes afecta, que hogares son más vulnerables y donde se localiza.

El desempleo constituye solo una parte del problema de empleo, que puede ser la más grave, pero claramente no constituye la mayor proporción del mismo. Por ello es importante avanzar en el seguimiento al tipo de inserción laboral y particularmente, identificar a aquellos que se encuentran ocupados en sectores de baja productividad y bajo que modalidades. Se sugiere incorporar los indicadores de brechas de ingreso y productividad por ocupación y tamaño y entre sector informal y el formal. Asimismo, es importante analizar la cobertura del reconocimiento legal de las relaciones laborales y las formas contractuales que se utilizan. Estas constituyen requisitos para el acceso a la protección laboral y social.

El seguimiento a la protección se sugiere mediante indicadores de resultados como los ya incorporados en las propuestas existentes que se refieren a cobertura, nivel relativo de las pensiones y efectos sobre el ingreso de los hogares. Se sugiere además, incorporar nuevos indicadores que vinculan la inserción laboral y el reconocimiento legal de la relación laboral con el acceso a la protección social.

El segundo módulo contribuye al seguimiento de la pertenencia también desde la perspectiva del empleo y la protección sugiriendo indicadores de participación y de seguridad laboral. La primera porque el sentido de pertenencia se relaciona no solo con la percepción individual sino además con la capacidad de representación colectiva y de manifestación de voz, lo que, en muchos casos, conduce a incorporar las demandas de la gente. Para ello se incorpora el indicador de participación en organizaciones funcionales ya sugerido y se agregan la participación de asalariados en sindicatos y de empresarios en organizaciones gremiales, las huelgas y paros y la cobertura de la negociación colectiva. Se agrega una sugerencia adicional, dependiendo de la información disponible, sobre organización y participación de los informales sea mediante organizaciones propias o de la participación en sindicatos y organizaciones empresariales.

Se sugiere incorpora el seguimiento de la seguridad laboral, mediante el análisis de indicadores de estabilidad en el empleo (antigüedad en el empleo y rotación laboral) y el acceso y la importancia de la protección laboral (legislación laboral, políticas de mercado de trabajo, seguros de desempleo y de accidentes de trabajo).

Por último, un módulo adicional se sugiere para considerar las percepciones de los ciudadanos en relación a su grado de vulnerabilidad ocupacional y a la vigencia de la meritocracia 
en el acceso y en la movilidad en el empleo. Se sugiere agregar dos indicadores específicos de percepción de seguridad en el empleo y de que el trabajo esforzado es recompensado.

El cuadro siguiente presenta la lista de indicadores sugeridos. Por último, la viabilidad de recolectar la información dependerá de las fuentes disponibles. CEPAL posee ya una base de información de encuestas de hogares que contienen una parte importante de los indicadores incluidos. Sin embargo, será necesario complementarlos con encuestas de establecimientos y de empleo y con registros administrativos tanto de protección como de participación.

\section{Cuadro 8}

INDICADORES DE EMPLEO Y PROTECCIÓN PARA LA COHESIÓN SOCIAL

\begin{tabular}{|c|c|c|c|}
\hline Tipo & Módulo & Propuesta (UE-Feres) & Nuevos indicadores sugeridos \\
\hline I. Distancia & 1. Empleo & $\begin{array}{l}\text { 1. Tasa de desempleo } \\
\text { 2. Tasa de desempleo de } \\
\text { larga duración } \\
\text { 3. \% de personas en hogares } \\
\text { con } 0 \text { que trabajan } \\
\text { 4. \% PEA sectores de baja } \\
\text { productividad } \\
\\
\text { 1. \%personas cotizan } \\
\text { previsión social } \\
\text { 2. razón pensión media/ línea } \\
\text { de pobreza } \\
\text { 3. \% hogares con principal } \\
\text { sostenedor pensionado }\end{array}$ & $\begin{array}{l}\text { - TD mujeres/hombres } \\
\text { - TD jóvenes (15-21)/ promedio } \\
\text { - Dispersión TD regionales por país } \\
\text { - Brechas productividad e ingresos: } \\
\text { por ocupación y tamaño } \\
\text { sector informal/formal } \\
\text { - \% asalariados s/contrato, con contrato } \\
\text { temporal u otros contratos } \\
\text { - \% cotizan por: ocupación, } \\
\text { - \% cotizan por contratos } \\
\text { - \% cotizan informal, formal } \\
\text { - \% cotizan salud }\end{array}$ \\
\hline II. Pertenencia & $\begin{array}{l}\text { 2. Seguridad } \\
\text { laboral } \\
\text { 3. Percepciones }\end{array}$ & $\begin{array}{l}\text { 1. \% en organizaciones } \\
\text { funcionales } \\
\text { 1. Estabilidad de empleo } \\
\text { 2. Protección laboral } \\
\text { 3. Vulnerabilidad y } \\
\text { meritocracia }\end{array}$ & $\begin{array}{l}\text { - \% sindicalizados/asalariados } \\
\text { - huelgas y paros (número, días perdidos) } \\
\text { - \% asalariados con negociación colectiva } \\
\text { - \% participación de informales } \\
\text { - antigüedad en el empleo actual (años) } \\
\text { - tasa de rotación laboral } \\
\text { - número de empleos anteriores } \\
\text { - seguridad en el puesto según ley } \\
\text { - políticas laborales activas y pasivas (\%/PIB) } \\
\text { - cobertura y duración seguro desempleo } \\
\text { - cobertura accidentes del trabajo } \\
\text { - percepción de seguridad en el empleo } \\
\text { - percepción de que trabajo duro genera éxito }\end{array}$ \\
\hline
\end{tabular}

Fuente: Elaboración propia del autor. 


\section{Serie}

\section{E P \& \& Políticas sociales}

\section{Números publicados}

\section{El listado completo de esta colección, así como las versiones electrónicas en pdf están disponibles en nuestro sitio web: www.cepal.org/publicaciones}

130. Victor Tokman, "Informalidad y cohesión social en América Latina", LC/L.2694-P), Número de venta: S.07.II.G.45, (US\$ 10.00), marzo de 2007. www

129. Christian Courtis y Nicolás Espejo, "Por un 'contrato de cohesión social': algunos apuntes exploratorios". LC/L.2699-P), Número de venta: S.07.II.G.49, (US\$ 10.00), marzo de 2007 www

128. Miguel Székely, "Un nuevo rostro en el espejo: percepciones sobre la discriminación y la cohesión social en México", (LC/L.2643-P), Número de venta: S.06.II.G.169, (US\$ 10.00), diciembre de 2006. www

127. Juan Carlos Gómez-Sabaini, "Cohesión social, equidad y tributación. Análisis y perspectivas para América Latina", (LC/L.2641P), Número de venta: S.06.II.G.167 (US\$ 10.00), diciembre de 2006. www

126. Guillermo Sunkel, "Las tecnologías de la información y la comunicación (TIC) en la educación en América Latina. Una exploración de indicadores", (LC/L.2638-P), Número de venta: S.06.II.G.165, (US\$ 10.00), diciembre de 2006. www

125. Camilo Sembler R., "Estratificación social y clases sociales. Una revisión analítica de los sectores medios", (LC/L.2637-P), Número de venta: S.06.II.G.164, (US\$ 10.00), diciembre de 2006. www

124. Gonzalo Wielandt, "Poblaciones vulnerables en América Latina y el Caribe: análisis de casos. (LC/L.2628-P), Número de venta: S.06.II.G.152, (US\$10.00), noviembre de 2006. www

123. Filip Filipov, "Post-conflict Peacebuilding: Strategies and Lessons from Bosnia and Herzegovina, El Salvador and Sierra Leone. Some Thoughts from the Rights to Education and Health" (LC/L.2613-P), Sales Number: E.06.II.G.138, (US\$ 10.00), September, 2006. www

122. María Rebeca Yánez, Sandra Acuña y Gloria Molina, "RISALC: hacia una herramienta estratégica para la gestión social” (LC/L.2585-P), Número de venta: S.06.II.G.115, (US\$ 10.00), agosto de 2006. www

121. Marcelo Drago, "La reforma al sistema de salud chileno desde la perspectiva de los derechos humanos", (LC/L.2359-P), Número de venta: S.06.II.G.86, (US\$10.00), abril de 2006. www

120. Guillermo Sunkel, "El papel de la familia en la protección social en América Latina", LC/L.2530-P), Número de venta: S.06.II.G.57, (US\$ 10.00), abril de 2006. www

119. Irma Arriagada, Cambios de las políticas sociales: políticas de género y familia”, LC/L.2519-P), Número de venta: S.06.II.G.46, (US\$10.00), abril de 2006. www

118. Martín Hopenhayn, Álvaro Bello, Francisca Miranda, "Los pueblos indígenas y afro descendientes ante el nuevo Milenio", LC/L.2518-P), Número de venta: S.06.II.G.45, (US\$ 10.00), abril de 2006. www

117. Andras Uthoff, "Brecha del Estado de Bienestar y reformas a los sistemas de pensiones en América Latina y el Caribe”, (LC/L.2498-P), Número de venta: S.06.II.G.30, (US\$ 10.00), abril de 2006. www

116. Sebastián Galiani, "Políticas sociales: instituciones, información y conocimiento", LC/L.-2482P), Número de venta: S.06.II.G.8, (US\$10.00), enero de 2006. www

115. Gonzalo Wielandt, "Hacia la construcción de lecciones de posconflicto en América Latina y el Caribe. Una mirada a la violencia juvenil en Centroamérica", LC/L.2451-P), Número de venta: S.05.II.G.197 (US\$ 10.00), diciembre de 2005. www

114. Irma Arriagada, Verónica Aranda y Francisca Miranda, "Políticas y programas de salud en América Latina. Problemas y propuestas", LC/L.2450-P), Número de venta: S.05.II.G.196, (US\$ 10.00), diciembre de 2005. www

113. Mariana Schnkolnik, Consuelo Araos y Felipe Machado, "Certificación por competencias como parte del sistema de protección social: la experiencia de países desarrollados y lineamientos para América Latina” LC/L.2438-P), Número de venta: S.05.II.G.184, (US\$10.00), diciembre de 2005. www

112. Rodrigo Martínez, Hambre y desigualdad en los países andinos. La desnutrición y la vulnerabilidad alimentaria en Bolivia, Colombia, Ecuador y Perú" (LC/L.2400-P), Número de venta: S.05.II.G.147, (US\$ 10.00), octubre de 2005. www 
111. Rodrigo Martínez, "Hambre y desnutrición en los países miembros de la Asociación de Estados del Caribe (AEC)" (LC/L.2374-P), Número de venta: S.05.II.G.119, (US\$ 10.00), septiembre de 2005. www

Rodrigo Martínez, "Hunger and Malnutrition in the Countries of the Association of Caribbean States (ACS)" (LC/L.2374-P), Sales Number: E.05.II.G.119, (US\$10.00), September, 2005. www

110. Carmen Artigas, "Una mirada a la protección social desde los derechos humanos y otros contextos internacionales", (LC/L.2354-P), Número de venta: S.05.II.G.98, (US\$ 10.00), agosto de 2005. www

109. Lucía Dammert, "Violencia criminal y seguridad ciudadana en Chile", (LC/L.2308-P), Número de venta: S.05.II.G.57, (US\$10.00), mayo del2005. www

108. María Rebeca Yáñez y Pablo Villatoro, "Las nuevas tecnologías de la información y de la comunicación (TIC) y la institucionalidad social: hacia una gestión basada en el conocimiento" (LC/L.2298-P), Número de venta: S.05.II.G.46, (US\$10.00), mayo de 2005. www

107. Richard N. Adams, "Etnicidad e igualdad en Guatemala, 2002", (LC/L.2286-P), Número de venta: S.05.II.G.30, (US\$ 10.00), mayo de 2005. www

106. Pablo Villatoro, "Diagnóstico y propuestas para el proyecto: Red en línea de Instituciones Sociales de América Latina y el Caribe RISALC”, (LC/L.2276-P), Número de venta: S.05.II.G.28, (US\$ 10.00), febrero de 2005. www

105. Alison Vásconez R., Rossana Córdoba y Pabel Muñoz, "La construcción de las políticas sociales en Ecuador durante los años ochenta y noventa: sentidos, contextos y resultados", (LC/L.2275-P), Número de venta: S.05.II.G.27, (US\$ 10.00), febrero de 2005. www

104. Mariana Schnkolnik, "Caracterización de la inserción laboral de los jóvenes" (LC/L2257-P), Número de venta: S.05.II.G.15, (US\$ 10.00), febrero de 2005. www

103. Carlos Américo Pacheco, "Políticas públicas, intereses y articulación política como se gestaron las recientes reformas al Sistema de Ciencia y Tecnología en Brasil", (LC/L.2251-P), Número de venta: S.05.II.G.9, (US\$ 10.00), enero de 2005. www

102. David Noe, Jorge Rodríguez Cabello e Isabel Zúñiga, "Brecha étnica e influencia de los pares en el rendimiento escolar: evidencia para Chile", (LC/L.2239-P), Número de venta: S.04.II.G.159, (US\$ 10.00), diciembre de 2004. www

101. Pablo Villatoro y Alisson Silva, "Estrategias, programas y experiencias de superación de la brecha digital y universalización del acceso a las nuevas tecnologías de la información y comunicación (TIC). Un panorama regional”, (LC/L2238-P), Número de venta: S.04.II.G.159, (US\$ 10.00), noviembre de 2004. www

100. Alejandro Portes y William Haller "La economía informal," (LC/L.2218-P), Número de venta: S.04.II.G.138, (US\$ 10.00), noviembre de 2004. www

99. Lorena Godoy, "Programas de renta mínima vinculada a la educación: las becas escolares en Brasil" (LC/L.2217-P), Número de venta: S.04.II.G.137, (US\$ 10.00), noviembre de 2004. www

98. Florencia Torche y Guillermo Wormald, "Estratificación y movilidad social en Chile: entre la adscripción y el logro", (LC/L.2209-P), Número de venta: S.04.II.G.132, (US\$ 10.00), octubre de 2004. www

97. Fabián Repetto y Guillermo Alonso, "La economía política de la política social argentina: una mirada desde la desregulación y la descentralización”, (LC/L.2193-P), Número de venta: S.04.II.G.120, (US\$ 10.00), septiembre de 2004. www

96. Raúl Atria, "Estructura ocupacional, estructura social y clases sociales", (LC/L.2192-P), Número de venta: S.04.II.G.119, (US\$ 10.00), septiembre de 2004. www

95. Eugenio Lahera P., "Política y políticas públicas", (LC/L.2176-P), Número de venta: S.04.II.G103, (US\$ 10.00), agosto de 2004. www

- $\quad$ El lector interesado en adquirir números anteriores de esta serie puede solicitarlos dirigiendo su correspondencia a la Unidad de Distribución, CEPAL, Casilla 179-D, Santiago, Chile, Fax (562) 210 2069, correo electrónico: publications@ @ cepal.org.

Nombre:

Actividad:

Dirección:

Código postal, ciudad, país:

Tel.:

Fax:

E.mail: 